\title{
Music and Social Interaction in the Treatment of Post-Stroke Aphasia
}

\section{HABILITATIONSSCHRIFT}

\author{
vorgelegt dem \\ Bereich Mathematik und Naturwissenschaften \\ der Technischen Universität Dresden \\ von \\ Dr. Benjamin Stahl \\ eingereicht am \\ 1. Juni 2021 \\ begutachtet von \\ Prof. Dr. Philipp Kanske \\ Prof. Dr. Elizabeth Rochon \\ Prof. Dr. Frank Jacobi
}

Probevorlesung und Abschluss des Verfahrens am

16. September 2021

Die vorliegende Habilitationsschrift wurde am

Institut für Klinische Psychologie und Psychotherapie angefertigt und umfasst den Zeitraum von April 2013 bis Mai 2021. 


\section{Acknowledgements}

Above all, I would like to thank my mentor Prof. Dr. Philipp Kanske for guiding me through the different steps of the habilitation procedure, as well as two dedicated external reviewers, Prof. Dr. Elizabeth Rochon and Prof. Dr. Frank Jacobi, for taking the time to evaluate the present work.

I am equally grateful to my scientific collaborators who have coauthored or otherwise supported the current work (in alphabetical order): Verena Büscher, Petra Denzler, Dr. Felix Dreyer, Prof. Dr. Katharine Farrell, Prof. Dr. Agnes Flöel, Bianca Gawron, PD Dr. Stefan Geyer, Prof. Dr. Jin Hyun Kim, Prof. Dr. Sonja Kotz, Dr. Guglielmo Lucchese, Saskia Millrose, Prof. Dr. Bettina Mohr, Anke Nicklas, Dr. Tudor Popescu, Prof. Dr. Friedemann Pulvermüller, Frank Regenbrecht, Mona Samuel, Lea Marie Sittig, Prof. Dr. Diethard Steube, Prof. Dr. Robert Turner, Prof. Dr. Diana Van Lancker Sidtis, and Dr. Miranka Wirth.

Finally, I would like to thank my student assistants and host teams at the local rehabilitation centers in Berlin for making the current work possible, as well as my patients for engaging in the-in some cases-challenging therapy and testing sessions. 


\section{Contents}

\section{PART I SUMMARY}

1 The present work: resources in speech-language therapy .................. 2

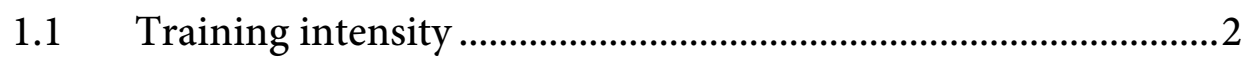

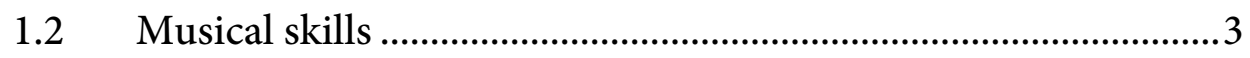

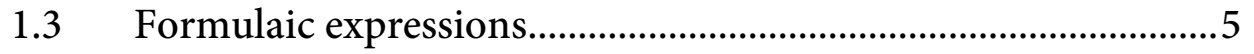

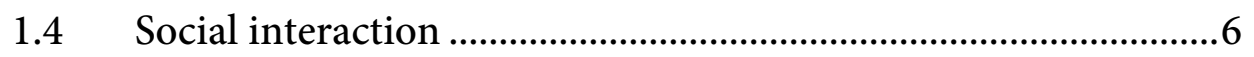

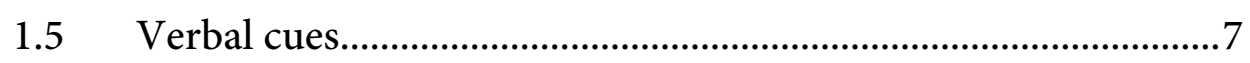

2 Upcoming work: post-stroke depression and aphasia ....................... 8

3 Concluding remarks: psychotherapy and aphasia ......................... 10

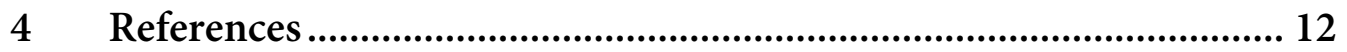

\section{PART II TRAINING INTENSITY}

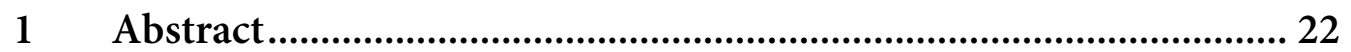

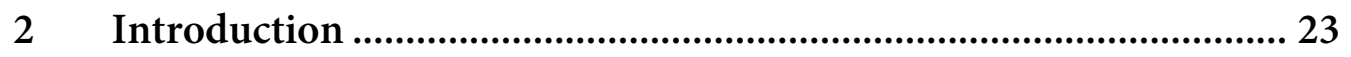

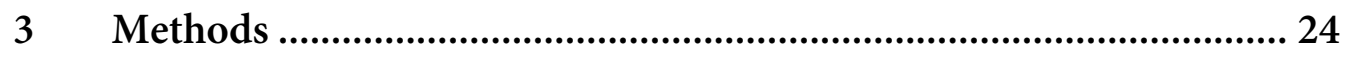

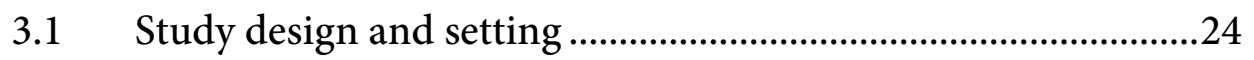

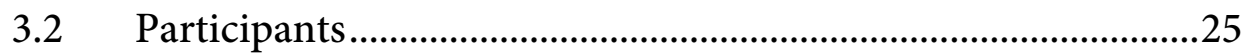

3.3 Randomization and blinding .................................................26

$3.4 \quad$ Treatment protocols, materials and procedures.........................27

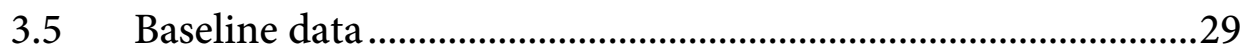

3.6 Testing and outcomes ..................................................................33

3.7 Statistical analyses.........................................................................34

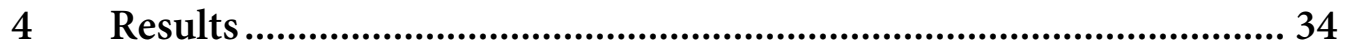

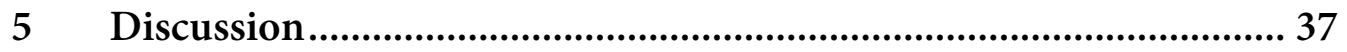

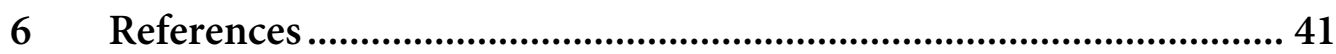




\section{PART III MUSICAL SKILLS}

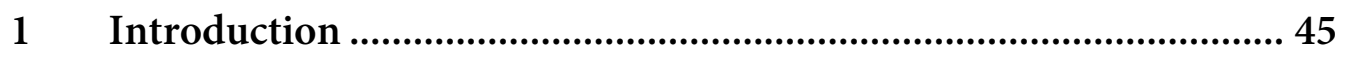

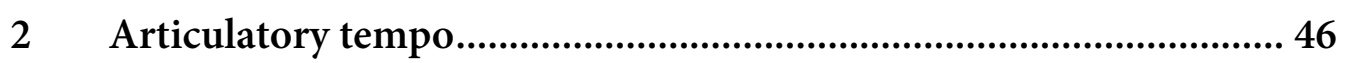

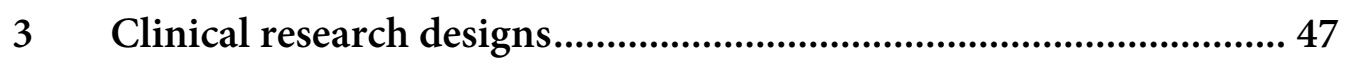

$4 \quad$ Formulaic language resources ..................................................... 48

5 Outlook on future research ........................................................ 49

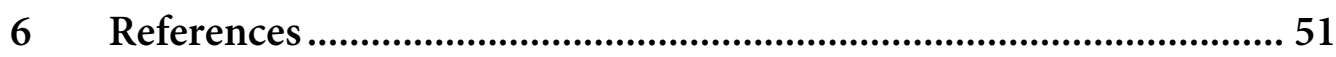

\section{PART IV FORMULAIC EXPRESSIONS}

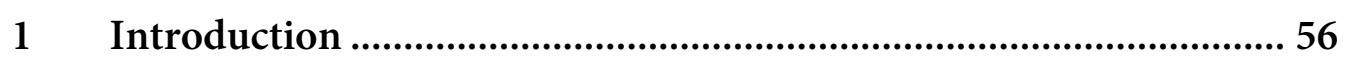

2 Utterance-centered approaches................................................ 57

3 Communicative-pragmatic rehabilitation programs ...................... 59

4 Possible impact on motivation, well-being, and quality of life ........ 60

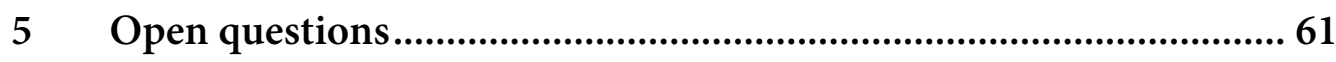

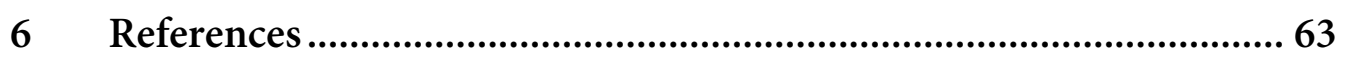

\section{PART V SOCIAL INTERACTION}

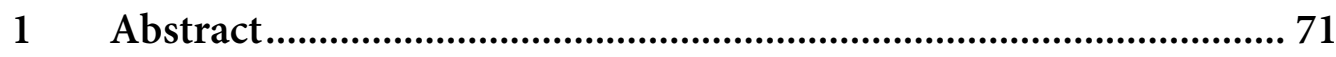

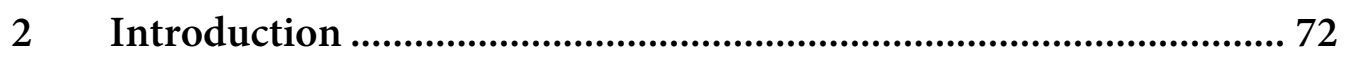

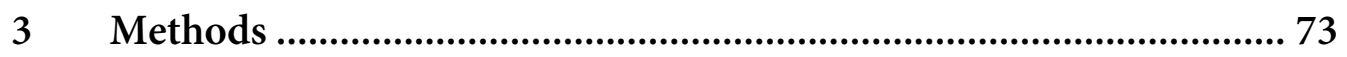

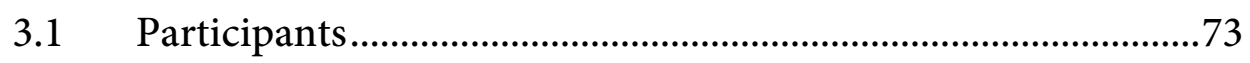

3.2 Study design and randomization ...............................................78

3.3 Treatment protocols and materials .............................................78

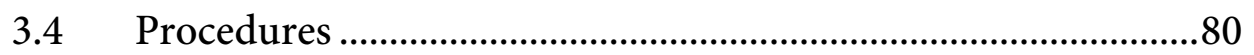

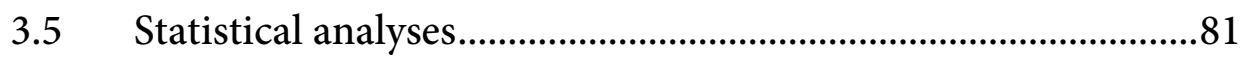

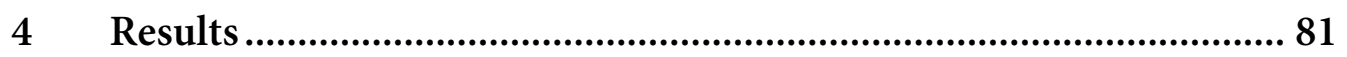




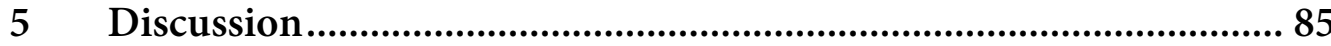

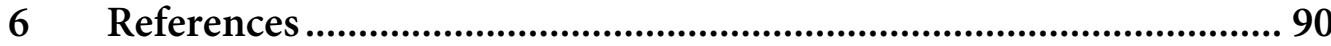

\section{PART VI VERBAL CUES}

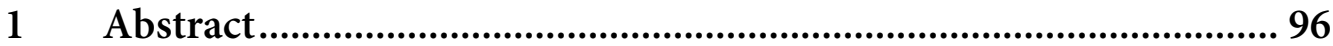

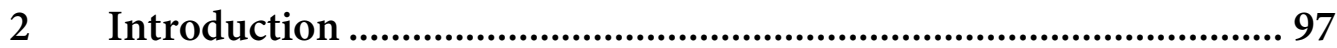

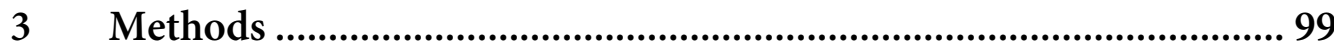

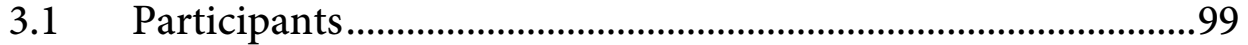

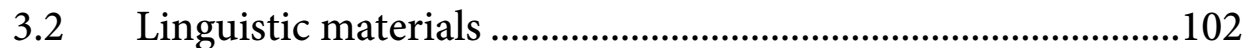

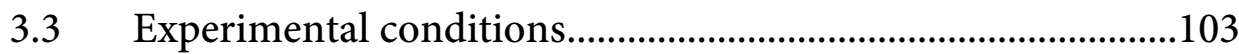

3.4 Procedures .....................................................................................105

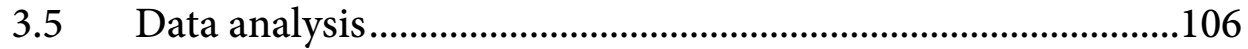

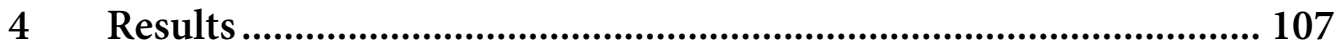

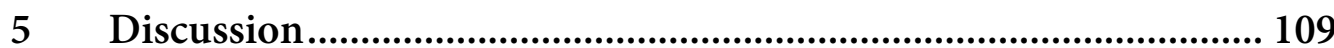

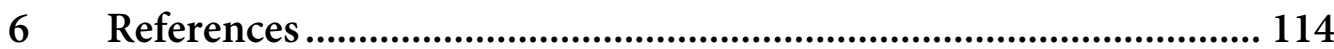


Part I

Summary 


\section{The present work: resources in speech-language therapy}

Cerebrovascular disease is a leading cause of disability and death worldwide, with about one third of stroke survivors initially suffering from communication disorders, including aphasia (Entgelter et al., 2006). Symptoms in aphasia vary from person to person, ranging from repeated failures in verbal expression to comprehension deficits that may occur in both the spoken and written modality (Flöel \& Stahl, 2019). The current work synthesizes almost a decade of research on aphasia following left-hemispheric stroke in individuals with preserved right-hemispheric function: musical skills and formulaic expressions embedded in social interaction. Moving beyond the traditional scope of clinical linguistics, this work argues that preserved right-hemispheric function not only provides valuable resources in speechlanguage therapy, but also a possible foundation for psychotherapy in individuals with post-stroke aphasia and concomitant depression.

The present summary-the first part of this book-introduces key developments in a line of research spanning from 2013 to 2021, to conclude with an outlook on forthcoming contributions and a commentary on the underlying conceptual framework. Each separate piece of research outlined below has been published previously in peer-reviewed journals. Here, the selected studies are assembled in an interdisciplinary context at the intersection of clinical neuroscience, speech-language pathology, and psychotherapy.

\subsection{Training intensity}

Until recently, meta-analyses on speech-language therapy have focused mainly on training intensity (e.g., Bhogal et al., 2003; Cherney et al., 2008; Allen et al., 2012). Today, the situation appears to be slightly different: although massed practice is still considered to be crucial in speech-language therapy (Breitenstein et al., 2017), factors other than training intensity have gained more attention, as reflected in comprehensive meta-analyses (e.g., 
Brady et al., 2016; RELEASE Collaboration, 2021). Among these factors are the specific linguistic approaches applied in speech-language therapy (e.g., Stahl et al., 2013, 2016, 2017, 2018). Moreover, speech-language therapy may benefit from non-linguistic technological advances, such as transcranial direct current stimulation-a claim investigated in an ongoing phase-III randomized controlled trial (Stahl et al., 2019; www.who.int registry identifier: NCT03930121).

Still, the role of training intensity remains controversial, mostly because meta-analyses cannot fully compensate for methodological limitations of the study design, including lack of randomization or adequate control group. Therefore, the second part of the present work addresses the influence of training intensity on the outcome of speech-language therapy, as determined in a randomized, parallel-group, blinded-assessment, controlled trial (Stahl et al., 2018). Thirty individuals with chronic post-stroke aphasia received speech-language therapy in two groups with different degrees of massed practice ( 4 hours versus 2 hours per day). Scores on a standardized outcome measure revealed no added value from more than 2 hours of daily speech-language therapy within four weeks. Instead, these data demonstrate that even a small two-week increase in treatment duration may contribute substantially to recovery from chronic post-stroke aphasia. While awaiting formal replication, the reported results emphasize that intensity may lose its impact once amount of weekly practice exceeds a certain threshold. This perspective leaves room for other, perhaps equally essential components in speech-language therapy - such as systematic use of preserved righthemispheric function.

\subsection{Musical skills}

Musical skills are commonly associated with right-hemispheric neural networks (Peretz, 2020). Accordingly, one of the most impressive findings in aphasia research is that individuals with communication disorders following left-hemispheric stroke often retain the ability to sing melodies (Jacome, 1984; Warren et al., 2003; Peretz et al., 2004) and words (Ya- 
madori et al., 1977). In particular, individuals are able to sing familiar lyrics (Ustvedt, 1937; Benton \& Joynt, 1960; Smith, 1966; Baur et al., 2000; Tomaino, 2010) and formulaic expressions, such as "I love you," "How are you?” or “Thank you” (Mills, 1904; Gerstmann, 1964; Keith \& Aronson, 1975). This finding has inspired a number of music-based rehabilitation programs (Keith \& Aronson, 1975; Jungblut, 2009), including a treatment known as Melodic Intonation Therapy (Albert et al., 1973; Sparks et al., 1974; Helm-Estabrooks et al., 1989). So far, randomized controlled trials have confirmed the efficacy of Melodic Intonation Therapy on standardized outcome measures in the late subacute or consolidation stage of aphasia (i.e., 6-12 months after stroke; van der Meulen et al., 2014), but not in the chronic stage of aphasia (i.e., more than 6-12 months after stroke; van der Meulen et al., 2016), where confound arising from spontaneous recovery is generally lower (Doppelbauer et al., 2021). This potential source of confound deserves special attention in meta-analyses on Melodic Intonation Therapy (Popescu, Stahl et al., under review).

Considering various aspects of singing in post-stroke aphasia, two studies have investigated how melodic intonation, rhythmic pacing, and type of verbal utterance affect immediate syllable production (Stahl et al., 2011) and performance on trained items after six weeks of practice (Stahl et al., 2013). Taken together, results from these studies revealed no short- or long-term superiority of melodic intonation over rhythmic speech in individuals with subacute or chronic post-stroke aphasia. However, type of verbal utterance proved to be important: immediate syllable production was significantly higher for well-known song lyrics and formulaic expressions than for unfamiliar word strings, whether they were sung or rhythmically spoken (Stahl et al., 2011). Likewise, both sung and rhythmically spoken repetition of formulaic expressions equally increased the production of trained items directly after the end of treatment and at a 3-month followup (Stahl et al., 2013). Subsequent studies with modified research designs yielded similar findings (Kershenbaum et al., 2017), while singing in syllable-timed languages such as French may add to the level of rhythmicity in a unique way (cf. Schmidt-Kassow et al., 2011; Zumbansen et al., 2014). Over- 
all, the findings mentioned here seem to contradict previous data in the literature (e.g., Racette et al. 2006). The third part of the present work-a methodological paper-discusses possible reasons for these discrepancies, such as overlap between right-hemispheric neural substrates of musical and communicative function (Stahl \& Kotz, 2014).

\subsection{Formulaic expressions}

A growing body of evidence suggests that formulaic expressions engage, in particular, right-hemispheric frontotemporal and bilateral subcortical neural networks (e.g., Hughlings-Jackson, 1878; Graves \& Landis, 1985; Speedie et al., 1993; Van Lancker Sidtis \& Postman, 2006; Sidtis et al., 2009; Van Lancker Sidtis et al., 2015; Stahl et al., in preparation). In analogy to musical skills, this may explain why individuals with aphasia due to lefthemispheric stroke are frequently able to communicate based on a repertoire of formulaic expressions. As a linguistic category, formulaic expressions differ from newly created, grammatical utterances in that they are stereotyped in form, often non-literal in meaning with attitudinal nuances, and closely related to communicative-pragmatic context (Van Lancker Sidtis \& Rallon, 2004). Although formulaic expressions prevail in many aspects of social interaction, relatively little is known about their use in speechlanguage therapy (Van Lancker Sidtis, 2021).

Current rehabilitation programs in speech-language therapy differ in how they take advantage of formulaic expressions to enhance social interaction. On the one hand, utterance-centered approaches focus mainly on isolated non-communicative skills in verbal expression, including the ability to name objects, describe scenes or repeat words and sentences. On the other hand, communicative-pragmatic rehabilitation programs build on the rich turn-taking structure of social interaction, thus encouraging the use of formulaic expressions in natural settings. As one prominent example of communicative-pragmatic rehabilitation programs, Intensive Language-Action Therapy requires individuals with post-stroke aphasia to use verbal utterances as a "tool" to accomplish communicative goals (Pulvermüller \& Roth, 
1991; Difrancesco et al., 2012). To date, randomized controlled trials have confirmed the efficacy of Intensive Language-Action Therapy on standardized outcome measures in chronic post-stroke aphasia (e.g., Pulvermüller et al., 2001; Meinzer et al., 2005, 2007; Berthier et al., 2009; Szaflarski et al., 2015; Stahl et al., 2016, 2017, 2018). In light of these findings, the fourth part of the present work-a theoretical paper-elaborates on the notion that training with formulaic expressions is more likely to promote generalization in speech-language therapy when embedded in social interaction (Stahl \& Van Lancker Sidtis, 2015).

\subsection{Social interaction}

Although formulaic expressions embedded in social interaction seem to be a promising resource in speech-language therapy, it long remained unclear to what extent this right-hemispheric function contributes to the overall efficacy of the treatment. The fifth part of the current work describes a randomized, crossover, blinded-assessment, controlled trial to investigate the influence of social interaction, including the repetitive use of formulaic expressions, in groups of three individuals with chronic post-stroke aphasia (Stahl et al., 2016). Eighteen individuals received, in counterbalanced order, Intensive Language-Action Therapy and a control intervention with carefully matched hours of weekly practice, total treatment duration, training materials, and number of verbal utterances. However, the control intervention provided less opportunity for social interaction and use of formulaic expressions. Scores on a standardized outcome measure consistently revealed significant progress in verbal expression with Intensive LanguageAction Therapy. In contrast, the control intervention improved verbal expression only at the onset of the treatment, but not after previous intensive training. Notably, treatment type explained up to 41 percent of the variance associated with changes in language performance. Given the small sample size, these results call for replication in a subsequent randomized controlled trial. 
Aside from the turn-taking structure, the game character, and the group experience of individuals with post-stroke aphasia, the use of formulaic expressions may be one major reason for the efficacy, practicability and popularity of Intensive Language-Action Therapy. The rehabilitation program encourages participants to request, and eventually obtain, depicted objects from fellow players. In doing so, participants tap into neural resources of verbal communication regardless of whether a request is accepted ("Here you are," "Thank you," "You're welcome"), rejected ("I'm sorry," "No problem," “Too bad") or unclear ("Pardon me?"). Most interestingly, players tend to be unaware of how successfully they exchange formulaic expressions throughout a session. Up until now, this observation has not been subject of systematic research and may have therapeutic potential especially for individuals with impaired speech-motor planning. Anecdotal evidence of such therapeutic potential may be the example of a person with impaired speech-motor planning who struggled to produce the phoneme /k/ for quite a while and, when offered a break, spontaneously responded with an impeccably articulated: "Okay."

\subsection{Verbal cues}

Many individuals with neurological communication disorders suffer from deficits in speech-motor planning, a syndrome mostly apparent in the production of word onsets (e.g., incorrect phoneme /k/ in "Coat"). Known as apraxia of speech, this syndrome often occurs in combination with aphasia (Ziegler et al., 2012). The sixth part of the present work details a proofof-concept study that seeks to determine whether or not using preserved formulaic language skills can relieve word-onset difficulties in apraxia of speech (Stahl et al., 2020). Twenty individuals with chronic moderate-tosevere apraxia of speech were asked to produce verbal cues (e.g., /gu:/ or /mu:/) and subsequent German target words (e.g., "Tanz") with critical onsets (e.g., /t/) in a cross-sectional repeated-measures design. Cues differed, for instance, in aspects of formulaicity (e.g., stereotyped prompt: /gui/, based on the formulaic expression "Guten Morgen"; unstereotyped prompt: 
/mu:/, based on the non-formulaic control word "Mutig"). Apart from systematic variation in stereotypy and communicative-pragmatic embeddedness, cues were matched for consonant-vowel structure, syllable-transition frequency, noun-verb classification, meter, and articulatory tempo.

Statistical analyses revealed significant increases in correctly produced word onsets after verbal cues with distinct features of formulaicity. Effect sizes were large. Although limited by the cross-sectional design, these results suggest that using preserved formulaic language skills may enable individuals to overcome word-onset difficulties in apraxia of speech. More specifically, retrieving intact speech-motor sequences within formulaic expressions may help restore incorrect initial segments of non-formulaic target utterances. If indeed preserved formulaic language skills are suitable to reduce failures in speech-motor planning, neuroscience data may clarify how such benefits relate to the interplay of left perilesional and right intact language networks in post-stroke rehabilitation. In this context, the reported behavioral results may establish a biological basis for future research on treatment-induced neuroplasticity of language function. Just as importantly, the results will hopefully inspire clinical trials on preserved formulaic language skills as a possible means to alleviate symptoms in apraxia of speech.

\section{Upcoming work: post-stroke depression and aphasia}

Individuals with neurological communication disorders often experience a profound loss of abilities to engage in social interaction. Such a loss is likely to diminish positive reinforcement obtained from the social environment, and therefore, may result in an increased risk of cognitiveaffective distress, as proposed by an influential model of depression aetiology (Lewinsohn, 1974). Aside from controversially debated neurological parameters such as lesion site (Carson et al., 2000; Bhogal et al., 2004; Robinson \& Jorge, 2016), this model explains, to some extent, why almost one third of patients meet official criteria of post-stroke depression (American 
Psychiatric Association, 2013; World Health Organization, 2019) within ten years after a cerebrovascular accident (Ayerbe et al., 2013). Crucially, metaanalyses indicate that diagnosis of aphasia increases the risk of depression by about 50\% (Mitchell et al., 2017). Individuals with post-stroke aphasia and depression commonly receive antidepressant medication, while classical forms of psychotherapy remain challenging due to constrained verbal expression and comprehension. These limitations coincide with the fact that non-pharmacological research on post-stroke depression rarely considers individuals with neurological communication disorders (Williams et al., 2007; Mitchell et al., 2009). To date, non-pharmacological research on poststroke aphasia and depression includes only a few randomized controlled trials (Thomas et al., 2013, 2019; Hilari et al., 2021) on interventions akin to behavioral activation (Richards et al., 2016) and peer companionship (Conwell et al., 2020).

Arguably, preserved right-hemispheric function may serve as a resource in the treatment of post-stroke aphasia and depression. Listening to pleasant music indeed appears to ease symptoms of post-stroke depression, as shown in randomized controlled trials (e.g., Särkämö et al., 2008) and meta-analyses (e.g., Baylan et al., 2016). A similarly promising evolution may be the recent spread of "aphasia choirs" in major cities around the globe. Focusing on verbal communication, a randomized controlled trial suggests that intensive use of formulaic expressions embedded in social interaction may have a positive impact on cognitive-affective distress in individuals with chronic post-stroke aphasia (Mohr, Stahl, et al., 2017). These individuals improved more on a standardized outcome measure of depression severity with Intensive Language-Action Therapy than with a control intervention that did not equally involve social interaction. However, none of the individuals met the full criteria of any affective disorder (American Psychiatric Association, 2013; World Health Organization, 2019), and none of them were within the first year after the onset of disease, where risk of post-stroke depression is especially high (Shi et al., 2014). These caveats point out the need to demonstrate the efficacy of Intensive Language-Action Therapy in fully developed post-stroke depression diagnosed in the late 
subacute or consolidation phase of aphasia. An upcoming randomized, parallel-group, blinded-assessment, controlled trial addresses this issue (Stahl et al., in preparation; www.who.int registry identifier: NCT04318951). The expected results will hopefully contribute to the field in substantiating the delivery of intensive social interaction as a potential treatment of post-stroke aphasia and depression.

\section{Concluding remarks: psychotherapy and aphasia}

According to late 19th century psychoanalysis, the "subconscious" becomes apparent in the relationship between patient and therapist as well as in metaphors and symbols revealed through unintended utterances, imaginative techniques, and dreams. To convey emotions and thoughts, this method relies on the use of spoken language. Likewise, spoken language remained central to the practice of psychotherapy in subsequent decades, as clinicians and researchers sought to translate and transform major claims of psychoanalysis into newer paradigms, the most prominent of them being cognitive-behavioral, client-centered, and family-systems psychotherapy. Given the prerequisite of verbal communication, psychotherapy and aphasia seem almost mutually exclusive. Still, a thought-provoking resemblance between psychotherapy and speech-language pathology may be the observation that research on aphasia was-and in many ways still is-primarily concerned with deficits in verbal expression and comprehension, with less efforts devoted to resources, including right-hemispheric function underlying musical skills and formulaic expressions. Similarly, the role of resources in psychotherapy has received full attention relatively late, prompted mainly by the emergence of family-systems psychotherapy in the past 50 years. The question is: can speech-language therapy learn from psychotherapy? If the answer is yes, the present work aims to raise awareness about resources of right-hemispheric function in post-stroke aphasia and depression. 
From a conceptual perspective, it may be equally interesting to reverse the question: can psychotherapy learn from research on aphasia? Moving beyond spoken language may, in principle, not only benefit the treatment of post-stroke aphasia and depression, but also complement existing methods in psychotherapy. Anecdotal evidence indeed provides preliminary support for the feasibility of externalization techniques from family-systems psychotherapy in the treatment of post-stroke aphasia and depression. As an example of externalization techniques, relationship mapping in "sculptures" attempts to make interpersonal problems visible in space, and therefore, easier to handle (Satir et al., 1991). This figurative approach may potentially compensate for mild-to-moderate communication difficulties, in analogy to the use of preserved right-hemispheric function in post-stroke aphasia and depression. The non-verbal aspect of relationship mapping in psychotherapy is particularly noticeable in individuals suffering from neurological communication disorders-and may be an indicator of "creativity" beyond spoken language, with a possible impact on treatment outcome. Obviously, these claims are speculative and need to be confirmed by data. A first step in such a direction may be an ongoing proof-of-concept study on music and psychotherapy in individuals with interpersonal problems of non-vascular origin (www.who.int registry identifier: NCT04830553). Exploring the interface of neurological communication disorders and psychotherapy, the current work encourages clinicians to consider research on aphasia as a "treasure" to spur innovation both within and outside the realm of speechlanguage therapy. In line with this view, the founding father of psychoanalysis once set out to develop a "talking cure" after completing a controversial treatise on-aphasia (Freud, 1891). 


\section{References}

Albert, M. L., Sparks, R. W., \& Helm, N. (1973). Melodic Intonation Therapy for aphasia. Archives of Neurology, 29(2), 130-131.

Allen, L., Mehta, S., McClure, J. A., \& Teasell, R. (2012). Therapeutic interventions for aphasia initiated more than six months post stroke: A review of the evidence. Topics in Stroke Rehabilitation, 19(6), 523535.

American Psychiatric Association (2013). Diagnostic and Statistical Manual of Mental Disorders (DSM-5). Arlington, VA: American Psychiatric Publishing.

Ayerbe, L., Ayis, S., Wolfe, C. D., \& Rudd, A. G. (2013). Natural history, predictors and outcomes of depression after stroke: Systematic review and meta-analysis. The British Journal of Psychiatry, 202(1), 14-21.

Baur, B., Uttner, I., Ilmberger, J., Fesl, G., \& Mai, N. (2000). Music memory provides access to verbal knowledge in a patient with global amnesia. Neurocase, 6(5), 415-421.

Baylan, S., Swann-Price, R., Peryer, G., \& Quinn, T. (2016). The effects of music listening interventions on cognition and mood post-stroke: A systematic review. Expert Review of Neurotherapeutics, 16(11), 12411249.

Benton, A. L., \& Joynt, R. J. (1960). Early descriptions of aphasia. Archives of Neurology, 3(2), 205-222.

Berthier, M. L., Green, C., Lara, J. P., Higueras, C., Barbancho, M. A., Dávila, G., et al. (2009). Memantine and Constraint-Induced Aphasia Therapy in chronic poststroke aphasia. Annals of Neurology, 65(5), $577-585$.

Bhogal, S. K., Teasell, R., \& Speechley, M. (2003). Intensity of aphasia therapy, impact on recovery. Stroke, 34(4), 987-993. 
Bhogal, S. K., Teasell, R., Foley, N., \& Speechley, M. (2004). Lesion location and poststroke depression: Systematic review of the methodological limitations in the literature. Stroke, 35(3), 794-802.

Brady, M. C., Kelly, H., Godwin, J., Enderby, P., \& Campbell, P. (2016). Speech and language therapy for aphasia following stroke. The Cochrane Database of Systematic Reviews, 2016(6), Article CD000425.

Breitenstein, C., Grewe, T., Flöel, A., Ziegler, W., Springer, L., Martus, P., et al. (2017). Intensive speech and language therapy in patients with chronic aphasia after stroke: A randomised, open-label, blindedendpoint, controlled trial in a health-care setting. Lancet, 389(10078), 1528-1538.

Carson, A. J., MacHale, S., Allen, K., Lawrie, S. M., Dennis, M., House, A., et al. (2000). Depression after stroke and lesion location: A systematic review. Lancet, 356(9224), 122-126.

Cherney, L. R., Patterson, J. P., Raymer, A., Frymark, T., \& Schooling, T. (2008). Evidence-based systematic review: Effects of intensity of treatment and Constraint-Induced Language Therapy for individuals with stroke-induced aphasia. Journal of Speech, Language, and Hearing Research, 51(5), 1282-1299.

Conwell, Y., Van Orden, K. A., Stone, D. B., McIntosh, W. K., Messing, S., Rowe, J., et al. (2020). Peer companionship for mental health of older adults in primary care: A pragmatic, nonblinded, parallel-group, randomized controlled trial. The American Journal of Geriatric Psychiatry. doi: 10.1016/j.jagp.2020.05.021

Difrancesco, S., Pulvermüller, F., \& Mohr, B. (2012). Intensive LanguageAction Therapy (ILAT): The methods. Aphasiology, 26(11), 13171351.

Doppelbauer, L., Mohr, B., Dreyer, F. R., Stahl, B., Büscher, V., \& Pulvermüller, F. (2021). Long-term stability of short-term Intensive LanguageAction Therapy in chronic aphasia: A 1-2 years follow-up study. Neurorehabilitation and Neural Repair. doi: 10.1177/15459683211029235 
Engelter, S. T., Gostynski, M., Papa, S., Frei, M., Born, C., Ajdacic-Gross, V., et al. (2006). Epidemiology of aphasia attributable to first ischemic stroke: Incidence, severity, fluency, etiology, and thrombolysis. Stroke, 37(6), 1379-1384.

Flöel, A., \& Stahl, B. (2019). Aphasie. In H. C. Diener, O. Kastrup, \& H. Steinmetz (Eds.), Referenz Neurologie (pp. 1045-1051). New York, NY: Thieme.

Freud, S. (1891). Zur Auffassung der Aphasien. Leipzig und Wien: Franz Deuticke.

Gerstmann, H. L. (1964). A case of aphasia. Journal of Speech and Hearing Disorders, 29, 89-91.

Graves, R., \& Landis, T. (1985). Hemispheric control of speech expression in aphasia. Archives of Neurology, 42(3), 249-251.

Helm-Estabrooks, N., Nicholas, M., \& Morgan, A. (1989). Melodic Intonation Therapy. Manual. Austin, TX: Pro-Ed.

Hilari, K., Behn, N., James, K., Northcott, S., Marshall, J., Thomas, S., et al. (2021). Supporting wellbeing through peer-befriending (SUPERB) for people with aphasia: A feasibility randomised controlled trial. Clinical Rehabilitation. doi: 10.1177/0269215521995671

Hughlings-Jackson, J. (1878). On affection of speech from disease of the brain. Brain, 2(3), 203-222.

Jacome, D. E. (1984). Aphasia with elation, hypermusia, musicophilia and compulsive whistling. Journal of Neurology, Neurosurgery and Psychiatry, 47(3), 308-310.

Jungblut, M. (2009). SIPARI: A music therapy intervention for patients suffering with chronic, nonfluent aphasia. Music and Medicine, 1(2), 102-105.

Keith, R. L., \& Aronson, A. E. (1975). Singing as therapy for apraxia of speech and aphasia: Report of a case. Brain and Language, 2(4), 483488. 
Kershenbaum, A., Nicholas, M. L., Hunsaker, E., \& Zipse, L. (2017). Speak along without the song: What promotes fluency in people with aphasia? Aphasiology, 33(4), 405-428.

Lewinsohn, P. M. (1974). A behavioral approach to depression. In R. J. Friedman, \& M. M. Katz (Eds.), Psychology of Depression: Contemporary Theory and Research (pp. 157-178). Oxford: Wiley.

Meinzer, M., Djundja, D., Barthel, G., Elbert, T., \& Rockstroh, B. (2005). Long-term stability of improved language functions in chronic aphasia after Constraint-Induced Aphasia Therapy. Stroke, 36(7), 1462-1466.

Meinzer, M., Streiftau, S., \& Rockstroh, B. (2007). Intensive language training in the rehabilitation of chronic aphasia: Efficient training by laypersons. Journal of the International Neuropsychological Society, 13(5), 846-853.

Mills, C. K. (1904). Treatment of aphasia by training. Journal of the American Medical Association, 43(26), 1940-1949.

Mitchell, A. J., Sheth, B., Gill, J., Yadegarfar, M., Stubbs, B., Yadegarfar, M., et al. (2017). Prevalence and predictors of post-stroke mood disorders: A meta-analysis and meta-regression of depression, anxiety and adjustment disorder. General Hospital Psychiatry, 47, 48-60.

Mitchell, P. H., Veith, R. C., Becker, K. J., Buzaitis, A., Cain, K. C., Fruin, M., et al. (2009). Brief psychosocial-behavioral intervention with antidepressant reduces poststroke depression significantly more than usual care with antidepressant-living well with stroke: Randomized, controlled trial. Stroke, 40(9), 3073-3078.

Mohr, B., Stahl, B., Berthier, M. L., \& Pulvermüller, F. (2017). Intensive communicative therapy reduces symptoms of depression in chronic non-fluent aphasia. Neurorehabilitation and Neural Repair, 31(12), 1053-1062.

Peretz, I. (2020). How Music Sculpts our Brain. Paris: Odile Jacob. 
Peretz, I., Gagnon, L., Hébert, S., \& Macoir, J. (2004). Singing in the brain: Insights from cognitive neuropsychology. Music Perception, 21(3), 373-390.

Pulvermüller, F., \& Roth, V. M. (1991). Communicative aphasia treatment as a further development of pace therapy. Aphasiology, 5(1), 39-50.

Pulvermüller, F., Neininger, B., Elbert, T., Mohr, B., Rockstroh, B., Koebbel, P., et al. (2001). Constraint-induced therapy of chronic aphasia after stroke. Stroke, 32(7), 1621-1626.

Racette, A., Bard, C., \& Peretz, I. (2006). Making non-fluent aphasics speak: Sing along! Brain, 129(10), 2571-2584.

RELEASE Collaboration (2021). Predictors of post-stroke aphasia recovery: A systematic review-informed individual participant data metaanalysis. Stroke, 52(5), 1778-1787.

Richards, D. A., Eker, D., McMillan, D., Taylor, R. S., Byford, S., Warren, F. C., et al. (2016). Cost and outcome of behavioural activation versus cognitive behavioural therapy for depression (COBRA): A randomised, controlled, non-inferiority trial. Lancet, 388(10047), 871880.

Robinson R. G., \& Jorge, R. E. (2016). Post-stroke depression: A review. The American Journal of Psychiatry, 173(3), 221-231.

Särkämö, T., Tervaniemi, M., Laitinen, S., Forsblom, A., Soinila, S., Mikkonen, M., et al. (2008). Music listening enhances cognitive recovery and mood after middle cerebral artery stroke. Brain, 131(3), 866-876.

Satir, V., Banmen, J., Gerber, J., \& Gomori, M. (1991). The Satir Model: Family Therapy and Beyond. Palo Alto, CA: Science and Behavior Books.

Schmidt-Kassow, M., Rothermich, K., Schwartze, M., \& Kotz, S. A. (2011). Did you get the beat? Late proficient French-German learners extract 
strong-weak patterns in tonal but not in linguistic sequences. Neuroimage, 54(1), 568-576.

Shi, Y. Z., Xiang, Y. T., Wu, S. L., Zhang, N., Zhou, J., Bai, Y., et al. (2014). The relationship between frontal lobe lesions, course of post-stroke depression, and 1-year prognosis in patients with first-ever ischemic stroke. PLOS ONE, 9(7), Article e100456.

Sidtis, D., Canterucci, G., \& Katsnelson, D. (2009). Effects of neurological damage on production of formulaic language. Clinical Linguistics \& Phonetics, 23(4), 270-284.

Smith, A. (1966). Speech and other functions after left (dominant) hemispherectomy. Journal of Neurology, Neurosurgery and Psychiatry, 29(5), 467-471.

Sparks, R. W., Helm, N., \& Albert, M. L. (1974). Aphasia rehabilitation resulting from Melodic Intonation Therapy. Cortex, 10(4), 303-316.

Speedie, L. J., Wertman, E., Ta'ir, J., \& Heilman, K. M. (1993). Disruption of automatic speech following a right basal ganglia lesion. Neurology, 43(9), 1768-1774.

Stahl, B., \& Kotz, S. A. (2014). Facing the music: Three issues in current research on singing and aphasia. Frontiers in Psychology, 5, Article 1033.

Stahl, B., \& Van Lancker Sidtis, D. (2015). Tapping into neural resources of communication: Formulaic language in aphasia therapy. Frontiers in Psychology, 6, Article 1526.

Stahl, B., Darkow, R., von Podewils, V., Meinzer, M., Grittner, U., Reinhold, T., et al. (2019). Transcranial direct current stimulation to enhance training effectiveness in chronic post-stroke aphasia: A randomized controlled trial protocol. Frontiers in Neurology, 10, Article 1089.

Stahl, B., Gawron, B., Regenbrecht, F., Flöel, A., \& Kotz, S. A. (2020). Formulaic language resources may help overcome difficulties in 
speech-motor planning after stroke. PLOS ONE, 15(6), Article e0233608.

Stahl, B., Henseler, I., Turner, R., Geyer, S., \& Kotz, S. A. (2013). How to engage the right brain hemisphere in aphasics without even singing: Evidence for two paths of speech recovery. Frontiers in Human Neuroscience, 7, Article 35.

Stahl, B., Kotz, S. A., Henseler, I., Turner, R., \& Geyer, S. (2011). Rhythm in disguise: Why singing may not hold the key to recovery from aphasia. Brain, 134(10), 3083-3093.

Stahl, B., Mohr, B., Büscher, V., Dreyer, F., Lucchese, G., \& Pulvermüller, F. (2018). Efficacy of intensive aphasia therapy in patients with chronic stroke: A randomised controlled trial. Journal of Neurology, Neurosurgery and Psychiatry, 89(6), 586-592.

Stahl, B., Mohr, B., Dreyer, F. R., Lucchese, G., \& Pulvermüller, F. (2016). Using language for social interaction: Communication mechanisms promote recovery from chronic non-fluent aphasia. Cortex, 85, 90-99.

Stahl, B., Mohr, B., Dreyer, F. R., Lucchese, G., \& Pulvermüller, F. (2017). Communicative-pragmatic assessment is sensitive and time-effective in measuring the outcome of aphasia therapy. Frontiers in Human Neuroscience, 11, Article 223.

Szaflarski, J. P., Ball, A. L., Vannest J., Dietz, A. R., Allendorfer, J. B., Martin, A. N., et al. (2015). Constraint-Induced Aphasia Therapy for treatment of chronic post-stroke aphasia: A randomized, blinded, controlled pilot trial. Medical Science Monitor, 21, 2861-2869.

Thomas, S. A., Drummond, A. E. R., Lincoln, N. B., Palmer, R. L., das Nair, R., Latimer, N. R., et al. (2019). Behavioural activation therapy for post-stroke depression: The BEADS feasibility RCT. Health Technology Assessment, 23(47), 1-176.

Thomas, S. A., Walker, M. F., Macniven, J. A., Haworth, H., \& Lincoln, N. B. (2013). Communication and low mood (CALM): A randomized 
controlled trial of behavioural therapy for stroke patients with aphasia. Clinical Rehabilitation, 27(5), 398-408.

Tomaino, C. M. (2010). Recovery of fluent speech through a musician's use of prelearned song repertoire: A case study. Music and Medicine, 2(2), $85-88$.

Ustvedt, H. J. (1937). Über die Untersuchung der musikalischen Funktionen bei Patienten mit Gehirnleiden, besonders bei Patienten mit Aphasie. Oslo: Helsingfors.

Van der Meulen, I., van de Sandt-Koenderman, M. E., Heijenbrok-Kal, M. H., Visch-Brink, E. G., \& Ribbers, G. M. (2014). The efficacy and timing of Melodic Intonation Therapy in subacute aphasia. Neurorehabilitation and Neural Repair, 28(6), 536-544.

Van der Meulen, I., van de Sandt-Koenderman, M. E., Heijenbrok-Kal, M. H., Visch-Brink, E. G., \& Ribbers, G. M. (2016). Melodic Intonation Therapy in chronic aphasia: Evidence from a pilot randomized controlled trial. Frontiers in Human Neuroscience, 10, Article 533.

Van Lancker Sidtis, D. (2021). Foundations of Familiar Language: Formulaic Expressions, Lexical Bundles, and Collocations at Work and Play. Oxford: Wiley.

Van Lancker Sidtis, D., \& Postman, W. A. (2006). Formulaic expressions in spontaneous speech of left- and right-hemisphere-damaged subjects. Aphasiology, 20(5), 411-426.

Van Lancker Sidtis, D., \& Rallon, G. (2004). Tracking the incidence of formulaic expressions in everyday speech: Methods for classification and verification. Language \& Communication, 24(3), 207-240.

Van Lancker Sidtis, D., Choi, J.-H., Alken, A., \& Sidtis, J. J. (2015). Formulaic language in Parkinson's and Alzheimer's disease: Complementary effects of subcortical and cortical dysfunction. Journal of Speech, Language, and Hearing Research, 58(5), 1493-1507. 
Warren, J. D., Warren, J. E., Fox, N. C., \& Warrington, E. K. (2003).

Nothing to say, something to sing: Primary progressive dynamic aphasia. Neurocase, 9(2), 140-155.

Williams, L. S., Kroenke, K., Bakas, T., Plue, L. D., Brizendine, E., Tu, W., et al. (2007). Care management of poststroke depression: A randomized, controlled trial. Stroke, 38(3), 998-1003.

World Health Organization (2019). International Classification of Diseases for Mortality and Morbidity Statistics (11th Revision). New York: World Health Organization.

Yamadori, A., Osumi, Y., Masuhara, S., \& Okubo, M. (1977). Preservation of singing in Broca's aphasia. Journal of Neurology, Neurosurgery and Psychiatry, 40(3), 221-224.

Ziegler, W., Aichert, I., \& Staiger, A. (2012). Apraxia of speech: Concepts and controversies. Journal of Speech, Language, and Hearing Research, 55(5), 1485-1501.

Zumbansen, A., Peretz, I., \& Hébert, S. (2014). The combination of rhythm and pitch can account for the beneficial effect of Melodic Intonation Therapy on connected speech improvements in Broca's aphasia.

Frontiers in Human Neuroscience, 8, Article 592. 


\section{Part II}

\section{Training intensity}

Original publication

Stahl, B., Mohr, B., Büscher, V., Dreyer, F., Lucchese, G., \& Pulvermüller, F. (2018). Efficacy of intensive aphasia therapy in patients with chronic stroke: A randomised controlled trial. Journal of Neurology, Neurosurgery and Psychiatry, 89(6), 586-592. 


\section{Abstract}

Purpose. Recent evidence has fueled the debate on the role of massed practice in the rehabilitation of chronic post-stroke aphasia. Here, we further determined the optimal daily dosage and total duration of intensive speech-language therapy.

Methods. Individuals with chronic aphasia more than one year poststroke received Intensive Language-Action Therapy in a randomized, parallel-group, blinded-assessment, controlled trial. Participants were randomly assigned to one of two outpatient groups who engaged in either highlyintensive practice (Group I: 4 hours daily) or moderately-intensive practice (Group II: 2 hours daily). Both groups went through an initial waiting period and two successive training intervals. Each phase lasted two weeks. Co-primary endpoints were defined after each training interval.

Results. Thirty individuals-15 per group-completed the study. A primary outcome measure (Aachen Aphasia Test) revealed no gains in language performance after the waiting period, but indicated significant progress after each training interval (gradual two-week $t$-score change [confidence interval]: $1.7[ \pm 0.4] ; 0.6[ \pm 0.5]$ ), independent of the intensity level applied (four-week change in Group I: $2.4[ \pm 1.2]$; in Group II: $2.2[ \pm 0.8]$ ). A secondary outcome measure (Action Communication Test) confirmed these findings in the waiting period and in the first training interval. In the second training interval, however, only individuals with moderately-intensive practice continued to make progress (Time-by-Group interaction: $p=0.009, \eta^{2}=0.13$ ).

Conclusions. Our results suggest no added value from more than 2 hours of daily speech-language therapy within four weeks. Instead, these results demonstrate that even a small two-week increase in treatment duration contributes substantially to recovery from chronic post-stroke aphasia. 


\section{Introduction}

A long-standing controversy has surrounded the appropriate quantity of speech-language therapy (SLT) in the rehabilitation of chronic poststroke aphasia. Although clinical research highlights the importance of massed practice in SLT (Breitenstein et al., 2017), the effective delivery of intensive regimens is not yet fully understood (Cherney et al., 2008). From a conceptual perspective, the outcome of intensive SLT may depend on two discrete features: (i) the amount of weekly practice, and (ii) the total duration of the training period. Literature reviews indeed suggest that a weekly dosage ranging from 5 to 10 hours, referred to as "moderately-intensive," is sufficient to ensure significantly improved language performance on standardized aphasia test batteries (Bhogal et al., 2003; Allen et al., 2012; Brady et al., 2016). However, studies so far do not offer insight into whether massed practice in a weekly dosage over and above 10 hours, referred to as "highlyintensive," leads to further gains in SLT. Moreover, weekly practice and overall treatment duration are negatively correlated across studies, thus making it difficult to determine the influence of the training period on symptom recovery. The current work seeks to address both of these issues.

To date, surprisingly few studies have focused on the amount of weekly practice and duration of the training period in intensive SLT. A randomized controlled trial (RCT) indicated a superiority of ConstraintInduced Aphasia Therapy administered in a highly-intensive fashion (weekly practice: ca. 16 hours; duration: two weeks) over traditional, moderately-intensive SLT (weekly practice: 6-8 hours; duration: 45 weeks; Pulvermüller et al., 2001). The design of this RCT balanced the total number of hours provided in each type of training, whereas it did not match the treatment protocols and clinical settings, such as the one-to-one or patient-group context, along with the selection and variety of therapists. Using well-matched treatment protocols and clinical settings, a subsequent non-RCT study revealed greater progress in language performance with moderately-intensive SLT (weekly practice: 6 hours; duration: eight weeks) compared to highly-intensive SLT (weekly practice: 16 hours; duration: 
three weeks; Dignam et al., 2015). Still, this study did not randomly assign individuals to the treatment groups, and therefore, prevents definitive conclusions with regard to the ideal amount of weekly practice and duration of the training period.

Here, we present the first RCT evidence on the efficacy of Intensive Language-Action Therapy (ILAT, an expanded version of ConstraintInduced Aphasia Therapy requiring request and planning communication) applied with different degrees of massed practice (12 hours versus 6 hours per week). Both intensity levels reached the estimated minimum dosage of 5-10 hours weekly to assess the potential benefit from further daily practice in individuals with chronic post-stroke aphasia (Bhogal et al., 2003; Allen et al., 2012; Brady et al., 2016). Apart from the intensity levels, the treatments were based on identical protocols, materials and procedures to overcome methodological problems of previous work. To explore the possible impact of treatment duration on symptom recovery, all individuals went through an initial waiting period and two successive training intervals (each phase lasting two weeks). Although specific predictions would be premature in light of currently available RCT and non-RCT results, these data do not rule out an added value (i) when increasing the amount of weekly practice over and above 5-10 hours, and (ii) when extending the duration of the training period up to one month (Robey et al., 1998).

\section{Methods}

\subsection{Study design and setting}

We conducted a randomized, parallel-group, blinded-assessment, controlled trial in an outpatient center at the Freie Universität Berlin, Germany, from 2015 to 2016. The trial was approved by the ethics review board at the Charité University Hospital in Berlin, Germany, and registered prospectively (www.who.int registry identifier: DRKS00007829). 


\subsection{Participants}

Recruitment was administered in collaboration with several local rehabilitation centers and support groups for individuals with aphasia. After routine referral to the study team, we contacted the potential participants and invited them to a screening session to check their eligibility. Inclusion criteria were: diagnosis of aphasia, as confirmed by the Aachen Aphasia Test (AAT; Huber et al., 1984); chronic stage of symptoms at least one year post-onset of stroke to prevent non-treatment effects related to spontaneous recovery; German as first native language; and right-handedness according to the Edinburgh Handedness Inventory (Oldfield et al., 1971). Exclusion criteria were: aphasia due to traumatic brain injury or neurodegenerative disease; severe non-verbal cognitive deficits, as confirmed by the Corsi Block-Tapping Task (Kessels et al., 2000); severe uncorrected vision or hearing disorders; other untreated medical conditions; and intensive SLT in the two years prior to study enrolment. Thirty individuals with chronic poststroke aphasia were recruited, screened and agreed to participate in the present RCT (for details, see Fig. 1). This sample size was calculated in a previous power analysis $(\alpha=0.05 ; 1-\beta=0.95$; number of groups: 2 ; number of repeated measures: 4; Cohen's $f=0.3$ for our primary outcome, the AAT, derived from Stahl et al., 2016; resulting $n=26$; assumed drop-out rate: 10\%; final $n=30$; Faul et al., 2009). On average, individuals were aged 60.1 years (standard deviation: 15.3 years) and 65.2 months post-onset of stroke (standard deviation: 64.3 months). 


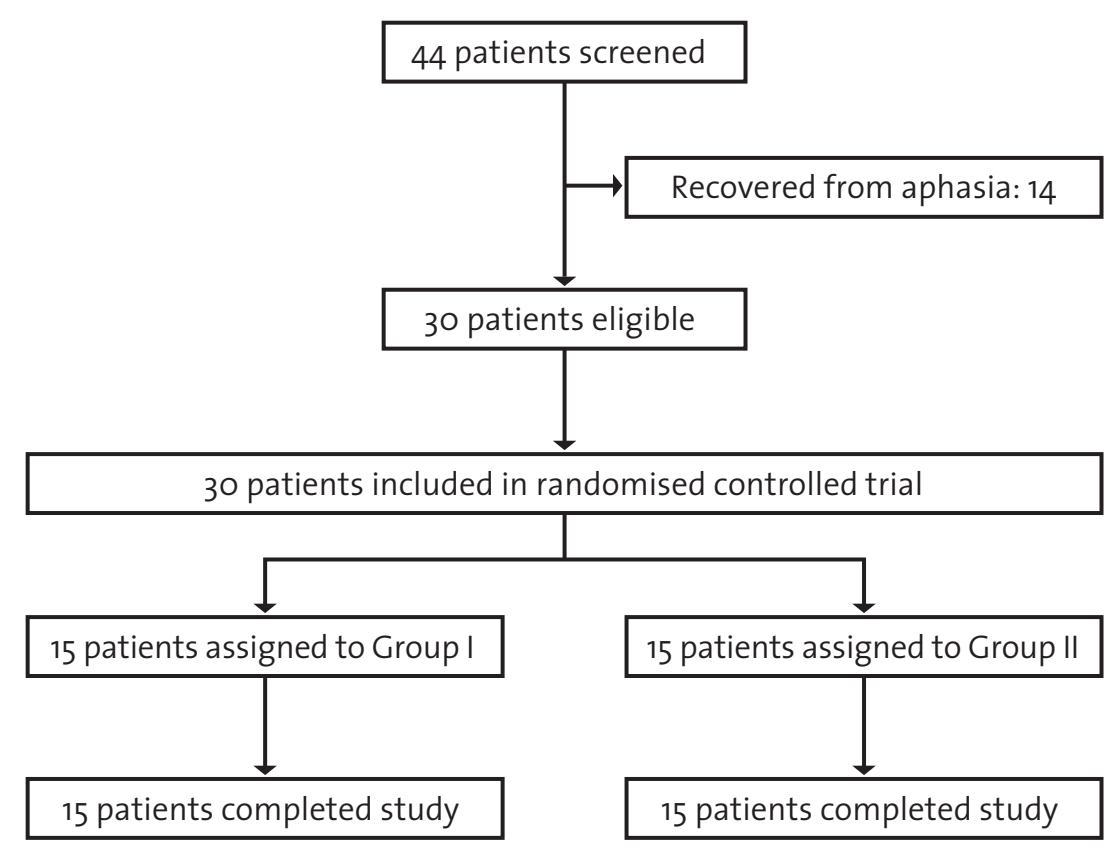

Figure 1. CONSORT Flow Diagram.

\subsection{Randomization and blinding}

A Python script generated a list of 30 random numbers ( 0 or 1$)$ resulting in treatment groups of the same size (each $n=15$ ). The script did not consider any additional variables. Instead, we included key baseline characteristics in our statistical analyses, as specified below. Individuals were randomly assigned to one of two treatment groups receiving ILAT with different degrees of massed practice (Group I: 4 hours of daily training; Group II: 2 hours of daily training). The group allocation was executed by an individual who alone had access to the list of random numbers and who did not participate in any stage of recruiting, screening, therapy or testing. A clinical linguist and neuroscientist performed all diagnostic sessions. The person was blinded to the group assignment and did not have patient contact aside from the testing. Data were unmasked only for final evaluation purposes by the study team who did not attend any of the diagnostic sessions. 


\subsection{Treatment protocols, materials and procedures}

ILAT required individuals to engage in everyday request and planning communication with related social interaction (Difrancesco et al., 2012). Groups of three individuals and a therapist were seated around a table and provided with picture cards showing different objects (e.g., bottle) or action scenes (e.g., drinking). Barriers on the table prevented players from seeing each others' cards. Each card had a duplicate that was owned by one of the other players. The goal was to obtain this duplicate from a fellow player by requesting the depicted object (e.g., "Give me the [...]") or by proposing an action based on the visualized scene (e.g., "Let's [...] together"). If the duplicate was available, the players compared the depicted objects or action scenes. In the case of a match, the addressee handed over the corresponding card to the person who initiated the request or action-planning sequence. If the duplicate was not available, the addressee rejected the request or proposed action. In the event of misunderstandings, the players asked clarifying questions. The complexity of the communicative interaction was tailored to the language skills of each individual by varying the difficulty level of the target words and sentence structures.

The training materials consisted of 336 items presented in separate cards sets, each including 12 picture pairs. For tailoring these sets to individual language skills, the following difficulty levels were available: nouns with high ( $n=48$ different pictures), medium $(n=48)$, and low $(n=48)$ normalized lemma frequency; nouns with phonological similarities (e.g., "ball" and "wall"; $n=96)$; nouns from only one semantic category $(n=48)$; action-related verbs with high $(n=24)$ and low $(n=24)$ normalized lemma frequency; and action-related verbs applied to one target object (e.g., "to peel, cut, grate or eat an apple"; $n=48$ ). Card sets of one difficulty level were matched for mean normalized lemma frequency. All 28 card sets were split into two parts with equal numbers of items per difficulty level and assigned to the two training intervals in counterbalanced order across treatment groups. In all training sessions, the therapist (i) encouraged players by giv- 
ing positive feedback, (ii) acted as a model by using appropriate sentence structures (e.g., polite requests for individuals with prevailing agrammatism: "Would you consider passing me the [...], please?"), and (iii) embedded semantic cues in turn-taking sequences, whenever helpful (e.g., proposals for individuals with word finding deficits: "May I offer you that tool to cut things?"- “Knife, yes!"). The therapist did not offer other types of cues, whether phonemic (e.g., initial word sounds: "It starts with /n/ ...”-“Knife.”) or graphemic ones (e.g., reading or writing), nor did the individuals repeat verbal utterances on instruction (e.g., "It is a knife. What is it?”-“Knife."). Self-cueing strategies were allowed, along with gestures to accompany-but not replace-spoken language.

Treatment was delivered by four therapists who received special training and continuous supervision before and during the trial. Notably, the selection and number of therapists did not differ between the treatment groups. Cohorts of three individuals who were relatively heterogeneous with regard to symptom severity underwent ILAT with the degree of massed practice determined by the randomization procedure described above ( 4 hours versus 2 hours of daily training). Therapy frequency was consistent across treatment groups (always three weekly sessions). Both treatment groups went through an initial waiting period and two successive training intervals. Each phase lasted two weeks ( 6 consecutive working days, always separated by a weekend). Depending on the intensity level, the two training intervals involved overall 48 hours (Group I) or 24 hours of practice (Group II) within four weeks (see Table 1). Individuals completed all training sessions and did not attend any other form of SLT throughout the entire trial. 
Table 1. Intensive regimens.

\begin{tabular}{lll}
\hline & Group I & Group II \\
\hline Intervention type & ILAT & ILAT \\
\hline Daily practice & 4 hours & 2 hours \\
\hline Weekly practice & 12 hours & 6 hours \\
\hline Therapy frequency & 3 weekly sessions & 3 weekly sessions \\
\hline Duration of each trial phase & 6 consecutive working days & 6 consecutive working days \\
\hline Total amount of practice & 48 hours & 24 hours \\
\hline Total treatment duration & 4 weeks & 4 weeks \\
\hline
\end{tabular}

Thirty individuals with chronic post-stroke aphasia were randomly assigned to one of two treatment groups receiving Intensive Language-Action Therapy (ILAT) with 4 hours (Group I) or with 2 hours of daily practice (Group II).

\subsection{Baseline data}

Each patient met the diagnostic criteria of aphasia according to the AAT (Huber et al., 1984). Since individuals with aphasia often suffer from concomitant deficits in motor planning, it is worth noting that Group I and Group II were similarly affected by apraxia of speech, as confirmed by two independent clinical linguists with high inter-rater agreements (100\%). Focusing on non-verbal short-term memory, our patient sample scored, on average, within the normal range on the Corsi Block-Tapping Task (Kessels et al., 2000). Structural $\mathrm{T}_{1}$-weighted magnetic resonance imaging was performed for all individuals using a 3T Magnetom Trio scanner (Siemens Medical Solutions, Erlangen, Germany). All individuals had suffered a single cerebrovascular accident with subsequent lesions in parts of the left frontal, parietal, and temporal lobes, as well as in adjacent subcortical areas. Two clinical neuroscientists manually delineated and superimposed the precise locations of lesioned voxels in each patient using the software MRIcron (Rorden \& Brett, 2000; for lesion overlay maps, see Fig. 2; for individual case histories and baseline test scores, see Table 2 and 3). 


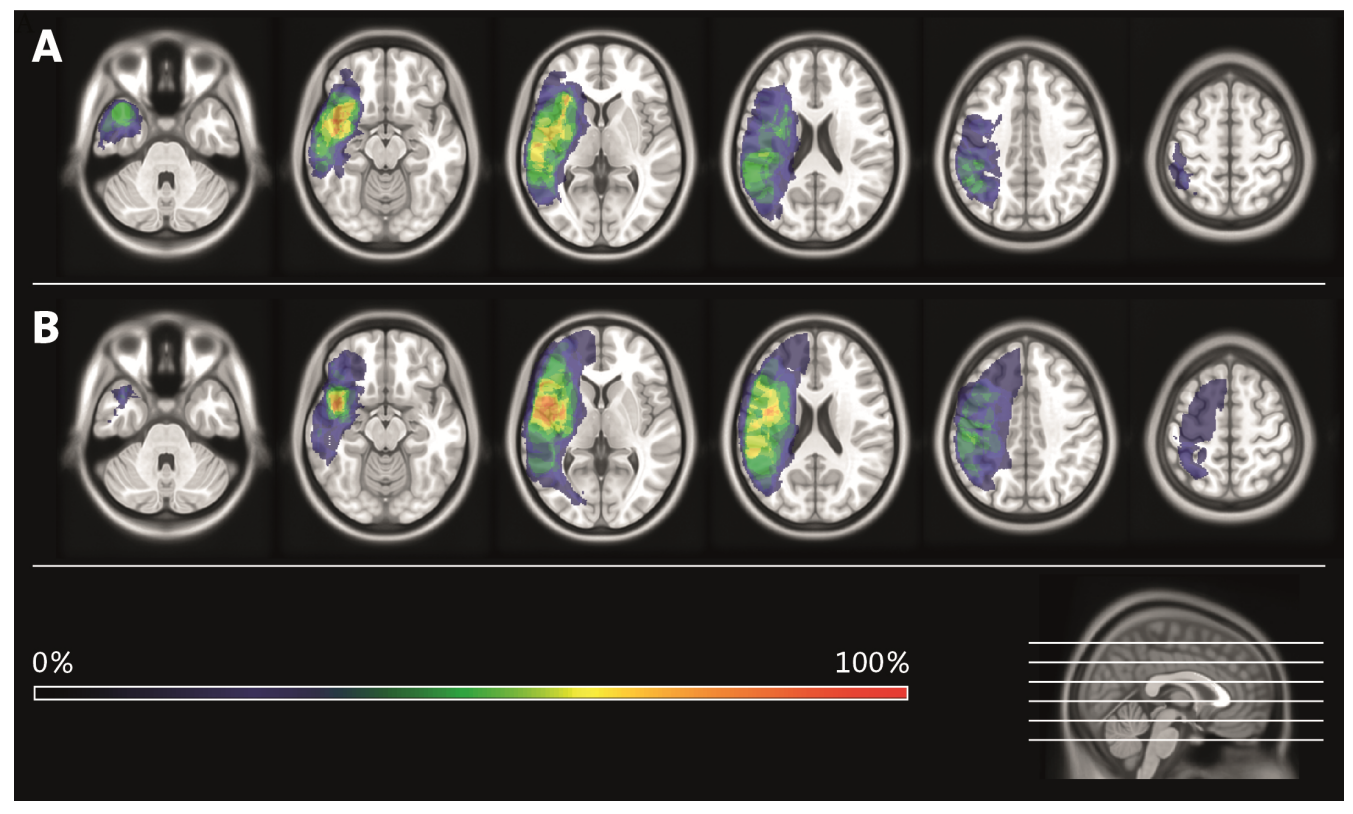

Figure 2. Lesion overlay maps. Individuals received Intensive Language-Action Therapy with 4 hours (Group I; see Panel A) or with 2 hours of daily practice (Group II; see Panel B). Different colors indicate the degree of lesion overlap in each treatment group. 
Table 2. Patient histories.

\begin{tabular}{|c|c|c|c|c|c|}
\hline Patient & Gender & $\begin{array}{l}\text { Age } \\
\text { (in years) }\end{array}$ & $\begin{array}{l}\text { Education level } \\
\text { (in years) }\end{array}$ & $\begin{array}{l}\text { Months after } \\
\text { onset of stroke }\end{array}$ & $\begin{array}{l}\text { Left-hemisphere } \\
\text { origin }\end{array}$ \\
\hline 01 & Male & 74 & 17 & 29 & MCA ischemia \\
\hline 02 & Male & 70 & 13 & 30 & MCA ischemia \\
\hline 03 & Male & 76 & 9 & 76 & MCA ischemia \\
\hline 04 & Female & 58 & 18 & 146 & MCA ischemia \\
\hline 05 & Male & 61 & 19 & 19 & MCA ischemia \\
\hline 06 & Female & 33 & 13 & 12 & MCA ischemia \\
\hline 07 & Female & 82 & 13 & 197 & MCA ischemia \\
\hline 08 & Female & 44 & 12 & 17 & MCA ischemia \\
\hline 09 & Female & 36 & 12 & 27 & MCA ischemia \\
\hline 10 & Male & 64 & 17 & 41 & MCA ischemia \\
\hline 11 & Female & 56 & 21 & 12 & MCA ischemia \\
\hline 12 & Male & 48 & 13 & 12 & MCA ischemia \\
\hline 13 & Male & 67 & 16 & 75 & BG hemorrhage \\
\hline 14 & Male & 57 & 21 & 74 & MCA ischemia \\
\hline 15 & Female & 51 & 13 & 178 & MCA ischemia \\
\hline \multicolumn{6}{|l|}{ Group I } \\
\hline Mean (SD) & & $58.5(14.3)$ & $15.1(3.6)$ & $63.0(62.3)$ & \\
\hline 16 & Male & 67 & 19 & 27 & MCA ischemia \\
\hline 17 & Female & 51 & 18 & 23 & MCA ischemia \\
\hline 18 & Female & 77 & 9 & 23 & MCA ischemia \\
\hline 19 & Male & 74 & 19 & 24 & MCA ischemia \\
\hline 20 & Male & 84 & 11 & 53 & MCA ischemia \\
\hline 21 & Female & 60 & 12 & 253 & MCA ischemia \\
\hline 22 & Female & 41 & 12 & 95 & MCA ischemia \\
\hline 23 & Female & 39 & 11 & 45 & MCA ischemia \\
\hline 24 & Male & 34 & 14 & 54 & MCA ischemia \\
\hline 25 & Male & 65 & 13 & 51 & MCA ischemia \\
\hline 26 & Male & 75 & 16 & 209 & MCA ischemia \\
\hline 27 & Male & 45 & 13 & 23 & MCA ischemia \\
\hline 28 & Female & 58 & 17 & 12 & MCA ischemia \\
\hline 29 & Male & 76 & 10 & 75 & MCA ischemia \\
\hline 30 & Male & 81 & 13 & 44 & MCA ischemia \\
\hline \multicolumn{6}{|l|}{ Group II } \\
\hline Mean (SD) & & $61.8(16.5)$ & $13.8(3.3)$ & $67.4(70.5)$ & \\
\hline
\end{tabular}

Patients are listed according to training intensity: Group I (4 hours per day); Group II (2 hours per day). MCA: Middle cerebral artery; BG: Basal ganglia; SD: Standard deviation 
Table 3. Baseline test scores.

\begin{tabular}{|c|c|c|c|c|c|c|}
\hline Patient & $\begin{array}{l}\text { AAT } \\
\text { Token Test }\end{array}$ & $\begin{array}{l}\text { AAT } \\
\text { Repetition }\end{array}$ & $\begin{array}{l}\text { AAT } \\
\text { Naming }\end{array}$ & $\begin{array}{l}\text { AAT } \\
\text { Comprehension }\end{array}$ & CBTT & $\begin{array}{l}\text { Aphasia } \\
\text { type }\end{array}$ \\
\hline 01 & 43 & 50 & 42 & 40 & 4 & Wernicke \\
\hline 02 & 52 & 45 & 49 & 52 & 7 & Broca \\
\hline 03 & 63 & 45 & 53 & 52 & 4 & Broca \\
\hline 04 & 66 & 59 & 61 & 59 & 5 & Broca \\
\hline 05 & 41 & 50 & 38 & 46 & 4 & Global \\
\hline 06 & 49 & 62 & 53 & 63 & 6 & Broca \\
\hline 07 & 47 & 49 & 48 & 46 & 4 & Broca \\
\hline 08 & 42 & 55 & 47 & 38 & 4 & Broca \\
\hline 09 & 33 & 42 & 42 & 39 & 7 & Broca \\
\hline 10 & 42 & 45 & 39 & 37 & 5 & Global \\
\hline 11 & 49 & 54 & 49 & 37 & 7 & Broca \\
\hline 12 & 48 & 51 & 47 & 39 & 6 & Broca \\
\hline 13 & 65 & 63 & 62 & 66 & 4 & Broca \\
\hline 14 & 54 & 51 & 59 & 64 & 7 & Broca \\
\hline 15 & 46 & 50 & 50 & 55 & 6 & Broca \\
\hline \multicolumn{7}{|l|}{ Group I } \\
\hline Mean (SD) & $49.3(9.4)$ & $51.4(6.3)$ & $49.3(7.4)$ & $48.9(10.6)$ & $5.3(1.3)$ & \\
\hline 16 & 46 & 58 & 49 & 55 & 5 & Broca \\
\hline 17 & 42 & 43 & 46 & 39 & 5 & Amnestic \\
\hline 18 & 49 & 41 & 48 & 47 & 6 & Broca \\
\hline 19 & 54 & 62 & 61 & 63 & 5 & Broca \\
\hline 20 & 58 & 50 & 60 & 50 & 4 & Broca \\
\hline 21 & 55 & 59 & 63 & 64 & 5 & Broca \\
\hline 22 & 47 & 48 & 51 & 39 & 6 & Broca \\
\hline 23 & 59 & 56 & 59 & 78 & 7 & Broca \\
\hline 24 & 57 & 59 & 68 & 78 & 7 & Broca \\
\hline 25 & 52 & 57 & 58 & 51 & 7 & Broca \\
\hline 26 & 46 & 44 & 41 & 36 & 6 & Broca \\
\hline 27 & 33 & 48 & 43 & 38 & 6 & Global \\
\hline 28 & 43 & 44 & 40 & 51 & 6 & Global \\
\hline 29 & 42 & 42 & 34 & 37 & 3 & Global \\
\hline 30 & 69 & 54 & 56 & 54 & 6 & Broca \\
\hline \multicolumn{7}{|l|}{ Group II } \\
\hline Mean (SD) & $50.1(8.9)$ & $51.0(7.2)$ & $51.8(9.8)$ & $52.0(13.8)$ & $5.6(1.1)$ & \\
\hline
\end{tabular}

Patients are listed according to training intensity: Group I (4 hours per day); Group II (2 hours per day). AAT: Aachen Aphasia Test; CBTT: Corsi Block-Tapping Task; SD: Standard deviation 


\subsection{Testing and outcomes}

All diagnostic sessions were conducted by a clinical linguist and neuroscientist who was blinded to the group allocation, as indicated above. In a repeated-measures design, testing took place two weeks before $\left(\mathrm{T}_{0}\right)$, one day before $\left(\mathrm{T}_{1}\right)$ and one day after the first training interval $\left(\mathrm{T}_{2}\right.$; co-primary endpoint with reference to $\mathrm{T}_{1}$ ), as well as one day after the second training interval ( $\mathrm{T}_{3}$; co-primary endpoint with reference to $\left.\mathrm{T}_{2}\right)$.

As a primary outcome measure, we administered an impairmentcentered aphasia test battery known for its good construct validity and testretest reliability, the AAT (Huber et al., 1984). Language performance was measured on four subscales of the battery: Token Test, Repetition, Naming, and Comprehension. We excluded the AAT subscales Spontaneous Speech (due to its partly insufficient construct validity) and Writing (given the focus on spoken language in our treatment). AAT results were designated as normally distributed $t$-scores, averaged across subscales.

As a secondary outcome measure, we used a newly created and published diagnostic instrument, the Action Communication Test (ACT; Stahl et al., 2017). Motivated by the lack of both linguistic and functional aphasia test batteries with documented psychometric properties, this instrument reflects impairment-centered and communicative-pragmatic aspects of language processing. In step one of the testing, sets of five real generic objects are presented on a table. The patient is asked to name each of these objects, one by one. In step two of the testing, the patient verbally requests sets of five objects presented on the table, again one by one. Whenever utterances are correct, the experimenter hands over the requested object to the patient who, in turn, places it in a bag. Materials of the ACT consisted of 50 common objects that were allocated to two parallel test versions, each including five sets of five items. Test versions were selected in counterbalanced order across patients. The scoring system was as follows: two points for correctly produced target words; one point for correctly produced target words on the second attempt or incorrect, but semantically or phonologically related utterances; no points for any further utterances or omis- 
sions. Based on these ratings, the average total number of points was expressed as $t$-scores.

\subsection{Statistical analyses}

For each outcome, a repeated-measures analysis of variance (ANOVA) was conducted, including within-subject factor Time $\left(\mathrm{T}_{0} ; \mathrm{T}_{1} ; \mathrm{T}_{2} ; \mathrm{T}_{3}\right)$ and between-subject factor Group (Group I; Group II), covaried for pre-treatment performance $\left(\mathrm{T}_{0}\right)$ on the AAT or ACT, and for history of previous intensive SLT (weekly dosage $\geq 5-10$ hours) more than two years prior to trial onset (yes; no). Two-tailed $p$ values and alpha levels of 0.05 were applied for all statistical tests; for multiple comparisons, we used the Bonferroni-Holm correction.

\section{Results}

According to independent-sample $t$-tests, the randomization procedure did not lead to significant differences between Group I and Group II with regard to: age, education level, months after onset of disease, non-verbal short-term memory, and individual lesion size. Crucially, independentsample $t$-tests also demonstrated that Group I and Group II did not differ significantly with regard to their performances on the AAT $[t(28)=1.64$, $p=0.62$, not significant (n.s.) $]$ or on the ACT $[t(28)=1.69, p=0.62$, n.s. $]$ at baseline $\left(\mathrm{T}_{0}\right)$. The treatment groups were comparable in terms of gender, clinical diagnoses, and history of SLT more than two years prior to study enrolment (for group averages and standard deviations, see Table 2 and 3 ).

Focusing on the AAT scores, the repeated-measures ANOVA revealed a significant main effect of the factor Time $\left[F(3,78)=4.10, p=0.009, \eta^{2}=\right.$ 0.11]. The ANOVA interaction of Time and Group failed statistical significance $[F(3,78)=0.80$, n.s. $]$. Subsequent post-hoc paired-sample $t$-tests indicated no significant changes in language performance after the initial waiting period [absolute increase in both groups between $\mathrm{T}_{0}$ and $\mathrm{T}_{1}$ (confidence 
interval): $0.3(0.5) ; t(29)=1.02$, n.s.], but showed significant progress in each of the two training intervals [increase between $\mathrm{T}_{1}$ and $\mathrm{T}_{2}: 1.7(0.4)$; $t(29)=7.73, p<0.001$; Cohen's $d_{z}=1.4$; between $\mathrm{T}_{2}$ and $\mathrm{T}_{3}: 0.6(0.5) ; t(29)=$ 2.31, $p=0.03$; Cohen's $d_{z}=0.4$ ] and across the entire therapy phase [increase between $\mathrm{T}_{1}$ and $\mathrm{T}_{3}: 2.3(0.7) ; t(29)=6.25, p<0.001$; Cohen's $d_{z}=1.1$; see Fig. 3A and Table 4].

Based on the ACT scores, the ANOVA yielded a significant interaction of the factors Time and Group $\left[F(3,78)=4.17, p=0.009, \eta^{2}=0.13\right]$. According to post-hoc paired-sample $t$-tests, changes in language performance were absent in the initial waiting period [absolute increase in both groups between $\mathrm{T}_{0}$ and $\mathrm{T}_{1}$ (confidence interval): $0.2(0.4) ; t(29)=0.95$, n.s.] and observed only in the first training interval [increase between $\mathrm{T}_{1}$ and $\mathrm{T}_{2}$ : $1.8(0.7) ; t(29)=5.47, p<0.001$; Cohen's $d_{z}=1.0$ ] as well as across the entire therapy phase [increase between $\mathrm{T}_{1}$ and $\mathrm{T}_{3}: 1.9(0.8)$; $t(29)=4.50, p<0.001$; Cohen's $\left.d_{z}=0.8\right]$. In the final training interval, only individuals with moderately-intensive practice continued to make progress [increase in Group II between $\mathrm{T}_{2}$ and $\mathrm{T}_{3}: 0.6(0.5) ; t(14)=2.32, p=0.04$; Cohen's $d_{z}=0.6$ ], while individuals with highly-intensive practice did not [decrease in Group I between $\mathrm{T}_{2}$ and $\mathrm{T}_{3}$ : $-0.4(0.5)$; $t(14)=-1.64$, n.s.; see Fig. $3 \mathrm{~B}$ and Table 4]. 

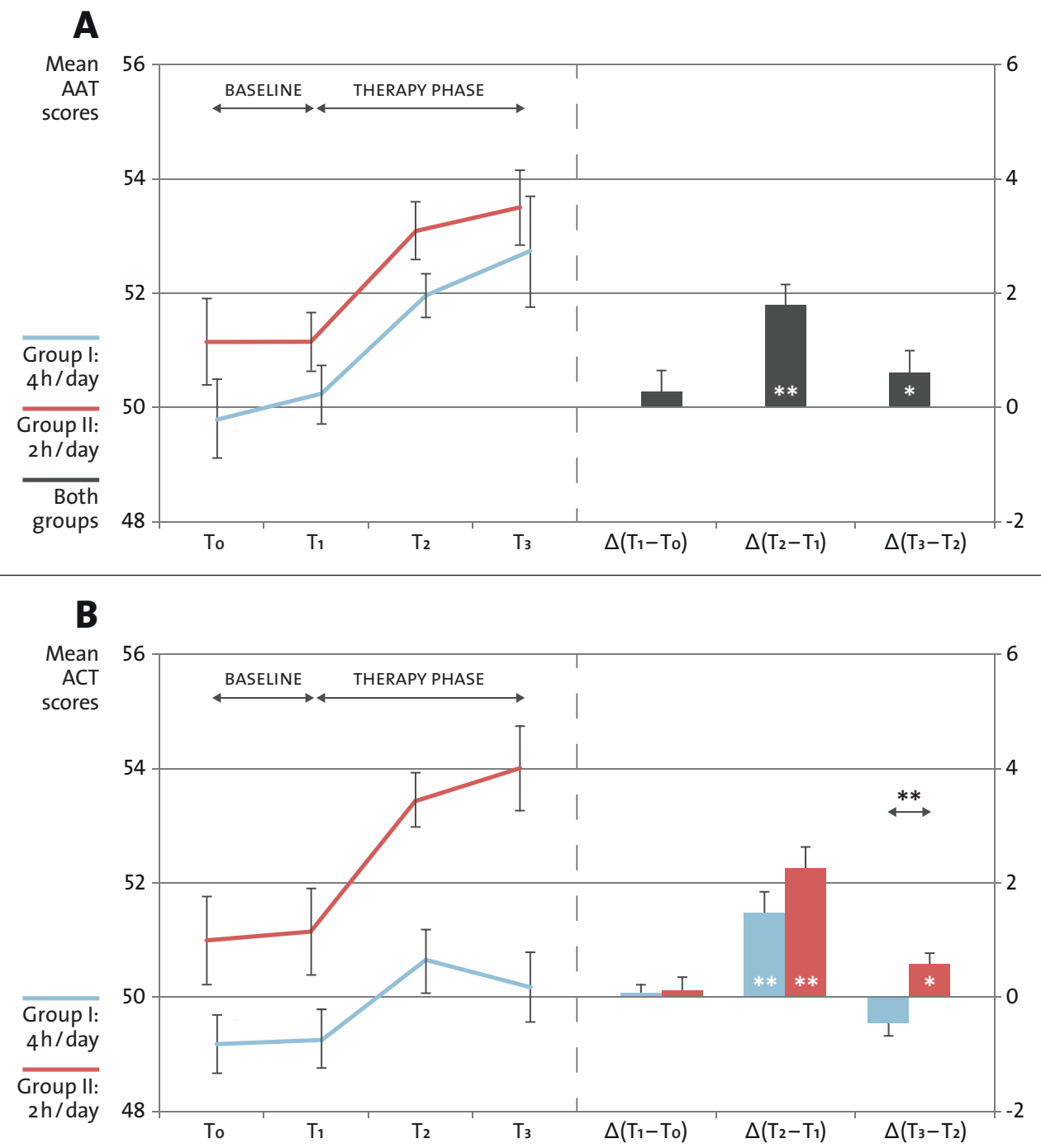

Figure 3. Aphasia test results. Changes in language performance on the Aachen Aphasia Test (AAT; see Panel A) and on the Action Communication Test (ACT; see Panel B). Thirty individuals with chronic post-stroke aphasia were randomly assigned to one of two Groups receiving Intensive Language-Action Therapy with 4 hours (Group I) or with 2 hours of daily practice (Group II). All individuals went through an initial waiting period ("baseline") and two successive training intervals ("therapy phase"). Each trial phase lasted two weeks. Testing took place at four points in Time: two weeks before treatment onset $\left(\mathrm{T}_{0}\right)$, at treatment onset $\left(\mathrm{T}_{1}\right)$, after the first training interval $\left(\mathrm{T}_{2}\right)$, and after the second training interval $\left(\mathrm{T}_{3}\right)$. Focusing on changes in language performance separately for each trial phase $\left[\Delta\left(\mathrm{T}_{1-}\right.\right.$ $\left.\left.\mathrm{T}_{0}\right) ; \Delta\left(\mathrm{T}_{2}-\mathrm{T}_{1}\right) ; \Delta\left(\mathrm{T}_{3}-\mathrm{T}_{2}\right)\right]$, statistics refer to significant paired-sample $t$-tests (asterisks embedded in bar graphs) and to a significant Time-by-Group interaction, as revealed by repeated-measures analyses of variance (asterisks displayed above bar graphs; $\left.{ }^{* *} p<0.01\right)$. Error bars represent confidence intervals corrected for between-subject variance (Loftus \& Masson, 1994). Independent-sample $t$-tests confirmed that Group I and Group II did not differ significantly with regard to their performances on the $\operatorname{AAT}(p=0.62)$ or on the ACT $(p=0.62)$ at baseline $\left(\mathrm{T}_{0}\right)$. 
Table 4. Aphasia test results.

\begin{tabular}{|c|c|c|c|c|c|c|c|c|}
\hline $\begin{array}{l}\text { Mean } \\
\text { AAT } \\
\text { scores }\end{array}$ & $\mathbf{T}_{0}$ & $\mathrm{~T}_{1}$ & $\mathrm{~T}_{2}$ & $\mathbf{T}_{3}$ & $\left(\mathrm{~T}_{1}-\mathrm{T}_{0}\right)$ & $\left(T_{2}-T_{1}\right)$ & $\left(\mathrm{T}_{3}-\mathrm{T}_{2}\right)$ & $\left(T_{3}-T_{1}\right)$ \\
\hline $\begin{array}{l}\text { Group I } \\
\text { (Cl) }\end{array}$ & $\begin{array}{l}49.7 \\
(3.7)\end{array}$ & $\begin{array}{l}50.3 \\
(4.1)\end{array}$ & $\begin{array}{l}51.9 \\
(4.3)\end{array}$ & $\begin{array}{l}52.7 \\
(4.7)\end{array}$ & $\begin{array}{l}0.6 \\
(0.8)\end{array}$ & $\begin{array}{l}1.6^{* * * *} \\
(0.6)\end{array}$ & $\begin{array}{l}0.8 \\
(0.8)\end{array}$ & $\begin{array}{l}2.4^{* *} \\
(1.2)\end{array}$ \\
\hline $\begin{array}{l}\text { Group II } \\
(\mathrm{Cl})\end{array}$ & $\begin{array}{l}51.2 \\
(4.5)\end{array}$ & $\begin{array}{l}51.2 \\
(4.3)\end{array}$ & $\begin{array}{l}53.0 \\
(4.7)\end{array}$ & $\begin{array}{l}53.4 \\
(4.8)\end{array}$ & $\begin{array}{l}0.0 \\
(0.6)\end{array}$ & $\begin{array}{l}1.8^{* * * *} \\
(0.6)\end{array}$ & $\begin{array}{l}0.4 \\
(0.6)\end{array}$ & $\begin{array}{l}2.2^{* * * *} \\
(0.8)\end{array}$ \\
\hline $\begin{array}{l}\text { Both } \\
\text { groups } \\
(\mathrm{Cl})\end{array}$ & $\begin{array}{l}50.5 \\
(2.9)\end{array}$ & $\begin{array}{l}50.7 \\
(3.0)\end{array}$ & $\begin{array}{l}52.5 \\
(3.1)\end{array}$ & $\begin{array}{l}53.1 \\
(3.3)\end{array}$ & $\begin{array}{l}0.3 \\
(0.5)\end{array}$ & $\begin{array}{l}1.7^{* * * *} \\
(0.4)\end{array}$ & $\begin{array}{l}0.6^{*} \\
(0.5)\end{array}$ & $\begin{array}{l}2.3^{* * * *} \\
(0.7)\end{array}$ \\
\hline $\begin{array}{l}\text { Mean } \\
\text { ACT } \\
\text { scores }\end{array}$ & $\mathrm{T}_{0}$ & $\mathbf{T}_{1}$ & $\mathrm{~T}_{2}$ & $\mathbf{T}_{3}$ & $\left(\mathrm{~T}_{1}-\mathrm{T}_{0}\right)$ & $\left(T_{2}-T_{1}\right)$ & $\left(T_{3}-T_{2}\right)$ & $\left(T_{3}-T_{1}\right)$ \\
\hline $\begin{array}{l}\text { Group I } \\
(\mathrm{Cl})\end{array}$ & $\begin{array}{l}49.1 \\
(4.7)\end{array}$ & $\begin{array}{l}49.2 \\
(4.8)\end{array}$ & $\begin{array}{l}50.6 \\
(5.0)\end{array}$ & $\begin{array}{l}50.2 \\
(4.9)\end{array}$ & $\begin{array}{l}0.1 \\
(0.3)\end{array}$ & $\begin{array}{l}1.4^{* *} \\
(0.9)\end{array}$ & $\begin{array}{l}-0.4 \\
(0.5)\end{array}$ & $\begin{array}{l}1.0 \\
(1.0)\end{array}$ \\
\hline $\begin{array}{l}\text { Group II } \\
(\mathrm{Cl})\end{array}$ & $\begin{array}{l}50.9 \\
(5.5)\end{array}$ & $\begin{array}{l}51.1 \\
(5.8)\end{array}$ & $\begin{array}{l}53.4 \\
(5.9)\end{array}$ & $\begin{array}{l}54.0 \\
(5.6)\end{array}$ & $\begin{array}{l}0.2 \\
(0.7)\end{array}$ & $\begin{array}{l}2.3^{* * * *} \\
(0.9)\end{array}$ & $\begin{array}{l}0.6^{*} \\
(0.5)\end{array}$ & $\begin{array}{l}2.9^{* * * *} \\
(1.2)\end{array}$ \\
\hline $\begin{array}{l}\text { Both } \\
\text { groups } \\
(\mathrm{Cl})\end{array}$ & $\begin{array}{l}50.0 \\
(3.6)\end{array}$ & $\begin{array}{l}50.2 \\
(3.7)\end{array}$ & $\begin{array}{l}52.0 \\
(3.8)\end{array}$ & $\begin{array}{l}52.1 \\
(3.7)\end{array}$ & $\begin{array}{l}0.2 \\
(0.4)\end{array}$ & $\begin{array}{l}1.8^{* * * *} \\
(0.7)\end{array}$ & $\begin{array}{l}0.1 \\
(0.4)\end{array}$ & $\begin{array}{l}1.9^{* * * *} \\
(0.8)\end{array}$ \\
\hline
\end{tabular}

Mean t-scores obtained on the Aachen Aphasia Test (AAT; Huber et al., 1984) and on the Action Communication Test (ACT; Stahl et al., 2017). Thirty individuals with chronic post-stroke aphasia were randomly assigned to one of two treatment groups receiving Intensive Language-Action Therapy with 4 hours (Group I) or with 2 hours of daily practice (Group II). Both treatment groups went through an initial waiting period and two successive training intervals. Each phase lasted two weeks. Individuals were tested at four points in time: two weeks before treatment onset $\left(T_{0}\right)$, at treatment onset $\left(T_{1}\right)$, after the first training interval $\left(T_{2}\right)$, and after the second training interval ( $\left.T_{3}\right)$. Asterisks refer to significant paired-sample $t$-tests $\left({ }^{*} p<0.05 ;{ }^{* *} p<0.01 ;{ }^{* * *} p<0.001\right)$ assessing changes in language performance separately for each time interval $\left[\Delta\left(\mathrm{T}_{1}-\mathrm{T}_{0}\right) ; \Delta\left(\mathrm{T}_{2}-\mathrm{T}_{1}\right)\right.$; $\left.\Delta\left(\mathrm{T}_{3}-\mathrm{T}_{2}\right)\right]$ and across the entire therapy phase $\left[\Delta\left(\mathrm{T}_{3}-\mathrm{T}_{1}\right)\right]$.

$\mathrm{Cl}$ : Confidence interval

\section{Discussion}

The present RCT aimed to determine the ideal amount of daily practice and total duration of the training period in intensive SLT. Thirty individuals with chronic post-stroke aphasia received ILAT in two groups with different degrees of massed practice (4 hours versus 2 hours per day). All individuals went through an initial waiting period and two successive training intervals. Each phase lasted two weeks. Co-primary endpoints were defined 
after each training interval. We carefully controlled for the experimental settings, including the patient-group context, the variety of items practiced throughout the training sessions, as well as the selection and number of therapists. A standardized aphasia test battery (AAT) revealed no changes in language performance after the waiting period, but indicated significant and clinically relevant progress after each of the two training intervals (ANOVA main effect of Time: $p=0.009$; increase in both groups between $\mathrm{T}_{1}$ and $\mathrm{T}_{2}$ [confidence interval]: $1.7\left[ \pm 0.4\right.$ ]; between $\mathrm{T}_{2}$ and $\mathrm{T}_{3}$ : $0.6[ \pm 0.5]$; medium-to-large effects in post-hoc paired-sample $t$-tests: $0.4<$ Cohen's $\left.d_{z} \leq 1.4\right)$. Crucially, any such progress did not depend on the intensity level applied (no significant ANOVA interaction of Time and Group; increase between $\mathrm{T}_{1}$ and $\mathrm{T}_{3}$ in Group I: 2.4 [ \pm 1.2$]$; in Group II: $2.2[ \pm 0.8]$ ). This finding is consistent with the observation that the AAT data showed similar patterns of individual changes in language performance over time, regardless of symptom severity. Both treatment groups completed all training sessions, confirming the good compliance of chronic patients in intensive SLT. The current results suggest no benefit from more than 2 hours of daily practice within one month, whereas a two-week extension of treatment duration adds to the efficacy of intensive SLT.

The findings reported here may seem in conflict with established Hebbian principles, according to which the repetitive and conjoint firing of neurons is likely to strengthen the synaptic connectivity between them (Hebb, 1949). Although this neurobiological model appears to imply that the functional reorganization of language increases with the amount of daily practice, it does not postulate unlimited learning capacities in a relatively short period of time (Berthier \& Pulvermüller, 2011). Instead, Hebbian principles do not rule out the possibility of a ceiling effect within a single day, if the treatment intensity exceeds a certain threshold. Support for this claim comes from learning psychology, predicting a decline of attention as a consequence of habituation (Mazur, 2016), and from clinical neuroscience, discussing a ceiling effect after intensive SLT and simultaneous dopaminergic medication (Breitenstein et al., 2015). We nonetheless wish to emphasize that, in the present RCT, we compared two intensive forms of SLT 
with 4 hours (Group I) or 2 hours of daily practice (Group II). In contrast, traditional SLT in most industrial countries rarely amounts to more than 3 hours of weekly practice, based on our experience. Such a low dosage fails to reach the estimated minimum of 5-10 hours weekly to ensure progress in SLT (Bhogal et al., 2003; Allen et al., 2012; Brady et al., 2016). In line with this view, a multiple-case study tended to deliver better results for Constraint-Induced Aphasia Therapy if administered in a weekly dosage of 15 hours compared to only 3 hours, in spite of a higher treatment duration in the latter group (Mozeiko et al., 2016). Therefore, a potential ceiling effect in our RCT should not undermine the importance of offering intensive SLT to individuals with chronic post-stroke aphasia.

The treatment protocols in the current RCT differed in their intensity level, but not in the communicative-pragmatic nature of the training itself. One may thus argue that our results do not generalize to other forms of SLT. However, we do not see any reasons why the observed benefit from a longer training period should be limited to communicative-pragmatic methods in SLT. Rather, it is worth considering that a second RCT with precisely matched degrees of massed practice and treatment duration has indicated a superiority of ILAT over confrontation naming in individuals with chronic non-fluent aphasia (Stahl et al., 2016). Taken together, these RCT data suggest a moderately-intensive use of communicative-pragmatic methods applied over an extended period of time. Additional evidence will be required to determine whether or not a further reduction in the daily amount of practice has an effect on the outcome of SLT. Likewise, it remains to be investigated whether a slight decrease or further increase in treatment duration leads to similar results.

The present RCT included an impairment-centered aphasia test battery (AAT; Huber et al., 1984), along with a dialogue-sensitive diagnostic instrument (ACT; Stahl et al., 2017). This secondary outcome measure was motivated by the communicative-pragmatic character of the training and its potential relevance to everyday discourse. Both outcome measures indeed revealed congruent changes on the ACT when focusing on the waiting period and the first training interval. In the second training interval, however, 
the ACT yielded significant progress only in individuals with 6 hours of weekly practice (ANOVA interaction of the factors Time and Group: $p=$ $0.009 ; \eta^{2}=0.13 ; t$-scores between $\mathrm{T}_{2}$ and $\mathrm{T}_{3}$ in Group I [confidence interval]: $-0.4[ \pm 0.5]$; in Group II: $0.6[ \pm 0.5])$. This finding is unlikely to arise from discrepant baseline performances between treatment groups, as individuals with highly-intensive practice seemed to have marginally-but nonsignificantly-more room for improvement over time. The finding also converges with previous non-RCT evidence, pointing to optimal gains in SLT with 6 hours of weekly practice provided over an extended period of time (Dignam et al., 2015). As one possible reason for the advantage of moderately-intensive practice on the ACT, we propose that keeping the daily quantity of SLT below a critical threshold may diminish posttreatment fatigue, and hence, facilitate immediate learning transfer to everyday situations after each training session. Although more research is needed to substantiate the particular influence of moderately-intensive practice on everyday discourse, such considerations should not overshadow the fact that both of our outcome measures consistently confirmed the success of prolonged SLT with at least 6 hours of weekly training.

This is the first RCT to directly compare the efficacy of intensive SLT with different degrees of massed practice and otherwise identical experimental conditions over the course of four weeks. The current results suggest no added value of treatment intensity over and above 2 hours of daily practice within four weeks. Instead, these results demonstrate that even a small two-week increase in treatment duration contributes to recovery from chronic post-stroke aphasia. In light of previous concerns about the feasibility of highly-intensive SLT, we here show that a lower-than-expected dosage of 2 hours per day is sufficient, and therefore, easier to achieve within the constraints of clinical practice. 


\section{References}

Allen, L., Mehta, S., McClure, J. A., \& Teasell, R. (2012). Therapeutic interventions for aphasia initiated more than six months post stroke: A review of the evidence. Topics in Stroke Rehabilitation, 19(6), 523535.

Berthier, M. L., \& Pulvermüller, F. (2011). Neuroscience insights improve neurorehabilitation of poststroke aphasia. Nature Reviews Neurology, 7(2), 86-97.

Bhogal, S. K., Teasell, R., \& Speechley, M. (2003). Intensity of aphasia therapy, impact on recovery. Stroke, 34(4), 987-993.

Brady, M. C., Kelly, H., Godwin, J., Enderby, P., \& Campbell, P. (2016). Speech and language therapy for aphasia following stroke. The Cochrane Database of Systematic Reviews, 2016(6), Article CD000425.

Breitenstein, C., Grewe, T., Flöel, A., Ziegler, W., Springer, L., Martus, P., et al. (2017). Intensive speech and language therapy in patients with chronic aphasia after stroke: A randomised, open-label, blindedendpoint, controlled trial in a health-care setting. Lancet, 389(10078), 1528-1538.

Breitenstein, C., Korsukewitz, C., Baumgärtner, A., Flöel, A., Zwitserlood, P., Dobel, C., et al. (2015). L-dopa does not add to the success of highintensity language training in aphasia. Restorative Neurology and Neuroscience, 33(2), 115-120.

Cherney, L. R., Patterson, J. P., Raymer, A., Frymark, T., \& Schooling, T. (2008). Evidence-based systematic review: Effects of intensity of treatment and Constraint-Induced Language Therapy for individuals with stroke-induced aphasia. Journal of Speech, Language, and Hearing Research, 51(5), 1282-1299. 
Difrancesco, S., Pulvermüller, F., \& Mohr, B. (2012). Intensive LanguageAction Therapy (ILAT): The methods. Aphasiology, 26(11), 13171351.

Dignam, J., Copland, D., McKinnon, E., Burfein, P., O’Brien, K., Farrell, A., et al. (2015). Intensive versus distributed aphasia therapy: A nonrandomized, parallel-group, dosage-controlled study. Stroke, 46(8), 2206-2211.

Faul, F., Erdfelder, E., Buchner, A., \& Lang, A.-G. (2009). Statistical power analyses using $\mathrm{G}^{\star}$ Power 3.1: Tests for correlation and regression analyses. Behavior Research Methods, 41(4), 1149-1160.

Hebb, D. O. (1949). The organization of Behavior. New York, NY: Wiley.

Huber, W., Poeck, K., \& Willmes, K. (1984). The Aachen Aphasia Test. Advances in Neurology, 42, 291-303.

Kessels, R. P., van Zandvoort, M. J., Postma, A., \& de Haan, E. H. (2000). The Corsi Block-Tapping Task: Standardization and normative data. Applied Neuropsychology, 7(4), 252-258.

Loftus, G. R., \& Masson, M. E. (1994). Using confidence intervals in withinsubject designs. Psychonomic Bulletin \& Review, 1(4), 476-490.

Mazur, J. E. (2016). Learning and Behavior. New York, NY: Routledge.

Mozeiko, J., Coelho, C. A., \& Myers, E. B. (2016). The role of intensity in Constraint-Induced Language Therapy for people with chronic aphasia. Aphasiology, 30(4), 339-363.

Oldfield, R. C. (1971). The assessment and analysis of handedness: The Edinburgh inventory. Neuropsychologia, 9(1), 97-113.

Pulvermüller, F., Neininger, B., Elbert, T., Mohr, B., Rockstroh, B., Koebbel, P., et al. (2001). Constraint-induced therapy of chronic aphasia after stroke. Stroke, 32(7), 1621-1626. 
Robey, R. R. (1998). A meta-analysis of clinical outcomes in the treatment of aphasia. Journal of Speech, Language, and Hearing Research, 41(1), 172-187.

Rorden, C., \& Brett, M. (2000). Stereotaxic display of brain lesions. Behavioural Neurology, 12(4), 191-200.

Stahl, B., Mohr, B., Dreyer, F. R., Lucchese, G., \& Pulvermüller, F. (2017). Communicative-pragmatic assessment is sensitive and time-effective in measuring the outcome of aphasia therapy. Frontiers in Human Neuroscience, 11, Article 223.

Stahl, B., Mohr, B., Dreyer, F. R., Lucchese, G., \& Pulvermüller, F. (2016). Using language for social interaction: Communication mechanisms promote recovery from chronic non-fluent aphasia. Cortex, 85, 90-99. 


\section{Part III}

\section{Musical skills}

Original publication

Stahl, B., \& Kotz, S. A. (2014). Facing the music: Three issues in current research on singing and aphasia. Frontiers in Psychology, 5, Article 1033. 


\section{Introduction}

Individuals with communication disorders due to left-hemispheric stroke are often able to sing entire pieces of text fluently. This finding has inspired a number of music-based rehabilitation programs, most prominent among them a treatment known as Melodic Intonation Therapy (Albert et al., 1973). According to the inventors of the treatment, singing should promote a transfer of language function from left frontotemporal neural networks to preserved right homotopic regions. Although singing indeed engages right frontotemporal areas (Callan et al., 2006; Özdemir et al., 2006), it does not seem to induce a transfer of language function from the left to the right hemisphere (Belin et al., 1996; Jungblut et al., 2014). Nonetheless, several studies confirmed the promising role of singing (Mills, 1904; Gerstmann, 1964; Keith \& Aronson, 1975; Tomaino, 2010) and the overall efficacy of Melodic Intonation Therapy in subacute post-stroke aphasia (van der Meulen et al., 2014).

Using an analytic research design, recent experiments explored whether singing, rhythmic pacing, and type of verbal utterance affect immediate syllable production (Stahl et al., 2011) and performance of trained items after six weeks of practice (Stahl et al., 2013). Contrary to earlier reports, the results did not indicate a short- or long-term superiority of singing over rhythmic speech in individuals with subacute or chronic poststroke aphasia. Instead, type of verbal utterance proved to be important: formulaic expressions-such as "Good morning," "Everything alright?" or "I'm fine"-yielded higher rates of correctly produced syllables than novel word sequences, whether they were sung or rhythmically spoken. Likewise, both sung and rhythmically spoken repetition of formulaic expressions equally increased the production of trained items directly after the end of treatment and at a 3-month follow-up (Stahl et al., 2013).

We readily acknowledge that singing in syllable-timed languages such as French possibly adds to the level of rhythmicity in a particular way (cf. Schmidt-Kassow et al., 2011; Zumbansen et al., 2014). Still, this 
does not fully explain the range of seemingly contradictory findings in the literature. In our opinion paper, we would like to address three issues in current research on singing and aphasia: articulatory tempo, clinical research designs, and formulaic language resources. We believe that these issues may account for some of the major discrepancies between past reports.

\section{Articulatory tempo}

Singing slows down articulatory tempo. This, in turn, has been found to benefit syllable production in individuals with neurological communication disorders (Beukelman \& Yorkston, 1977; Laughlin et al., 1979; Pilon et al., 1998; Hustad et al., 2003). Although the relationship between articulatory tempo and syllable production may be extremely useful in therapy, it potentially causes problems in experimental work. For example, a crosssectional study required eight individuals with post-stroke aphasia to sing and naturally speak novel lyrics in two conditions: alone (solo word production), and together with a vocal playback (choral word production; Racette et al., 2006). During solo word production, the number of intelligible words was identical, regardless of whether they were sung or spoken. During choral word production, the number of intelligible words was generally higher, with more sung than spoken words articulated correctly. Based on these results, one may conclude that choral singing facilitates word production in individuals with post-stroke aphasia.

Taking a closer look at the experimental design, some details of the study are worth noting. The sung playback voice produced words only half as fast as the spoken playback voice. This difference also affected the participants' actual performance. During solo word production, the participants were free to choose their preferred articulatory tempo (mean $[M] \mathrm{du}-$ ration of sung syllables: $M=572 \mathrm{~ms}$; spoken syllables: $M=494 \mathrm{~ms} ; \Delta=$ 78 ms; cf. Racette et al., 2006). During choral word production, the participants adapted to the articulatory tempo of the sung and spoken vocal playbacks (sung syllables: $M=696 \mathrm{~ms}$; spoken syllables: $M=426 \mathrm{~ms} ; \Delta=$ 
$270 \mathrm{~ms}$ ). Hence, the mean difference in syllable duration between singing and speaking $(\Delta)$ was 3.5 times larger during choral word production than during solo word production.

This comparison reveals that the participants had more time to articulate well when they were singing to vocal playback. Obviously, such caveats do not generally rule out a facilitating effect of choral word production per se, whether sung or spoken. However, these results do not necessarily indicate a benefit from choral singing. What seems like a choral singing effect may actually arise from differences in articulatory tempo. The effect of choral singing over choral speech does not appear to persist when controlling for articulatory tempo (cf. Stahl et al., 2011). In summary, the role of articulatory tempo may be crucial in experimental work that seeks to determine how different forms of vocal expression affect syllable production in individuals with neurological communication disorders.

\section{Clinical research designs}

Another issue concerns clinical studies that address the neural mechanisms of music-based aphasia therapy. A multiple-case study investigated the efficacy of Melodic Intonation Therapy (Schlaug et al., 2008). A nonstandardized language test indicated that Melodic Intonation Therapy was more effective than a non-musical control intervention in two individuals with chronic post-stroke aphasia. Although these results may not generalize to a larger clinical population, they nonetheless serve as preliminary evidence for the therapeutic potential of Melodic Intonation Therapy. However, the results may be less suitable for gaining insight into the efficacy of any particular element included in the program — such as singing — and its underlying neural mechanisms, as revealed by structural and functional imaging.

Melodic Intonation Therapy includes various forms of vocal expression and multi-modal feedback: singing minor thirds; rhythmic speech with exaggerated prosody; tactile stimulation via left-hand tapping; choral word 
and phrase production; solo word and phrase repetition; auditory cueing of initial word and phrase syllables; and so on (cf. Helm-Estabrooks et al., 1989). Given the number of elements used in Melodic Intonation Therapy, it is challenging to assess their relative contribution to the efficacy of the entire program. This problem becomes especially apparent when comparing Melodic Intonation Therapy to non-musical control interventions.

In the study mentioned above, the non-musical control intervention did not include singing, rhythmic speech or left-hand tapping (cf. Schlaug et al., 2008). That is, the treatments did not only differ in singing, but also in other aspects of vocal expression and sensorimotor feedback. Consequently, the results do not necessarily confirm the efficacy of singing and its underlying neural mechanisms. What seems like a benefit from singing may actually be the effect of rhythmic pacing, prosody, tactile stimulation or any of their combinations. Considering this range of possible interpretations, the results are consistent with reports on similar gains from singing and rhythmic speech on trained items (cf. Stahl et al., 2013). In summary, future studies should be clear about whether the research design focuses on musicbased aphasia therapy as an entire program or on its specific mechanisms.

\section{Formulaic language resources}

One reason for the success of music-based aphasia therapy may be its use of common phrases. The original manual of Melodic Intonation Therapy proposes phrases such as "I love you," "How are you?" or "Thank you" at the lower proficiency level of the program (Helm-Estabrooks et al., 1989). The phrases are stereotyped in form, tied to social context, and therefore, fall into the category of formulaic language (Van Lancker Sidtis \& Rallon, 2004). According to present knowledge, the production of formulaic language engages bilateral neural networks, including right frontotemporal areas, the right basal ganglia and, possibly, the right cerebellum (HughlingsJackson, 1878; Speedie et al., 1993; Ackermann et al., 1998; Van Lancker Sidtis et al., 2003; Van Lancker Sidtis \& Postman, 2006; Sidtis et al., 2009). 
Formulaic expressions may be viewed as a valuable language resource in individuals with communication disorders following left-hemispheric stroke. It is also conceivable that propositional-grammatical utterances gradually become part of the formulaic repertoire by means of massed practice: individuals may eventually retrieve trained items as a coherent unit from the mental lexicon by engaging bilateral neural networks (cf. Wolf et al., 2014). The feasibility of massed practice may rely, at least to a degree, on the motivating effect resulting from formulaic language competence especially in individuals with otherwise severely constrained communication skills.

The crucial role of formulaic language in music-based aphasia therapy challenges the interpretation of structural and functional neuroimaging data. For example, the sensitivity of right frontotemporal areas to Melodic Intonation Therapy has been associated with neural plasticity of propositional-grammatical utterances (Schlaug et al., 2008; 2009; Vines et al., 2011). However, these imaging data may equally emerge from the plasticity of right-hemispheric neural networks supporting the production of formulaic language. What seems like a music-based transfer of language function from the left to the right hemisphere may actually be the neural correlate reflecting the intensive use of formulaic expressions. Tentative behavioral evidence for this claim comes from the finding that music-based aphasia therapy improved the production of formulaic expressions irrespective of whether participants were singing or speaking rhythmically (cf. Stahl et al., 2013). In summary, future studies need to consider the possible interplay of music-based aphasia therapy and right-hemispheric neural networks involved in formulaic language processing.

\section{Outlook on future research}

Without a doubt, music-based aphasia therapy_including Melodic Intonation Therapy-is a promising approach for some individuals with neurological communication disorders. The repetitive character and focus 
on a limited formulaic repertoire may be appropriate to deal with severely impaired verbal expression and comprehension typically observed in global aphasia. Simultaneous training of formulaic and propositional-grammatical utterances may indirectly compensate for difficulties associated with agrammatism, as is the case in individuals with Broca's aphasia. Rhythmic elements of the program may help overcome deficits in syllabic segmentation commonly found in apraxia of speech.

Up until now, studies on music-based aphasia therapy have addressed the overall efficacy of current rehabilitation programs (holistic research designs) and some of their underlying mechanisms (analytic research designs). The long-term goal of analytic methods is to tailor future rehabilitation programs to the specific needs of individuals with neurological communication disorders. One may argue that analytic research on music-based aphasia therapy takes a reductionist view, for example, by disentangling the close relationship between melody and rhythm (cf. Merrett et al., 2014). However, analytic research on music-based aphasia therapy has actually compared singing - that is, the combined use of melody and rhythm - with other forms of vocal expression, including rhythmic speech. Available data are therefore consistent with the idea that rhythmicity is naturally inherent in singing.

Still, analytic research on music-based aphasia therapy should not overshadow the value of holistic approaches. We believe that both holistic and analytic methods are important and usually depend on each other. Many clinical hypotheses are derived from analytic research and then tested in holistic designs, and vice versa. Acting in concert, holistic and analytic methods may advance the quality of research in the field and contribute to our understanding of music-based aphasia therapy. 


\section{References}

Ackermann, H., Wildgruber, D., Daum, I., \& Grodd, W. (1998). Does the cerebellum contribute to cognitive aspects of speech production? A functional magnetic resonance imaging (fMRI) study in humans. Neuroscience Letters, 247(2-3), 187-190.

Albert, M. L., Sparks, R. W., \& Helm, N. (1973). Melodic Intonation Therapy for aphasia. Archives of Neurology, 29(2), 130-131.

Belin, P., Zilbovicius, M., Remy, P., Francois, C., Guillaume, S., Chain, F., et al. (1996). Recovery from nonfluent aphasia after Melodic Intonation Therapy: A PET study. Neurology, 47(6), 1504-1511.

Beukelman, D. R., \& Yorkston, K. (1977). A communication system for the severely dysarthric speaker with an intact language system. Journal of Speech and Hearing Disorders, 42(2), 265-270.

Callan, D. E., Tsytsarev, V., Hanakawa, T., Callan, A. M., Katsuhara, M., Fukuyama, H., et al. (2006). Song and speech: Brain regions involved with perception and covert production. Neuroimage, 31(1), 13271342.

Gerstmann, H. L. (1964). A case of aphasia. Journal of Speech and Hearing Disorders, 29, 89-91.

Helm-Estabrooks, N., Nicholas, M., \& Morgan, A. (1989). Melodic Intonation Therapy. Manual. Austin, TX: Pro-Ed.

Hughlings-Jackson, J. (1878). On affection of speech from disease of the brain. Brain, 2(3), 203-222.

Hustad, K. C., Jones, T., \& Dailey, S. (2003). Implementing speech supplementation strategies: Effects on intelligibility and speech rate of individuals with chronic severe dysarthria. Journal of Speech, Language, and Hearing Research, 46(2), 462-474.

Jungblut, M., Huber, W., Mais, C., \& Schnitker, R. (2014). Paving the way for speech: Voice-training-induced plasticity in chronic aphasia and 
apraxia of speech-three single cases. Neural Plasticity, 2014, Article 841982.

Keith, R. L., \& Aronson, A. E. (1975). Singing as therapy for apraxia of speech and aphasia: Report of a case. Brain and Language, 2(4), 483488.

Laughlin, S. A., Naeser, M. A., \& Gordon, W. P. (1979). Effects of three syllable durations using the Melodic Intonation Therapy technique. Journal of Speech and Hearing Research, 22(2), 311-320.

Merrett, D. L., Peretz, I., \& Wilson, S. J. (2014). Neurobiological, cognitive and emotional mechanisms in Melodic Intonation Therapy. Frontiers in Human Neuroscience, 8, Article 401.

Mills, C. K. (1904). Treatment of aphasia by training. Journal of the American Medical Association, 43(26), 1940-1949.

Özdemir, E., Norton, A., \& Schlaug, G. (2006). Shared and distinct neural correlates of singing and speaking. Neuroimage, 33(2), 628-635.

Pilon, M. A., McIntosh, K. W., \& Thaut, M. H. (1998). Auditory vs visual speech timing cues as external rate control to enhance verbal intelligibility in mixed spastic ataxic dysarthric speakers: A pilot study. Brain Injury, 12(9), 793-803.

Racette, A., Bard, C., \& Peretz, I. (2006). Making non-fluent aphasics speak: Sing along! Brain, 129(10), 2571-2584.

Schlaug, G., Marchina, S., \& Norton, A. (2008). From singing to speaking: Why singing may lead to recovery of expressive language function in patients with Broca's aphasia. Music Perception, 25(4), 315-323.

Schlaug, G., Marchina, S., \& Norton, A. (2009). Evidence for plasticity in white-matter tracts of patients with chronic Broca's aphasia undergoing intense intonation-based speech therapy. Annals of the New York Academy of Sciences, 1169, 385-394.

Schmidt-Kassow, M., Rothermich, K., Schwartze, M., \& Kotz, S. A. (2011). Did you get the beat? Late proficient French-German learners extract 
strong-weak patterns in tonal but not in linguistic sequences. Neuroimage, 54(1), 568-576.

Sidtis, D., Canterucci, G., \& Katsnelson, D. (2009). Effects of neurological damage on production of formulaic language. Clinical Linguistics \& Phonetics, 23(4), 270-284.

Speedie, L. J., Wertman, E., Ta'ir, J., \& Heilman, K. M. (1993). Disruption of automatic speech following a right basal ganglia lesion. Neurology, 43(9), 1768-1774.

Stahl, B., Henseler, I., Turner, R., Geyer, S., \& Kotz, S. A. (2013). How to engage the right brain hemisphere in aphasics without even singing: Evidence for two paths of speech recovery. Frontiers in Human Neuroscience, 7, Article 35.

Stahl, B., Kotz, S. A., Henseler, I., Turner, R., \& Geyer, S. (2011). Rhythm in disguise: Why singing may not hold the key to recovery from aphasia. Brain, 134(10), 3083-3093.

Tomaino, C. M. (2010). Recovery of fluent speech through a musician's use of prelearned song repertoire: A case study. Music and Medicine, 2(2), $85-88$.

Van der Meulen, I., van de Sandt-Koenderman, M. E., Heijenbrok-Kal, M. H., Visch-Brink, E. G., \& Ribbers, G. M. (2014). The efficacy and timing of Melodic Intonation Therapy in subacute aphasia. Neurorehabilitation and Neural Repair, 28(6), 536-544.

Van Lancker Sidtis, D., \& Postman, W. A. (2006). Formulaic expressions in spontaneous speech of left- and right-hemisphere-damaged subjects. Aphasiology, 20(5), 411-426.

Van Lancker Sidtis, D., \& Rallon, G. (2004). Tracking the incidence of formulaic expressions in everyday speech: Methods for classification and verification. Language \& Communication, 24(3), 207-240. 
Van Lancker Sidtis, D., McIntosh, A. R., \& Grafton, S. (2003). PET activation studies comparing two speech tasks widely used in surgical mapping. Brain and Language, 85(2), 245-261.

Vines, B. W., Norton, A. C., \& Schlaug. G. (2011). Non-invasive brain stimulation enhances the effects of Melodic Intonation Therapy. Frontiers in Psychology, 2, Article 230.

Wolf, R., Van Lancker Sidtis, D., \& Sidtis, J. J. (2014). The ear craves the familiar: Pragmatic repetition in left and right cerebral damage. Aphasiology, 28(5), 596-615.

Zumbansen, A., Peretz, I., \& Hébert, S. (2014). The combination of rhythm and pitch can account for the beneficial effect of Melodic Intonation Therapy on connected speech improvements in Broca's aphasia. Frontiers in Human Neuroscience, 8, Article 592. 


\section{Part IV}

\section{Formulaic expressions}

Original publication

Stahl, B., \& Van Lancker Sidtis, D. (2015). Tapping into neural resources of communication: Formulaic language in aphasia therapy.

Frontiers in Psychology, 6, Article 1526. 


\section{Introduction}

Decades of research highlight the importance of formulaic expressions in everyday spoken language (Vihman, 1982; Wray, 2002; Kuiper, 2009). Along with idioms, expletives, and proverbs, this linguistic category includes conversational speech formulas, such as "You've got to be kidding," “Excuse me?" or "Hang on a minute" (Fillmore, 1979; Pawley \& Syder, 1983; Schegloff, 1988). In their modern conception, formulaic expressions differ from newly created, grammatical utterances in that they are fixed in form, often non-literal in meaning with attitudinal nuances, and closely related to communicative-pragmatic context (Van Lancker Sidtis \& Rallon, 2004). Although the proportion of formulaic expressions to spoken language varies with type of measure and discourse, these utterances are widely regarded as crucial in determining the success of social interaction in many communicative aspects of daily life (Van Lancker Sidtis, 2010).

The unique role of formulaic expressions in spoken language is reflected at the level of their functional neuroanatomy. While left perisylvian areas of the brain support primarily propositional-grammatical utterances, the processing of conversational speech formulas was found to engage, in particular, right-hemispheric cortical areas and the bilateral basal ganglia (Hughlings-Jackson, 1878; Graves \& Landis, 1985; Speedie et al., 1993; Van Lancker Sidtis \& Postman, 2006; Sidtis et al., 2009; Van Lancker Sidtis et al., 2015). It is worth pointing out that some of these neural networks are intact in individuals with left-hemispheric lesions, leading to the intriguing observation that individuals with classical speech and language disorders are often able to communicate comparatively well based on a repertoire of formulaic expressions (McElduff \& Drummond, 1991; Lum \& Ellis, 1994; Stahl et al., 2011). An upper limit of such expressions has not yet been identified, with estimates reaching into the hundreds of thousands (Jackendoff, 1995).

The above literature suggests that formulaic expressions may be viewed as a valuable resource in speech-language therapy. However, surprisingly little is known about their potential impact on the success of popular 
programs in clinical rehabilitation. The current opinion paper seeks to address this matter by outlining the contribution of formulaic expressions to seminal approaches in recovery from communication disorders after stroke.

\section{Utterance-centered approaches}

According to analytical language philosophy and communicativepragmatic theory, the meaning of an utterance emerges from its ordinary use by performing so-called "speech acts," such as greeting a person (Wittgenstein, 1953; Austin, 1962; Searle, 1969; Horn \& Ward, 2008). Adopting this idea for clinical practice, rehabilitation programs in speech-language therapy should be grounded in behaviorally relevant situations that enable individuals to benefit from a range of communicative features, including the turn-taking structure underlying everyday conversation (Pulvermüller, 1990). For example, the speech act of greeting offers the conversation partner a number of possibilities to respond-typically by using formulaic expressions, such as "Good to see you," "How's it going?" or "Long time no see." One may claim that incorporating this turn-taking structure in speechlanguage therapy does not provide any added value for the outcome of the treatment. If this is true, the training of formulaic expressions in communicative-pragmatic context should be as successful as exercises that focus on articulatory quality of the same utterances, regardless of their social function. However, it remains questionable how effective such utterance-centered approaches are in improving everyday language abilities over and above articulatory quality of trained expressions.

Prominent examples of utterance-centered approaches in speechlanguage therapy are, in some respect, music-based rehabilitation programs, among them a treatment known as Melodic Intonation Therapy (Albert et al., 1973). The treatment protocol requires individuals with non-fluent aphasia to produce propositional-grammatical and formulaic sentences and phrases in different modalities, including singing and rhythmic speech (HelmEstabrooks et al., 1989). While the higher difficulty levels of the protocol en- 
courage the use of grammatical utterances, the lower levels involve formulaic expressions, such as "I am fine," "How are you?" or "Thank you." Although most of these expressions may occur naturally in a conversation, their repetitive training does not meet the criteria of communicativepragmatic speech-language therapy. Among other caveats, Melodic Intonation Therapy does not benefit systematically from the turn-taking structure underlying everyday conversation in the training sessions. This may limit the transfer of trained sentences and phrases into real life, a goal of primary importance in clinical practice.

In line with this view, randomized controlled trials on Melodic Intonation Therapy did not consistently reveal generalized effects on standardized aphasia test batteries, even if the sample of trained sentences and phrases was relatively large (cf. van der Meulen et al., 2014, 2015). Nonetheless, music-based rehabilitation programs have been demonstrated to directly benefit the production of trained expressions in individuals with chronic non-fluent aphasia and apraxia of speech (Wilson et al., 2006; Stahl et al., 2013; Zumbansen et al., 2014). One may argue that the reported progress in the production of such expressions depends, at least in part, on increased activity in right-hemispheric neural networks engaged in formulaic language processing, especially when considering the repetitive character of the training (cf. Berthier et al., 2014). If this notion is correct, it would explain conflicting results from neuroimaging studies, indicating either left perilesional or right frontotemporal reorganization of language function in individuals treated with Melodic Intonation Therapy (Belin et al., 1996; Schlaug et al., 2008, 2009; Vines et al., 2011). Future trials will hopefully determine whether or not these discrepant findings arise from different degrees of formulaicity in the experimental tasks (Stahl \& Kotz, 2014). 


\section{Communicative-pragmatic rehabilitation programs}

Communicative-pragmatic rehabilitation programs aim at training verbal expressions in behaviorally relevant settings, so-called "language games” (Davis \& Wilcox, 1985; Pulvermüller \& Roth, 1991; Bastiaanse \& Prins, 1994). Based on a variety of utterances, individuals communicate with fellow players by performing different types of speech acts, such as verbal requests. Importantly, the turn-taking structure of language games offers the conversation partner a number of possibilities to respond, including a repertoire of formulaic expressions. In contrast to utterance-centered approaches, language games focus less on articulatory quality of sentences and phrases rather than on their suitability in communicative-pragmatic context. One may therefore claim that such approaches should, in principle, be effective in improving everyday language abilities over and above articulatory quality of trained expressions.

Prominent examples of communicative-pragmatic approaches are clinical language games, including a treatment known as Intensive Language-Action Therapy (Difrancesco et al., 2012). The treatment protocol requires up to three individuals with aphasia and a therapist to obtain picture cards from each other, for instance, by making verbal requests. Utterances are combined with manual actions by handing over corresponding picture cards to fellow players. Depending on the availability of picture cards, the players use adequate sets of formulaic expressions to indicate whether a request was accepted ("Here you are," "Thank you," "You're welcome"), rejected ("I'm sorry," "No problem," "Too bad") or unclear ("Pardon me?"). That is, the repetitive interaction with formulaic expressions benefits from the rich turn-taking structure underlying everyday conversation, with possible implications on the success of language games.

There is indeed ample evidence from randomized controlled trials suggesting that Intensive Language-Action Therapy induces generalized effects on standardized aphasia test batteries (Pulvermüller et al., 2001; 
Meinzer et al., 2005, 2007; Berthier et al., 2009). Although several elements included in the program are likely to contribute to this finding, the use of formulaic expressions may particularly account for the practicability of communicative-pragmatic approaches by allowing individuals to tap into right-hemispheric language resources in the training sessions. Interestingly, neuroimaging studies have revealed either left perilesional or right frontotemporal functional reorganization in individuals treated with Intensive Language-Action Therapy (Meinzer et al., 2004, 2008; Pulvermüller et al., 2005; Breier et al., 2006, 2009; MacGregor et al., 2014; Mohr et al., 2014; Barbancho et al., 2015). Future trials may clarify to what degree these results reflect increased activity in neural networks supporting formulaic language.

\section{Possible impact on motivation, well- being, and quality of life}

Individuals with speech and language disorders following lefthemispheric stroke often experience a sudden inability to engage in communication with others based on propositional-grammatical utterances. This loss of social interaction skills may be one reason for the high prevalence of mental disorders in the first year following acquired brain injury (cf. Lewinsohn, 1974). Depending on the epidemiological measure, up to half of the patients suffer from post-stroke depression during this period of time (Kauhanen et al., 1999; Fleminger et al., 2003; Schönberger et al., 2011). While antidepressant medication is an option for most individuals with neurological communication disorders, classical forms of psychotherapy remain challenging due to constrained verbal expression and comprehension.

A number of approaches in psychotherapy seek to identify and activate resources in order to overcome cognitive-affective distress (Priebe et al., 2014). Adopting this goal for clinical rehabilitation, formulaic expressions frequently remain one of the few resources available to communicate for individuals with extended left-hemispheric lesions. However, individuals 
are commonly unaware of their ability to perform formulaic expressions correctly. Using these utterances in therapy may therefore play a key role in compensating for loss of social interaction, with a possible beneficial influence on motivation, subjective well-being, and quality of life (Doering et al., 2011; Hilari et al., 2012; Kuenemund et al., 2013). Although anecdotal evidence confirms the positive non-linguistic effects of formulaic language in individuals with neurological communication disorders, this hypothesis has not been studied experimentally.

We wish to emphasize that current programs in speech-language therapy differ considerably in how they take advantage of formulaic expressions, drawing on neural resources of communication to support social interaction. As discussed previously, utterance-centered approaches focus mainly on articulatory quality in the training sessions. In contrast, communicativepragmatic approaches benefit from the rich turn-taking structure underlying everyday conversation, thus encouraging the use of formulaic expressions in natural settings. We believe that methods relying on preserved language abilities in the context of social interaction may have a substantial impact on recovery from cognitive-affective distress, especially in individuals with concomitant post-stroke depression-a claim yet to be confirmed empirically.

\section{Open questions}

A growing body of research provides compelling evidence for the contribution of right-hemispheric cortical and bilateral subcortical neural systems to the production and comprehension of formulaic language. These data are consistent with the notion that the efficacy of prominent approaches in speech-language therapy depends, to some degree, on the intensive use of formulaic expressions. However, it is still poorly understood how exactly the language system of the damaged brain benefits from neural resources associated with formulaic expressions. There are in fact a range of 
neurophysiological scenarios that may account for descriptions of preserved language skills in clinical rehabilitation.

According to Hebbian learning, the synchronous firing of cell assemblies is likely to strengthen the neural connectivity between them, even if they are located in distributed areas of the brain; in other words, "cells that fire together, wire together" (Hebb, 1949). This neurobiological model may be appropriate in addressing three fundamental questions in future research: (i) Does intensive training of formulaic expressions stimulate neural activity in right-hemispheric cortical and bilateral subcortical language circuits? (ii) Does the combined training of propositional-grammatical utterances and formulaic expressions lead to functional reorganization in the interplay of left perilesional and right intact language networks? (iii) Does this bilateral neural interplay affect treatment-induced generalized effects observed on standardized aphasia test batteries?

With this article, we wish to increase the awareness for neural resources of communication in the treatment of individuals with lefthemispheric lesions. Based on our experience, the ability to use formulaic expressions is often well documented in clinical practice, commonly under a variety of different terms. However, the possible influence of such expressions on clinical rehabilitation frequently remains unnoticed. Uncovering the behavioral and neural dynamics of formulaic expressions may therefore be crucial in identifying and activating resources of communication more systematically. This may improve the success of current attempts to promote recovery from communication disorders and cognitive-affective distress after stroke. 


\section{References}

Albert, M. L., Sparks, R. W., \& Helm, N. (1973). Melodic Intonation Therapy for aphasia. Archives of Neurology, 29(2), 130-131.

Austin, L. (1962). How to do things with words. Oxford: Clarendon Press.

Barbancho, M. A., Berthier, M. L., Navas-Sánchez, P., Dávila, G., GreenHeredia, C., García-Alberca, J. M., et al. (2015). Bilateral brain reorganization with memantine and Constraint-Induced Aphasia Therapy in chronic post-stroke aphasia: An ERP study. Brain and Language, 145-146(1), 1-10.

Bastiaanse, R., \& Prins, R. S. (1994). Communicative speech therapy in aphasia: What does it mean, can it be effective and how should it be done? Aphasiology, 8(5), 482-488.

Belin, P., Zilbovicius, M., Remy, P., Francois, C., Guillaume, S., Chain, F., et al. (1996). Recovery from nonfluent aphasia after Melodic Intonation Therapy: A PET study. Neurology, 47(6), 1504-1511.

Berthier, M. L., Dávila, G., Green-Heredia, C., Torres, I. M., Juárez y Ruiz de Mier, R., De-Torres, I., et al. (2014). Massed sentence repetition training can augment and speed up recovery of speech production deficits in patients with chronic conduction aphasia receiving donepezil treatment. Aphasiology, 28(14), 188-218.

Berthier, M. L., Green, C., Lara, J. P., Higueras, C., Barbancho, M. A., Dávila, G., et al. (2009). Memantine and Constraint-Induced Aphasia Therapy in chronic poststroke aphasia. Annals of Neurology, 65(5), $577-585$.

Breier, J. I., Juranek, J., Maher, L. M., Schmadeke, S., Men, D., \& Papanicolaou, A. C. (2009). Behavioral and neurophysiologic response to therapy for chronic aphasia. Archives of Physical Medicine and Rehabilitation, 90(12), 2026-2033. 
Breier, J. I., Maher, L. M., Novak, B., \& Papanicolaou, A. C. (2006). Functional imaging before and after Constraint-Induced Language Therapy for aphasia using magnetoencephalography. Neurocase, 12(6), 322-331.

Davis, G. A., \& Wilcox, M. J. (1985). Adult aphasia rehabilitation: Applied pragmatics. San Diego, CA: College-Hill Press.

Difrancesco, S., Pulvermüller, F., \& Mohr, B. (2012). Intensive LanguageAction Therapy (ILAT): The methods. Aphasiology, 26(11), 13171351.

Doering, B. K., Conrad, N., Rief, W., \& Exner, C. (2011). Living with acquired brain injury: Self-concept as mediating variable in the adjustment process. Neuropsychological Rehabilitation, 21(1), 42-63.

Fillmore, C. (1979). On fluency. In C. J. Fillmore, D. Kempler, \& W. S.-Y. Wang (Eds.), Individual Differences in Language Ability and Language Behavior (pp. 85-102). London: Academic Press.

Fleminger, S., Oliver, D. L., Williams, W. H., \& Evans, J. (2003). The neuropsychiatry of depression after brain injury. Neuropsychological Rehabilitation, 13(1-2), 65-87.

Graves, R., \& Landis, T. (1985). Hemispheric control of speech expression in aphasia. Archives of Neurology, 42(3), 249-251.

Hebb, D. O. (1949). The Organization of Behavior. New York, NY: Wiley.

Helm-Estabrooks, N., Nicholas, M., \& Morgan, A. (1989). Melodic Intonation Therapy. Manual. Austin, TX: Pro-Ed.

Hilari, K., Needle, J. J., \& Harrison, K. L. (2012). What are the important factors in health-related quality of life for people with aphasia? A systematic review. Archives of Physical Medicine and Rehabilitation, 93, 86-95.

Horn, L. R., \& Ward, G. (2008). The Handbook of Pragmatics. Malden, MA: Blackwell. 
Hughlings-Jackson, J. (1878). On affection of speech from disease of the brain. Brain, 2(3), 203-222.

Jackendoff, R. (1995). The boundaries of the lexicon. In M. Everaert, E.-J. van der Linden, A. Schenk, \& R. Schreuder (Eds.), Idioms: Structural and Psychological Perspectives (pp. 133-166). Hillsdale, NJ: Lawrence Erlbaum Associates.

Kauhanen, M.-L., Korpelainen, J. T., Hiltunen, P., Brusin, E., Mononen, H., Määttä, R., et al. (1999). Poststroke depression correlates with cognitive impairment and neurological deficits. Stroke, 30(9), 18751880 .

Kuenemund, A., Zwick, S., Doering, B. K., Conrad, N., Rief, W., \& Exner, C. (2013). Decline in attainability of communion and agency life goals over 2 years following acquired brain injury and the impact on subjective well-being. Neuropsychological Rehabilitation, 23(5), 678697.

Kuiper, K. (2009). Formulaic Genres. Basingstoke: Palgrave Macmillan.

Lewinsohn, P. M. (1974). A behavioral approach to depression. In R. J. Friedman, \& M. M. Katz (Eds.), Psychology of Depression: Contemporary Theory and Research (pp. 157-178). Oxford: Wiley.

Lum, C. C., \& Ellis A. W. (1994). Is “nonpropositional” speech preserved in aphasia? Brain and Language, 46(3), 368-391.

MacGregor, L. J., Difrancesco, S., Pulvermüller, F., Shtyrov, Y., \& Mohr, B. (2014). Ultra-rapid access to words in chronic aphasia: The effects of Intensive Language Action Therapy (ILAT). Brain Topography, 28(2), 279-291.

McElduff, K., \& Drummond, S. S. (1991). Communication functions of automatic speech in non-fluent aphasia. Aphasiology, 5(3), 265-278.

Meinzer, M., Djundja, D., Barthel, G., Elbert, T., \& Rockstroh, B. (2005). Long-term stability of improved language functions in chronic aphasia after Constraint-Induced Aphasia Therapy. Stroke, 36(7), 1462-1466. 
Meinzer, M., Elbert, T., Wienbruch, C., Djundja, D., Barthel, G., \& Rockstroh, B. (2004). Intensive language training enhances brain plasticity in chronic aphasia. BMC Biology, 2(1), Article 20.

Meinzer, M., Flaisch, T., Breitenstein, C., Wienbruch, C., Elbert, T., \& Rockstroh B. (2008). Functional re-recruitment of dysfunctional brain areas predicts language recovery in chronic aphasia. Neuroimage, 39(4), 2038-2046.

Meinzer, M., Streiftau, S., \& Rockstroh, B. (2007). Intensive language training in the rehabilitation of chronic aphasia: Efficient training by laypersons. Journal of the International Neuropsychological Society, 13(5), 846-853.

Mohr, B., Difrancesco, S., Evans, S., Harrington, K., \& Pulvermüller, F. (2014). Changes of right-hemispheric activation after constraintinduced, intensive language action therapy in chronic aphasia: fMRI evidence from auditory semantic processing. Frontiers in Human Neuroscience, 8, Article 919.

Pawley, A., \& Syder, F. H. (1983). Two puzzles for linguistic theory: Nativelike selection and nativelike fluency. In J. C. Richard, \& R. Schmidt (Eds.), Language and Communication (pp. 191-226). London: Longman.

Priebe, S., Omer, S., Giacco, D., \& Slade, M. (2014). Resource-oriented therapeutic models in psychiatry: Conceptual review. British Journal of Psychiatry, 204, 256-261.

Pulvermüller, F., \& Roth, V. M. (1991). Communicative aphasia treatment as a further development of pace therapy. Aphasiology, 5(1), 39-50.

Pulvermüller, F., Hauk, O., Zohsel, K., Neininger, B., \& Mohr, B. (2005). Therapy-related reorganization of language in both hemispheres of patients with chronic aphasia. Neuroimage, 28(2), 481-489. 
Pulvermüller, F., Neininger, B., Elbert, T., Mohr, B., Rockstroh, B., Koebbel, P., et al. (2001). Constraint-induced therapy of chronic aphasia after stroke. Stroke, 32(7), 1621-1626.

Pulvermüller, P. (1990). Aphasische Kommunikation: Grundfragen ihrer Analyse und Therapie. Tübingen: Gunter Narr Verlag.

Schegloff, E. (1988). Discourse as an interactional achievement: An exercise in conversation analysis. In D. Tannen (Ed.), Linguistics in Context: Connecting Observation and Understanding (pp. 135-158). Norwood, NY: Ablex.

Schlaug, G., Marchina, S., \& Norton, A. (2008). From singing to speaking: Why singing may lead to recovery of expressive language function in patients with Broca's aphasia. Music Perception, 25(4), 315-323.

Schlaug, G., Marchina, S., \& Norton, A. (2009). Evidence for plasticity in white-matter tracts of patients with chronic Broca's aphasia undergoing intense intonation-based speech therapy. Annals of the New York Academy of Sciences, 1169, 385-394.

Schönberger, M., Ponsford, J., Gould K. R., \& Johnston, L. (2011). The temporal relationship between depression, anxiety, and functional status after traumatic brain injury: A cross-lagged analysis. Journal of the International Neuropsychological Society, 17(5), 781-787.

Searle, J. R. (1969). Speech acts: An essay in the philosophy of language. Cambridge: Cambridge University Press.

Sidtis, D., Canterucci, G., \& Katsnelson, D. (2009). Effects of neurological damage on production of formulaic language. Clinical Linguistics \& Phonetics, 23(4), 270-284.

Speedie, L. J., Wertman, E., Ta'ir, J., \& Heilman, K. M. (1993). Disruption of automatic speech following a right basal ganglia lesion. Neurology, 43(9), 1768-1774. 
Stahl, B., \& Kotz, S. A. (2014). Facing the music: Three issues in current research on singing and aphasia. Frontiers in Psychology, 5, Article 1033.

Stahl, B., Henseler, I., Turner, R., Geyer, S., \& Kotz, S. A. (2013). How to engage the right brain hemisphere in aphasics without even singing: Evidence for two paths of speech recovery. Frontiers in Human Neuroscience, 7, Article 35.

Stahl, B., Kotz, S. A., Henseler, I., Turner, R., \& Geyer, S. (2011). Rhythm in disguise: Why singing may not hold the key to recovery from aphasia. Brain, 134(10), 3083-3093.

Van der Meulen, I. (2015). The effect of Melodic Intonation Therapy in the subacute and in the chronic stage. Talk presented at the Dutch Congress of Rehabilitation Medicine, Rotterdam, The Netherlands.

Van der Meulen, I., van de Sandt-Koenderman, M. E., Heijenbrok-Kal, M. H., Visch-Brink, E. G., \& Ribbers, G. M. (2014). The efficacy and timing of Melodic Intonation Therapy in subacute aphasia. Neurorehabilitation and Neural Repair, 28(6), 536-544.

Van Lancker Sidtis, D. (2010). Formulaic and novel expressions in mind and brain: Empirical studies and a dual process model of language competence. In J. Guendouzi, F. Loncke, \& M. Williams (Eds.), The Handbook of Psycholinguistic \& Cognitive Processes: Perspectives in Communication Disorders (pp. 247-272). London: Taylor \& Francis.

Van Lancker Sidtis, D., \& Postman, W. A. (2006). Formulaic expressions in spontaneous speech of left- and right-hemisphere-damaged subjects. Aphasiology, 20(5), 411-426.

Van Lancker Sidtis, D., \& Rallon, G. (2004). Tracking the incidence of formulaic expressions in everyday speech: Methods for classification and verification. Language \& Communication, 24(3), 207-240.

Van Lancker Sidtis, D., Choi, J.-H., Alken, A., \& Sidtis, J. J. (2015). Formulaic language in Parkinson's and Alzheimer's disease: 
Complementary effects of subcortical and cortical dysfunction. Journal of Speech, Language, and Hearing Research, 58(5), 1493-1507.

Vihman, M. M. (1982). Formulas in first and second language acquisition. In L. K. Obler, \& L. Menn (Eds.), Exceptional Language and Linguistics (pp. 261-284). New York, NY: Academic Press.

Vines, B. W., Norton, A. C., \& Schlaug. G. (2011). Non-invasive brain stimulation enhances the effects of Melodic Intonation Therapy. Frontiers in Psychology, 2, Article 230.

Wilson, S. J., Parsons, K., \& Reutens, D. C. (2006). Preserved singing in aphasia: A case study of the efficacy of Melodic Intonation Therapy. Music Perception, 24(1), 23-36.

Wittgenstein, L. (1953). Philosophical Investigations. Oxford: Blackwell Publishers.

Wray, A. (2002). Formulaic Language and the Lexicon. Cambridge: Cambridge University Press.

Zumbansen, A., Peretz, I., \& Hébert, S. (2014). The combination of rhythm and pitch can account for the beneficial effect of Melodic Intonation Therapy on connected speech improvements in Broca's aphasia. Frontiers in Human Neuroscience, 8, Article 592. 


\section{Part V}

\section{Social interaction}

Original publication

Stahl, B., Mohr, B., Dreyer, F. R., Lucchese, G., \& Pulvermüller, F. (2016).

Using language for social interaction: Communication mechanisms promote recovery from chronic non-fluent aphasia. Cortex, 85, 90-99. 


\section{Abstract}

Purpose. Clinical research highlights the importance of massed practice in the rehabilitation of chronic post-stroke aphasia. However, while necessary, massed practice may not be sufficient for ensuring progress in speech-language therapy. Motivated by linguistic theory and neuroscience data, it has been claimed that using language as a "tool" for communication and social interaction leads to synergistic effects in left perisylvian eloquent areas. Here, we conducted a crossover randomized controlled trial to determine the influence of communicative language function on the outcome of intensive aphasia therapy.

Methods. Eighteen individuals with left-hemispheric lesions and chronic non-fluent aphasia each received two types of training in counterbalanced order: (i) Intensive Language-Action Therapy (ILAT) embedding verbal utterances in communicative-pragmatic context, and (ii) Naming Therapy focusing on speech production per se. Both types of training were delivered with the same high intensity ( 3.5 hours per session) and duration (6 consecutive working days), with therapy materials and number of utterances matched between treatment groups.

Results. A standardized aphasia test battery revealed significantly improved language performance with ILAT, independent of when this method was administered. In contrast, Naming Therapy tended to benefit language performance only when given at the onset of the treatment, but not when applied after previous intensive training.

Conclusions. The current results challenge the notion that massed practice alone promotes recovery from chronic post-stroke aphasia. Instead, our results demonstrate that using language for communication and social interaction increases the efficacy of intensive aphasia therapy. 


\section{Introduction}

After decades of debate on the success of speech-language therapy (SLT) in neurological patients (Lincoln et al., 1984), clinical research has confirmed the relative efficacy of intensive regimes in the neurorehabilitation of chronic post-stroke aphasia (Brady et al., 2016). In particular, randomized controlled trial (RCT) data have demonstrated the short- and long-term benefit from Intensive Language-Action Therapy (ILAT), an extended form of Constraint-Induced Aphasia Therapy, even if delivered years following the onset of the disease (Pulvermüller et al., 2001; Meinzer et al., 2005; Szaflarski et al., 2015). Apart from its high intensity with up to 30 hours of practice in less than two weeks, ILAT emphasizes the training of language skills in communicative-pragmatic context (Difrancesco et al., 2012).

Motivation for ILAT comes from linguistic theory, stating that the primary function of language emerges from its everyday use (Wittgenstein, 1953; Tomasello, 2005), and from neuroscience data (Berthier \& Pulvermüller, 2011). Crucially, recent studies revealed an increase of brain activity with communicative function, showing that requesting objects from a person elicits stronger neurophysiological and neuroimaging responses in cortical language and motor regions than picture naming performed with the same verbal utterances (Egorova et al., 2013, 2014, 2016). Further neuroscience evidence suggests that the neural bases of language and action are functionally interlinked (e.g., Pulvermüller et al., 2005; Glenberg et al., 2008; Willems et al., 2011). Therefore, it has been argued that the co-activation of these neural systems potentially leads to synergistic effects, which might improve the outcome of SLT if verbal utterances are embedded in behaviorally relevant settings (Pulvermüller \& Fadiga, 2010). Still, the major variable currently seen as essential for the success of SLT in general, and ILAT in particular, is the intensity of the treatment, while the role of communication and social interaction remains not fully understood (Cherney et al., 2008). 
The present crossover RCT seeks to determine the impact of communication and social interaction on the efficacy of intensive SLT. Individuals with chronic non-fluent aphasia each received two types of intensive training in counterbalanced order: communicative-pragmatic treatment focusing on verbal requests (ILAT), and utterance-centered confrontation naming (Naming Therapy). The design controlled for the influence of training intensity and duration, with therapy materials and number of utterances matched between treatment groups. According to traditional views in aphasia rehabilitation, the ability to name objects may be a precondition for successful communication, hence predicting that Naming Therapy should yield greater progress than ILAT (Shewan \& Bandur, 1986). Conversely, linguistic theory and neuroscience data summarized above suggest that embedding verbal utterances in communication and social interaction may be key to facilitating language processing in left perisylvian eloquent areas, thus predicting better outcomes with ILAT than Naming Therapy.

\section{Methods}

\subsection{Participants}

Eighteen individuals with a neurological diagnosis of chronic aphasia were eligible and agreed to participate in the current crossover RCT (for details, see Fig. 1). This sample size was consistent with a previous power analysis $(\alpha=0.05 ; 1-\beta=0.95$; number of groups: 2 ; number of repeated measures: 3; estimated Cohen's $f=0.4$, derived from Pulvermüller et al., 2001, and equivalent to an increase of 2 points per training period on our standardized aphasia test battery; cf. Faul et al., 2009). All individuals were native speakers of German who had not received intensive SLT in the year prior to inclusion in the study. Individuals were aged 32 to 73 years (mean age: 51 years; standard deviation: 12 years) and right-handed according to the Edinburgh Handedness Inventory (Oldfield, 1971). The trial excluded individuals with severe non-verbal cognitive deficits that often occur in the 
visual domain and may have caused problems in the testing or in the therapy sessions (cf. Hachioui et al., 2014). All individuals met this requirement, showing visual short-term memory within the normal range, as revealed by the Corsi Block-Tapping Task (Kessels et al., 2000). To prevent nontreatment effects related to spontaneous recovery of symptoms, individuals were at least one year post-onset of disease at the time of initial testing (cf. Kertesz, 1984). The trial was approved by the ethics review board at the Charité University Hospital in Berlin, Germany, and registered prospectively (www.who.int registry identifier: DRKS00005482).

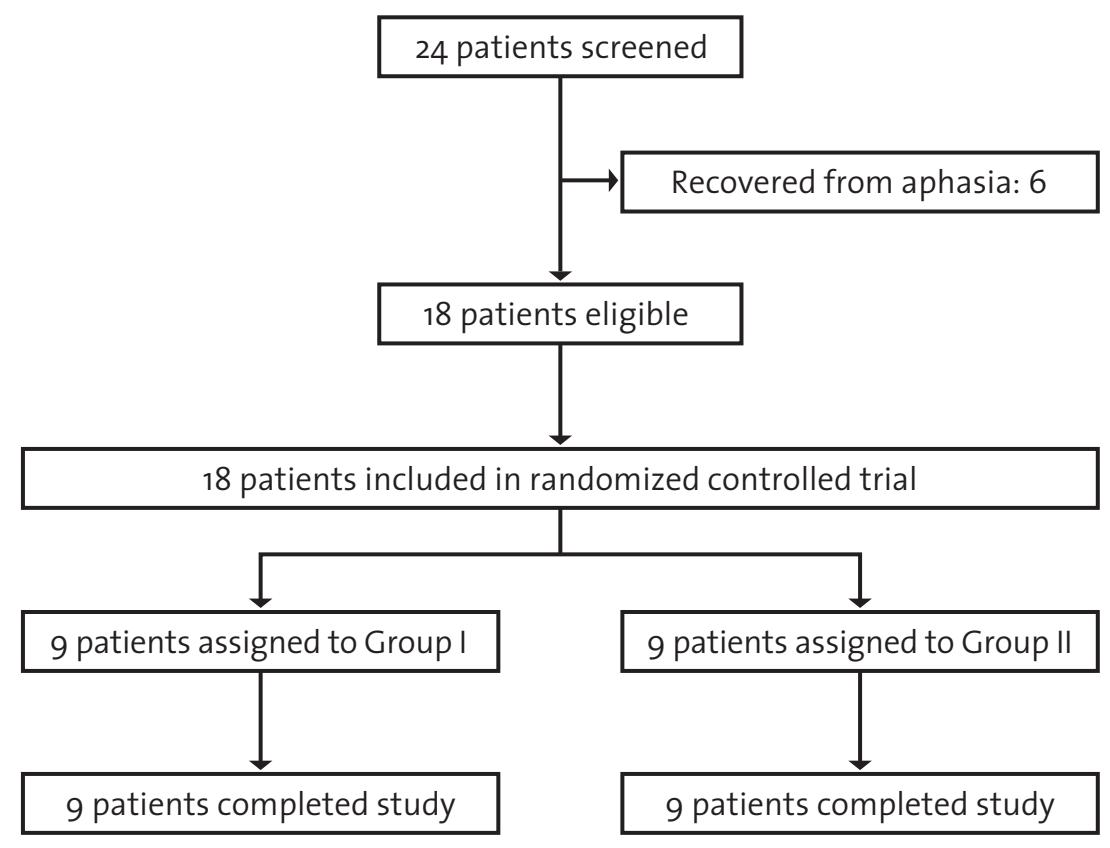

Figure 1. CONSORT Flow Diagram.

Language abilities at baseline were assessed using a standardized diagnostic instrument, the Aachen Aphasia Test (AAT; Huber et al., 1984). The neurological diagnosis of aphasia was confirmed in all individuals, as indicated by the AAT Token Test (cf. Orgass \& Poeck, 1966). Structural $T_{1}$ weighted magnetic resonance imaging was performed for all individuals using a 3T Magnetom Trio scanner (Siemens Medical Solutions, Erlangen, 
Germany). Sixteen individuals had suffered a single cerebrovascular accident with subsequent lesions in parts of the left frontal, parietal, and temporal lobes, as well as in adjacent subcortical areas. The sample included two additional individuals with left-hemispheric lesions resulting from traumatic brain injury (patient 03) and viral encephalopathy (patient 15). Lesions in both of these individuals were most prominent in left perisylvian and adjacent subcortical areas. Two clinical neuroscientists manually delineated and superimposed the precise locations of lesioned voxels in each patient using the software MRIcron (Rorden \& Brett, 2000; for lesion overlay maps, see Fig. 2; for individual case histories and baseline test scores, see Table 1 and 2).

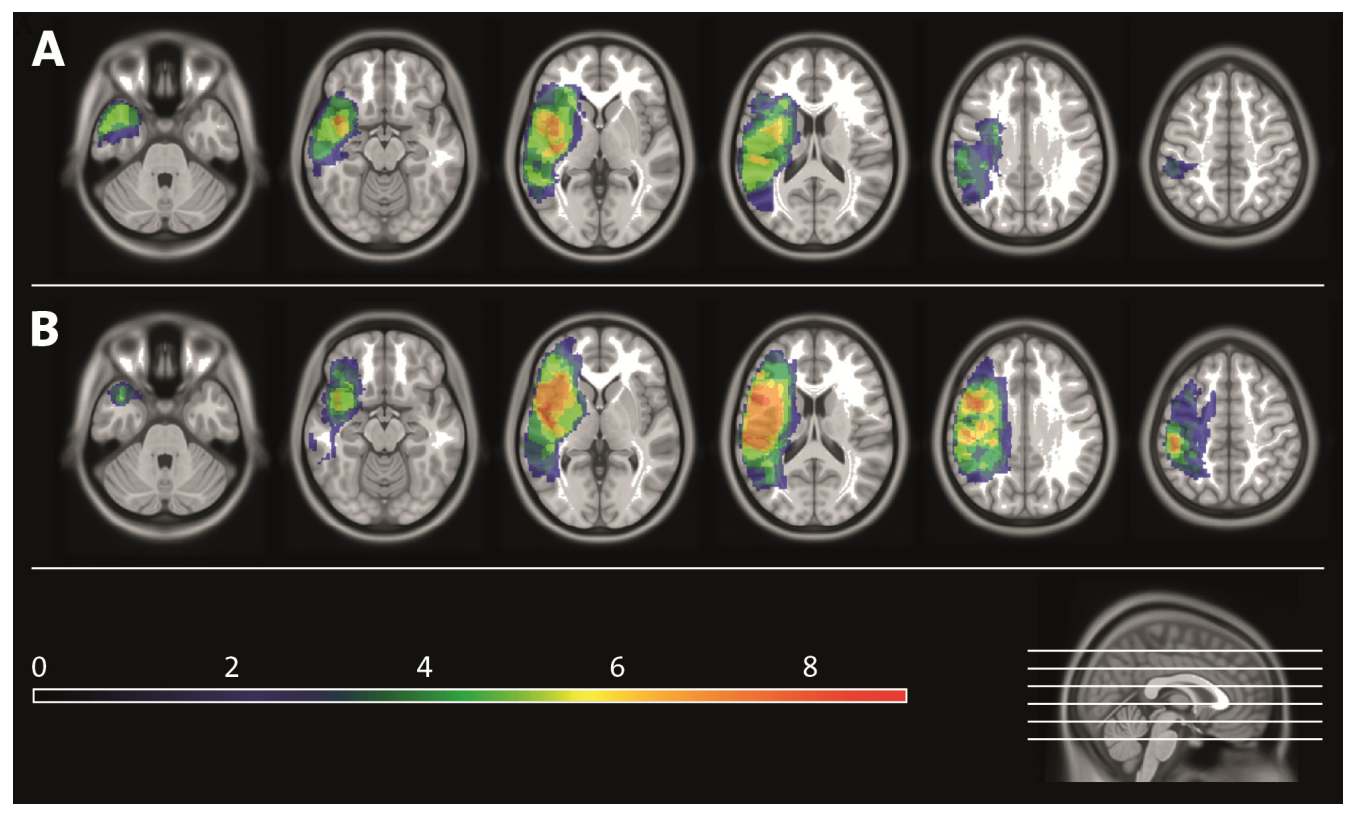

Figure 2. Lesion overlay maps. Individuals received Intensive Language-Action Therapy prior to Naming Therapy (Group I; see Panel A) or vice versa (Group II; see Panel B). Different colors indicate the number of lesion overlaps in each treatment group. 
Table 1. Patient histories.

\begin{tabular}{llllll}
\hline Patient & Gender & $\begin{array}{l}\text { Age } \\
\text { (in years) }\end{array}$ & $\begin{array}{l}\text { Education level } \\
\text { (in years) }\end{array}$ & $\begin{array}{l}\text { Months after } \\
\text { onset of stroke }\end{array}$ & $\begin{array}{l}\text { Left-hemisphere } \\
\text { origin }\end{array}$ \\
\hline 01 & Male & 49 & 13 & 41 & MCA ischemia \\
\hline 02 & Male & 63 & 16 & 45 & MCA ischemia \\
\hline 03 & Female & 45 & 21 & 49 & Perisylvian TBI \\
\hline 04 & Female & 41 & 18 & 97 & MCA ischemia \\
\hline 05 & Male & 49 & 14 & 52 & MCA ischemia \\
\hline 06 & Male & 54 & 21 & 49 & MCA ischemia \\
\hline 07 & Female & 35 & 12 & 13 & MCA ischemia \\
\hline 08 & Male & 32 & 14 & 40 & MCA ischemia \\
\hline 09 & Male & 62 & 17 & 23 & \\
\hline
\end{tabular}

\begin{tabular}{llllll}
\hline $\begin{array}{l}\text { Group I } \\
\text { Mean (SD) }\end{array}$ & & $\mathbf{4 7 . 8}(\mathbf{1 0 . 2})$ & $\mathbf{1 6 . 2} \mathbf{( 3 . 1 )}$ & $\mathbf{4 5 . 4} \mathbf{( 2 1 . 9 )}$ & \\
\hline 10 & Male & 73 & 19 & 61 & MCA ischemia \\
\hline 11 & Female & 39 & 12 & 78 & MCA ischemia \\
\hline 12 & Female & 49 & 13 & 149 & MCA ischemia \\
\hline 13 & Male & 51 & 12 & 42 & MCA ischemia \\
\hline 14 & Male & 63 & 13 & 31 & MCA ischemia \\
\hline 15 & Male & 66 & 13 & 77 & perisylvian VE \\
\hline 16 & Female & 47 & 12 & 245 & MCA ischemia \\
\hline 17 & Female & 37 & 11 & 30 & MCA ischemia \\
\hline 18 & Male & 65 & 25 & 239 & MCA ischemia \\
\hline
\end{tabular}

\section{Group II}

Mean (SD)

$54.4(12.0) \quad 14.4(4.3)$

$105.8(80.3)$

Patients are listed according to treatment order: Group I (ILAT; Naming Therapy); Group II (Naming Therapy; ILAT).

$\mathrm{MCA}=$ middle cerebral artery; $\mathrm{TBI}$ = traumatic brain injury; $\mathrm{VE}=$ viral encephalopathy; $\mathrm{SD}=$ standard deviation 
Table 2. Baseline test scores.

\begin{tabular}{|c|c|c|c|c|c|c|}
\hline Patient & $\begin{array}{l}\text { AAT } \\
\text { Token Test }\end{array}$ & $\begin{array}{l}\text { AAT } \\
\text { Repetition }\end{array}$ & $\begin{array}{l}\text { AAT } \\
\text { Naming }\end{array}$ & $\begin{array}{l}\text { AAT } \\
\text { Comprehension }\end{array}$ & CBTT & $\begin{array}{l}\text { Aphasia } \\
\text { type }\end{array}$ \\
\hline 01 & 37 & 48 & 48 & 47 & 4 & Broca \\
\hline 02 & 66 & 62 & 59 & 61 & 6 & Broca \\
\hline 03 & 42 & 57 & 41 & 44 & 3 & Global \\
\hline 04 & 51 & 59 & 53 & 70 & 6 & Broca \\
\hline 05 & 51 & 61 & 53 & 64 & 7 & Broca \\
\hline 06 & 48 & 45 & 56 & 62 & 6 & Broca \\
\hline 07 & 33 & 37 & 39 & 47 & 7 & Broca \\
\hline 08 & 56 & 54 & 57 & 78 & 7 & Broca \\
\hline 09 & 42 & 43 & 39 & 47 & 5 & Global \\
\hline \multicolumn{7}{|l|}{ Group I } \\
\hline Mean (SD) & $47.3(9.5)$ & $51.8(8.4)$ & $49.4(7.5)$ & $57.8(11.4)$ & $5.7(1.3)$ & \\
\hline 10 & 41 & 42 & 41 & 34 & 3 & Global \\
\hline 11 & 44 & 46 & 47 & 45 & 6 & Broca \\
\hline 12 & 48 & 48 & 48 & 53 & 4 & Broca \\
\hline 13 & 51 & 45 & 49 & 49 & 6 & Broca \\
\hline 14 & 54 & 52 & 49 & 48 & 6 & Broca \\
\hline 15 & 33 & 43 & 39 & 46 & 3 & Global \\
\hline 16 & 55 & 59 & 68 & 62 & 6 & Broca \\
\hline 17 & 54 & 53 & 53 & 57 & 6 & Broca \\
\hline 18 & 47 & 52 & 46 & 49 & 6 & Broca \\
\hline \multicolumn{7}{|l|}{ Group II } \\
\hline Mean (SD) & $47.4(6.8)$ & $48.9(5.2)$ & 48.9 (7.9) & $49.2(7.5)$ & $5.1(1.3)$ & \\
\hline
\end{tabular}

Patients are listed according to treatment order: Group I (ILAT; Naming Therapy); Group II (Naming Therapy; ILAT).

AAT: Aachen Aphasia Test; CBTT: Corsi Block-Tapping Task; SD: Standard deviation 


\subsection{Study design and randomization}

In a crossover design, individuals were randomly assigned to one of two treatment orders: ILAT prior to Naming Therapy (Group I; $n=9$ ), and vice versa (Group II; $n=9$ ). The group allocation was consistent with a previously determined computer-generated series of random numbers ( 0 or 1 ) and executed by an individual who alone had access to this list. Importantly, the individual did not participate in any stage of recruiting, screening, consenting, therapy or testing. According to Mann-Whitney $U$ tests, the randomization procedure did not lead to significant differences between Group I and Group II with regard to: age, education level, months after onset of disease, individual lesion size, non-verbal short-term memory, and weekly hours of SLT before inclusion in the study. Crucially, differences were also absent on the mean AAT scores at baseline $(z=0.58, p=0.61$, not significant [n.s.]). Moreover, the treatment groups were comparable in terms of gender and clinical diagnoses (for group averages and standard deviations, see Table 1 and 2). Since individuals with aphasia usually suffer from concomitant neurological communication disorders, it is worth noting that Group I and Group II were similarly affected by apraxia of speech, as diagnosed by two clinical linguists.

\subsection{Treatment protocols and materials}

ILAT was shaped according to everyday request communication (cf. Difrancesco et al., 2012). Three individuals and a therapist were seated around a table and provided with picture cards showing different objects. Each card had a duplicate that was owned by one of the fellow players. Barriers on the table prevented players from seeing each others' cards. The goal was to obtain a pair of identical cards by verbally requesting the duplicate from fellow players. Request utterances included the name of an object embedded in a carrier phrase (e.g., "I want the [...]," "Could I please have the [...]"). If the duplicate was available, the players compared the depicted objects and, in the case of a match, the addressee handed over the corresponding card to 
the requesting person. If the duplicate was not available, the addressee rejected the request. In the event of misunderstandings, the players asked clarifying questions. This rich turn-taking structure encouraged the use of formulaic expressions (e.g., "Here you are," "Thank you," "You're welcome"; cf. Stahl \& Van Lancker Sidtis, 2015). The complexity of the communicative interaction was tailored to the language skills of each individual by varying the difficulty level of the target words and the carrier phrases.

Naming Therapy was conceived to resemble ILAT in as many ways as possible, except for the fact that the players did not use verbal utterances for communication and social interaction. Instead, the goal was to name or describe objects shown on the picture cards. Three individuals and a therapist were seated around the table, on which cards were placed exactly as during ILAT, but with the barriers removed. The players took turns in clockwise order, picking a card from their own set and finding an appropriate designation for the depicted object. The name of an object was embedded in a carrier phrase of similar length and syntactic complexity as during ILAT (e.g., "This is a [...]," "Here I can see a [...]"). Individuals were able to observe whether or not other players identified an object correctly. Unlike ILAT, Naming Therapy did not encourage the use of formulaic expressions. Critically, the total number of verbal utterances did not differ between ILAT and Naming Therapy. Again, the difficulty level of the target words and the carrier phrases was tailored to the language skills of each individual.

In both types of training, the therapist (i) acted as a model by using individual carrier phrases, (ii) provided instruction and advice, whenever helpful, and (iii) motivated participants by giving positive feedback. The training materials were designed for the purpose of the current trial. Each set of cards included 12 picture pairs. For tailoring these sets to individual language skills, the following difficulty levels were available: items with high ( $n=48$ different pictures), medium $(n=48)$, and low $(n=48)$ normalized lemma frequency; phonological minimal pairs $(n=96)$; and items from only one semantic category $(n=48)$. Card sets of one difficulty level were matched for mean normalized lemma frequency to ensure that items of each category were similarly challenging. All 24 card sets were split into two 
packets with equal numbers of items per difficulty level and assigned to ILAT or Naming Therapy in counterbalanced order across treatment groups.

\subsection{Procedures}

Recruitment, screening and training sessions took place at an outpatient rehabilitation center located in Berlin, Germany. The training was delivered by a clinical neuroscientist serving as a therapist. Groups of three individuals who were relatively heterogeneous with regard to symptom severity underwent ILAT and Naming Therapy in the order determined by the randomization procedure described above. The schedule included a 6-day recreation interval between the two treatments (see Fig. 3). Both types of training were administered with the same high intensity (3.5 hours per session with short breaks, if necessary) and duration (6 consecutive working days), resulting in overall 42 hours of treatment within less than 4 weeks. Individuals completed all training sessions and did not attend any other form of SLT throughout the entire trial (cf. Hoffmann et al., 2014).

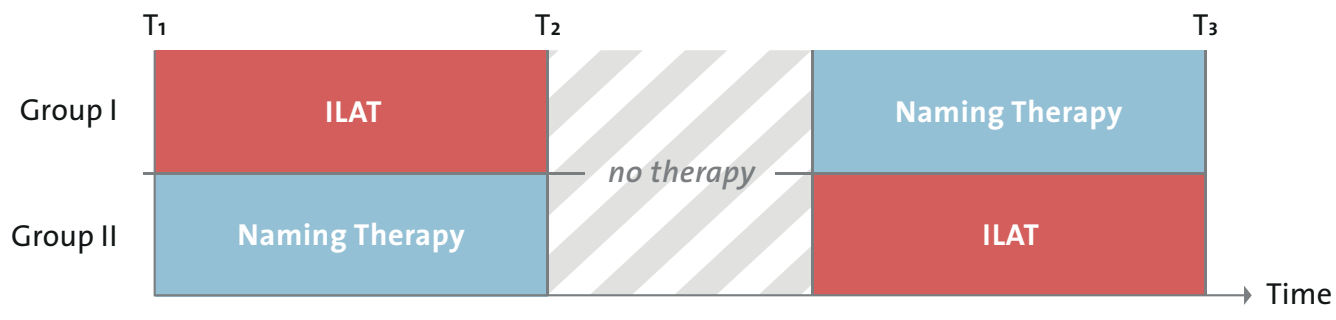

Figure 3. Study design. Group I received Intensive Language-Action Therapy (ILAT) prior to Naming Therapy, while Group II attended both types of training in reverse order. Individuals underwent testing before treatment onset $\left(\mathrm{T}_{1}\right)$, after the first treatment $\left(\mathrm{T}_{2}\right)$, and after the second treatment $\left(\mathrm{T}_{3}\right)$. 
A clinical neuropsychologist tested each individual one day before $\left(\mathrm{T}_{1}\right)$ and one day after the first training period $\left(\mathrm{T}_{2}\right)$, as well as one day after the second training period $\left(\mathrm{T}_{3}\right)$. The neuropsychologist was blinded to the group assignment and did not have patient contact apart from the testing sessions. Changes in language abilities were assessed using a standardized aphasia test battery, known for its good test-retest reliability (AAT; Huber et al., 1984). Language performance was measured on four subscales of the battery: Token Test, Repetition, Naming, and Comprehension. Test items on each of these subscales overlapped only marginally (5\%) with therapy materials in any type of training to minimize "trivial" learning effects. AAT results were designated as normally distributed $t$-scores, averaged across subscales. These mean AAT scores served as primary outcome measure to investigate changes in general language performance over time. As both types of training focused on verbal expression, we considered scores on the combined AAT subscales requiring speech production-Naming and Repetition- as a second measure of interest.

\subsection{Statistical analyses}

Statistical evaluations indicated negligible carryover effects in our crossover design, suggesting interpretable data in both training periods $[t(16)=-1.54, p=0.15$, n.s.; for details, see Jones \& Kenward, 2002]. Repeated-measures analyses of variance (ANOVAs) were conducted, including within-subject factor Time $\left(\mathrm{T}_{1} ; \mathrm{T}_{2} ; \mathrm{T}_{3}\right)$ and between-subject factor Group (Group I; Group II), with two-tailed $p$ values and alpha levels of 0.05 applied for all statistical tests.

\section{Results}

A repeated-measures ANOVA revealed a significant interaction of Time and Group based on the mean AAT scores $[F(2,30)=6.91, p=0.003$, $\left.\eta^{2}=0.12\right]$. This complex interaction was explored in subsequent ANOVA 
contrasts. In the first training period, ILAT yielded better outcomes than Naming Therapy [Time $\times$ Group interaction between $\mathrm{T}_{1}$ and $\mathrm{T}_{2}: F(1,15)=$ $\left.4.72, p=0.046, \eta^{2}=0.08\right]$. In the second training period, this differential pattern of results was even more pronounced [Time $\times$ Group interaction between $\mathrm{T}_{2}$ and $\mathrm{T}_{3}: F(1,15)=15.85, p=0.001, \eta^{2}=0.41$; see Fig. $4 \mathrm{~A}$ and Table 3].

The ANOVA focusing on mean AAT production scores revealed a significant interaction of Time and Group $\left[F(2,30)=5.48, p=0.009, \eta^{2}=\right.$ $0.14]$. Subsequent exploratory ANOVA contrasts indicated a superiority of ILAT over Naming Therapy in the first training period [Time $\times$ Group interaction between $\mathrm{T}_{1}$ and $\left.\mathrm{T}_{2}: F(1,15)=5.87, p=0.03, \eta^{2}=0.21\right]$ and in the second training period [Time $\times$ Group interaction between $\mathrm{T}_{2}$ and $\mathrm{T}_{3}: F(1$, $15)=10.43, p=0.006, \eta^{2}=0.53$; see Fig. $4 \mathrm{~B}$ and Table 3].

Comparing the mean AAT scores from both training periods before and after each type of intervention in post-hoc evaluations, the ANOVA suggested significant progress in language performance with ILAT [main effect of Time: $F(1,15)=108.24, p<0.001, \eta^{2}=0.87$ ], independent of whether the treatment had been applied initially or in second position [Time $\times$ Group interaction: $F(1,15)=0.55$, n.s.]. Naming Therapy did not consistently lead to progress in language performance [main effect of Time: $F(1,15)=1.46$, n.s.), but this treatment was relatively more effective initially than in second position [Time $\times$ Group interaction: $F(1,15)=4.55, p=0.049, \eta^{2}=0.22$ ]

Further post-hoc analyses demonstrated that excluding the two individuals with aphasia following traumatic brain injury (patient 03) and viral encephalopathy (patient 15) did not alter the significant interaction of Time and Group $\left[F(2,26)=4.88, p=0.02, \eta^{2}=0.09\right]$. 
A

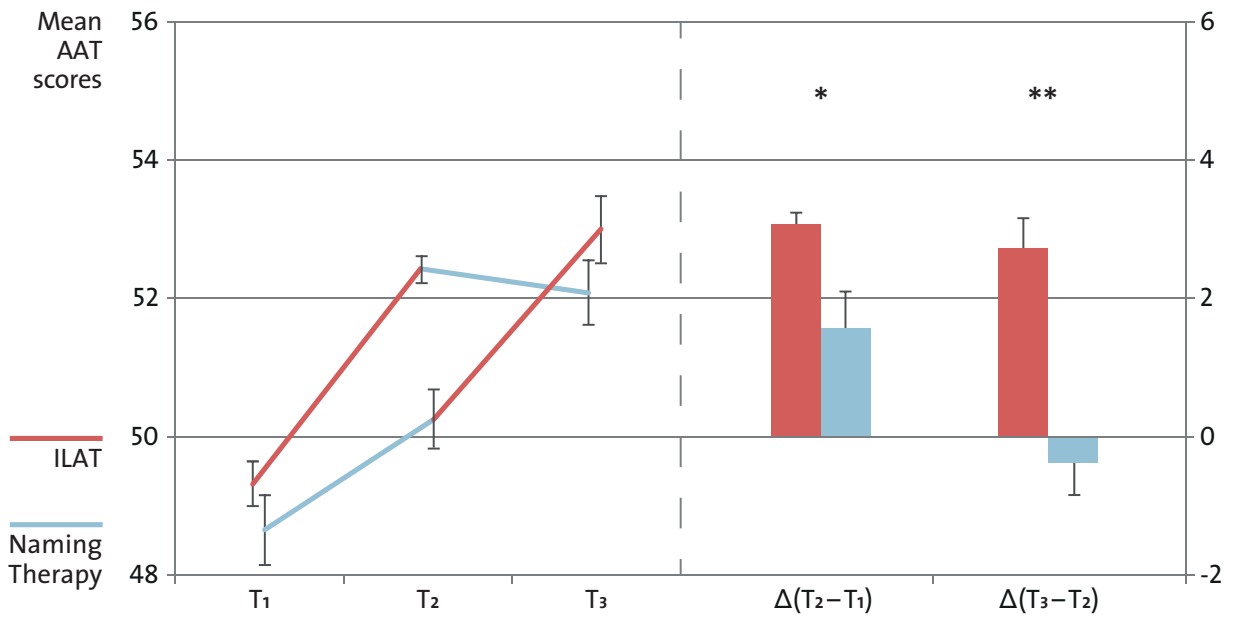

\section{B}

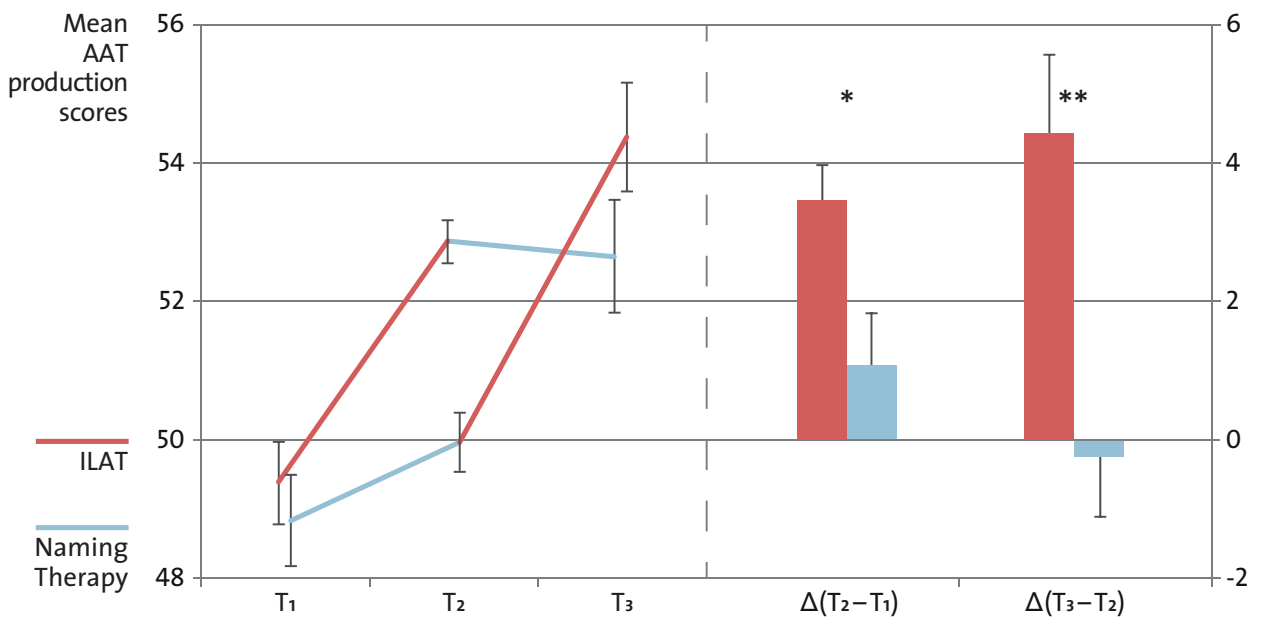

Figure 4. Aphasia test results. Changes in language performance on the Aachen Aphasia Test (AAT), based on mean scores across all subscales (Panel A) and speech production measures only (Panel B). Individuals with chronic aphasia were randomly assigned to one of two Groups: Intensive Language-Action Therapy (ILAT) administered prior to Naming Therapy or vice versa. Individuals were tested at three points in Time: before treatment onset $\left(\mathrm{T}_{1}\right)$, after the first treatment $\left(\mathrm{T}_{2}\right)$, and after the second treatment $\left(\mathrm{T}_{3}\right)$. AAT results indicate significant interactions of Time and Group in the first training period $\left(\Delta \mathrm{T}_{2}-\mathrm{T}_{1}\right)$ and in the second training period $\left(\Delta \mathrm{T}_{3}-\mathrm{T}_{2}\right)$, as revealed by repeated-measures analyses of variance $\left({ }^{*} p<0.05 ;{ }^{* *} p<0.01\right)$. 
Table 3. Aphasia test results.

\begin{tabular}{|c|c|c|c|c|c|}
\hline $\begin{array}{l}\text { Mean AAT } \\
\text { scores }\end{array}$ & $\mathrm{T}_{1}$ & $\mathbf{T}_{2}$ & $T_{3}$ & $\Delta\left(\mathbf{T}_{2}-\mathrm{T}_{1}\right)$ & $\Delta\left(\mathbf{T}_{3}-\mathrm{T}_{2}\right)$ \\
\hline Group I (SD) & $49.4(9.4)$ & $52.5(9.5)$ & $52.1(10.8)$ & $3.1(0.5)^{*}$ & $.0 .4(1.7)$ \\
\hline Group II (SD) & $48.7(6.7)$ & $50.3(7.0)$ & $52.9(7.5)$ & $1.5(2.0)$ & $2.7(1.5)^{*}$ \\
\hline $\begin{array}{l}\text { Mean AAT } \\
\text { production } \\
\text { scores }\end{array}$ & $\mathrm{T}_{1}$ & $\mathbf{T}_{2}$ & $T_{3}$ & $\Delta\left(\mathbf{T}_{2}-\mathbf{T}_{1}\right)$ & $\Delta\left(T_{3}-T_{2}\right)$ \\
\hline Group I (SD) & $49.4(7.0)$ & $52.8(8.0)$ & $52.6(9.9)$ & $3.4(1.6)^{*}$ & $.0 .3(2.8)$ \\
\hline Group II (SD) & $48.9(6.7)$ & $49.9(5.6)$ & $54.4(7.6)$ & $1.1(2.3)$ & $4.4(3.2)^{* *}$ \\
\hline
\end{tabular}

Aachen Aphasia Test (AAT) results averaged across all subscales (Mean AAT scores) and subscales requiring speech production (Mean AAT production scores). Individuals with chronic aphasia were randomly assigned to one of two treatment groups: Intensive Language-Action Therapy prior to Naming Therapy (Group I) or vice versa (Group II). Testing was administered at three points in time: before treatment $\left(T_{1}\right)$, after the first treatment $\left(T_{2}\right)$, and after the second treatment $\left(T_{3}\right)$. Wilcoxon signed-rank tests revealed significantly increased aphasia test scores with ILAT $\left(* p<0.05 ;{ }^{* *} p<0.01\right)$ in the first training period $\left[\Delta\left(\mathrm{T}_{2}-\mathrm{T}_{1}\right)\right]$ and in the second training period $\left[\Delta\left(T_{3}-T_{2}\right)\right]$.

$\mathrm{SD}=$ standard deviation 


\section{Discussion}

The present crossover RCT aimed to determine whether or not embedding language in the context of communication and social interaction increases the efficacy of intensive aphasia therapy. Individuals with chronic non-fluent aphasia each received two types of intensive training in counterbalanced order: communicative-pragmatic treatment focusing on verbal requests (ILAT), and utterance-centered confrontation naming (Naming Therapy). Both types of training were delivered with the same high intensity and duration, with therapy materials and number of utterances matched between treatment groups. Scores on a standardized aphasia test battery revealed significant progress in language performance with ILAT, independent of when this method was administered. In contrast, Naming Therapy failed to produce significant progress in language performance, leading to a positive trend only at the onset of the treatment, but not when applied after previous intensive training. Notably, treatment type explained 41 percent of the variance associated with changes in language performance in the later training period. This strong effect is consistent with the observation that our data indicated similar patterns of individual changes in aphasia test scores, irrespective of symptom severity. Increases in aphasia test scores were most prominent on speech production measures, possibly reflecting that both types of training focused on spoken language in individuals with prevailing expressive deficits. The current results demonstrate the overall efficacy of communicative-pragmatic treatment in chronic non-fluent aphasia, whereas any benefit from utterance-centered object naming appears to be limited to the early training period. Future research will be required to substantiate these findings with regard to generalization to discourse in everyday life.

We wish to emphasize that all of our patients signed up to intensive SLT with great expectations, hoping for better outcomes relative to the standard treatment available in Germany, which rarely amounts to more than 3 hours of training per week. Consequently, progress in language performance observed during the early training phase might be interpreted as a non-specific placebo effect. However, the superiority of ILAT over 
Naming Therapy in this early training phase reached statistical significance (manifest as an interaction of Time and Group on aphasia test scores; ANOVA contrast: $p=0.046$ ). The superiority of ILAT over Naming Therapy was most apparent on speech production measures (ANOVA contrast: $p=0.03$ ). Although we acknowledge the increased risk of false-positive results arising from multiple comparisons in our dataset, these findings rule out the possibility that a non-specific effect explains all changes in the initial training period.

A number of clinical trials indicate that improved scores on standardized aphasia tests remain stable in the weeks and months following ILAT (Meinzer et al., 2005; Berthier et al., 2009) and intensive regimes including utterance-centered object naming (Rose et al., 2013; Berthier et al., 2014). Hence, progress in language performance observed during the second training period is unlikely to result from the preceding treatment, regardless of whether individuals had previously received ILAT or Naming Therapy. Statistical evaluations lend support to this claim, suggesting uncontaminated data in the second training period (cf. Jones \& Kenward, 2002). However, we appreciate that statistical evaluations cannot guarantee the absence of carryover effects in crossover designs. We therefore recommend interpreting data from the final phase of the treatment with caution, whereas the superiority of ILAT over Naming Therapy in the early training period should be robust to such criticism.

The randomization procedure applied proved to be successful, as statistical analyses did not reveal between-group differences before therapy on any of our variables assessed (see section Methods). Nonetheless, Group I tended towards higher education levels and elevated aphasia test scores at baseline that, arguably, may bear the danger of ceiling effects. In contrast, Group II tended to have older age and longer time after onset of disease, possibly putting these individuals in a slight disadvantage. We wish to highlight that such numerical differences were mostly due to outlier values in individuals who otherwise showed treatment-related changes in language performance consistent with the remaining patient sample. Crucially, the treatment groups appear to be well matched according to the baseline scores 
on the AAT Token Test (averages: 47.3 versus 47.4; see Table 2), an outcome measure known to reflect the severity level of aphasia (cf. Huber et al., 1984). Overall, these results do not provide evidence of systematic between-group differences that may limit the interpretation of our data.

The current patient sample included 16 individuals with chronic aphasia following a left-hemispheric cerebrovascular accident. Our data replicate the finding that ILAT is a relatively effective treatment of chronic poststroke aphasia, as demonstrated by earlier RCT evidence (Pulvermüller et al., 2001; Meinzer et al., 2005; Szaflarski et al., 2015) and further well designed studies (Maher et al., 2006; Barthel et al., 2008; Kurland et al., 2012; Rose et al., 2013). In addition to participants with vascular aetiologies, our patient sample included two individuals with chronic aphasia following traumatic brain injury and viral encephalopathy. We wish to point out that statistical analyses without these two individuals fully confirmed any group result. Moreover, the two individuals showed numerical increases in aphasia test scores consistent with individuals suffering from chronic post-stroke aphasia. Future trials will be needed to clarify whether or not benefits from ILAT can be extended to individuals with chronic aphasia of non-vascular origin.

The most important question opened by the present crossover RCT addresses the underlying reasons for the superiority of ILAT over Naming Therapy, yet without challenging the efficacy of traditional utterancecentered approaches as such (cf. Howard et al., 1985). Many factors are unlikely to account for our differential outcome, as the design controlled for the influence of training intensity and duration, treatment order, the clinical setting in patient groups, as well as the number of utterances. Guided by neuroscience research, we submit that the rich turn-taking structure of ILAT was essential for its overall success. Three more specific sub-aspects of this turn-taking structure deserve closer attention, as each of them offers a separate view on the potential neural mechanisms of speech and language recovery after stroke. 
(I) With a request performed during ILAT, players are able to predict a set of possible partner moves. For example, players may anticipate whether or not the conversation partner accepts a request and hands over the corresponding picture card. Neuroscience evidence suggests that the prediction of such linguistic and non-linguistic action sequences involves the cortical motor system (Carota et al., 2010). Further evidence indicates that engagement of the cortical motor system can be causal for language processing in left perisylvian eloquent areas (Schomers et al., 2015). Given that at least part of the motor system was intact in all of our patients, activity in these neural circuits may have supported linguistic representations in left perilesional language networks (Pulvermüller \& Fadiga, 2010). In contrast to ILAT, Naming Therapy did not provide a similarly rich turn-taking structure. The superiority of ILAT in the current trial may thus result from the fact that this type of training was more effective in exploiting neural resources of the cortical motor system (Berthier \& Pulvermüller, 2011).

(II) A similar point touches on other neural mechanisms underpinning higher cognitive functions relevant for communication and social interaction. For example, the prediction of possible partner moves in ILAT entails "common ground" between individuals, including assumptions about intentions and strategies of a fellow player. Neuroscience evidence suggests that the range of skills necessary to attribute mental states to other individuals, known as "theory of mind," depends on bilateral prefrontal and temporoparietal areas, part of which were intact in our patients (Sebastian et al., 2012). As features related to common ground are less prominent in Naming Therapy, one further reason for the general efficacy of ILAT may emerge from potential synergies between left perisylvian eloquent areas and neural circuits associated with theory of mind processing. Previous studies confirm that cortical language (Broca's area) and motor regions (precentral gyrus) are more strongly involved during requesting than during naming (Egorova et al., 2013, 2014, 2016). Still, future research will be required to delineate the precise neuroplastic changes carrying distinct outcomes of ILAT (e.g., Meinzer et al., 2004; Pulvermüller et al., 2005; Barbancho et al., 2015). 
(III) Consistent with patterns of communicative interaction frequently observed in everyday life, the rich turn-taking structure of ILAT encourages the use of formulaic expressions (cf. Stahl \& Van Lancker Sidtis, 2015). Depending on the availability of picture cards, players interact with sets of formulaic expressions to indicate whether a request was accepted ("Here you are," "Thank you," "You're welcome"), rejected ("I'm sorry," "No problem," “Too bad") or unclear ("Pardon me?"). Neuroscience evidence suggests that this linguistic category of utterances engages, in particular, righthemispheric cortical and bilateral subcortical areas (e.g., Speedie et al., 1993; Van Lancker Sidtis \& Postman, 2006; Sidtis et al., 2009). As a result, formulaic expressions are often preserved in aphasic speech and may be viewed as a valuable motivational resource in therapy (Stahl et al., 2011). Analyses of audiotaped sessions indeed demonstrate that the proportion of formulaic expressions during ILAT exceeds $33 \%$ of all recorded verbal utterances. To compensate for the higher proportion of formulaic expressions in ILAT, the amount of non-formulaic target-related words and sentences was larger in Naming Therapy, thus balancing the total number of utterances between the two types of training. In summary, an additional strength of ILAT may arise from its communicative-pragmatic nature that enables individuals to tap into neural resources of formulaic expressions.

This is the first RCT that provides direct clinical evidence for the impact of communicative language function on recovery from chronic nonfluent aphasia. Our results highlight the possibility that using language as a "tool" for communication and social interaction makes intensive aphasia therapy more effective. In contrast, the strategy to focus on utterances per se seems to be less effective, at least in the current non-communicative context of confrontation naming. This finding casts doubt on a once common view in aphasia rehabilitation, according to which utterance-centered approaches are necessary to facilitate word and sentence processing before communicative-pragmatic SLT can be successful. In conclusion, it appears that the damaged left perisylvian language system of the human brain benefits most when linguistic forms are practiced in communicative interaction. 


\section{References}

Barbancho, M. A., Berthier, M. L., Navas-Sánchez, P., Dávila, G., GreenHeredia, C., García-Alberca, J. M., et al. (2015). Bilateral brain reorganization with memantine and Constraint-Induced Aphasia Therapy in chronic post-stroke aphasia: An ERP study. Brain and Language, 145-146(1), 1-10.

Barthel, G., Meinzer, M., \& Djundja, D. (2008). Intensive language therapy in chronic aphasia: Which aspects contribute most? Aphasiology, $22(4), 408-421$.

Berthier, M. L., \& Pulvermüller F. (2011). Neuroscience insights improve neurorehabilitation of poststroke aphasia. Nature Reviews Neurology, $7(2), 86-97$.

Berthier, M. L., Dávila, G., Green-Heredia, C., Torres, I. M., Juárez y Ruiz de Mier, R., De-Torres, I., et al. (2014). Massed sentence repetition training can augment and speed up recovery of speech production deficits in patients with chronic conduction aphasia receiving donepezil treatment. Aphasiology, 28(2), 188-218.

Berthier, M. L., Green, C., Lara, J. P., Higueras, C., Barbancho, M. A, Dávila, G., et al. (2009). Memantine and Constraint-Induced Aphasia Therapy in chronic poststroke aphasia. Annals of Neurology, 65(5), 577-585.

Brady, M. C., Kelly, H., Godwin, J., Enderby, P., \& Campbell, P. (2016). Speech and language therapy for aphasia following stroke. Cochrane Database of Systematic Reviews, 6, Article CD000425.

Carota, F., Posada, A., Harquel, S., Delpuech, C., Bertrand, O., \& Sirigu, A. (2010). Neural dynamics of the intention to speak. Cerebral Cortex, 20(8), 1891-1897.

Cherney, L. R., Patterson, J. P., Raymer, A., Frymark, T., \& Schooling, T. (2008). Evidence-based systematic review: Effects of intensity of treatment and Constraint-Induced Language Therapy for individuals 
with stroke-induced aphasia. Journal of Speech, Language, and Hearing Research, 51(5), 1282-1299.

Difrancesco, S., Pulvermüller, F., \& Mohr, B. (2012). Intensive LanguageAction Therapy (ILAT): The methods. Aphasiology, 26(2), 1317-1351.

Egorova, N., Pulvermüller, F., \& Shtyrov, Y. (2014). Neural dynamics of speech act comprehension: An MEG study of naming and requesting. Brain Topography, 27(3), 375-392.

Egorova, N., Shtyrov, Y., \& Pulvermüller, F. (2016). Brain basis of communicative actions in language. Neuroimage, 125, 857-867.

Egorova, N., Shtyrov, Y., \& Pulvermüller, F. (2013). Early and parallel processing of pragmatic and semantic information in speech acts: Neurophysiological evidence. Frontiers in Human Neuroscience, 7 , Article 86.

El Hachioui, H., Visch-Brink, E. G., Lingsma, H. F., van de SandtKoenderman, M. W., Dippel, D. W., Koudstaal, P. J., et al. (2014). Nonlinguistic cognitive impairment in poststroke aphasia: A prospective study. Neurorehabilitation and Neural Repair, 28(3) 273281.

Faul, F., Erdfelder, E., Buchner, A., \& Lang, A. G. (2009). Statistical power analyses using $G^{\star}$ Power 3.1: Tests for correlation and regression analyses. Behavior Research Methods, 41(4), 1149-1160.

Glenberg, A. M., Sato, M., \& Cattaneo, L. (2008). Use-induced motor plasticity affects the processing of abstract and concrete language. Current Biology, 18(7), 290-291.

Hoffmann, T. C., Glasziou, P. P., Boutron, I., Milne, R., Perera, R., Moher, D., et al. (2014). Better reporting of interventions: Template for intervention description and replication (TIDieR) checklist and guide. BMJ, 348, Article g1687. 
Howard, D., Patterson, K., \& Franklin, S., Orchard-Lisle, V., \& Morton, J. (1985). Treatment of word retrieval deficits in aphasia. A comparison of two therapy methods. Brain, 108(4), 817-829.

Huber, W., Poeck, K., \& Willmes, K. (1984). The Aachen Aphasia Test. Advances in Neurology, 42, 291-303.

Jones, B., \& Kenward, M. G. (2002). Design and Analysis of Cross-Over Trials. Boca Raton, FL: Chapman \& Hall.

Kertesz, A. (1984). Recovery from aphasia. Advances in Neurology, 42, 2339.

Kessels, R. P., van Zandvoort, M. J., Postma, A., Kappelle, L. J., \& de Haan, E. H. (2000). The Corsi Block-Tapping Task: Standardization and normative data. Applied Neuropsychology, 7(4), 252-258.

Kurland, J., Pulvermüller, F., Silva, N., Burke, K., \& Andrianopoulos, M. (2012). Constrained versus unconstrained intensive language therapy in two individuals with chronic, moderate-to-severe aphasia and apraxia of speech: Behavioral and fMRI outcomes. American Journal of Speech-Language Pathology, 21(2), 65-87.

Lincoln, N. B., McGuirk, E., Mulley, G. P., Jones, A. C., \& Mitchell, J. R. (1984). Effectiveness of speech therapy for aphasic stroke patients: A randomised controlled trial. Lancet, 1(8388), 1197-1200.

Maher, L. M., Kendall, D., Swearengin, J. A., Rodriguez, A., Leon, S. A., Pingel, K., et al. (2006). A pilot study of use-dependent learning in the context of Constraint Induced Language Therapy. Journal of the International Neuropsychological Society, 12(6), 843-852.

Meinzer, M., Djundja, D., Barthel, G., Elbert, T., \& Rockstroh, B. (2005). Long-term stability of improved language functions in chronic aphasia after Constraint-Induced Aphasia Therapy. Stroke, 36(7), 1462-1466.

Meinzer, M., Elbert, T., Wienbruch, C., Djundja, D., Barthel, G., \& Rockstroh B. (2004). Intensive language training enhances brain plasticity in chronic aphasia. BMC Biology, 2, Article 20. 
Oldfield, R. C. (1971). The assessment and analysis of handedness: The Edinburgh inventory. Neuropsychologia, 9(1), 97-113.

Orgass, B., \& Poeck, K. (1966). Clinical validation of a new test for aphasia: An experimental study on the Token Test. Cortex, 2(2), 222-243.

Pulvermüller, F., \& Fadiga, L. (2010). Active perception: Sensorimotor circuits as a cortical basis for language. Nature Reviews Neuroscience, 11(5), 351-360.

Pulvermüller, F., Hauk, O., Nikulin, V. V., \& Ilmoniemi, R. J. (2005). Functional links between motor and language systems. European Journal of Neuroscience, 21(3), 793-797.

Pulvermüller, F., Hauk, O., Zohsel, K., Neininger, B., \& Mohr B. (2005). Therapy-related reorganization of language in both hemispheres of patients with chronic aphasia. Neuroimage, 28(2), 481-489.

Pulvermüller, F., Neininger, B., Elbert, T., Mohr, B., Rockstroh, B., Koebbel, P., et al. (2001). Constraint-induced therapy of chronic aphasia after stroke. Stroke, 32(7), 1621-1626.

Rorden, C., \& Brett, M. (2000). Stereotaxic display of brain lesions. Behavioural Neurology, 12(4), 191-200.

Rose, M. L., Attard, M. C., Mok, Z., Lanyon, L. E., \& Foster, A. M. (2013). Multi-modality aphasia therapy is as efficacious as a ConstraintInduced Aphasia Therapy for chronic aphasia: A phase 1 study. Aphasiology, 27(8), 938-971.

Schomers, M., Kirilina, E., Weigand, A., Bajbouj, M., \& Pulvermüller, F. (2015). Causal influence of articulatory motor cortex on comprehending single spoken words: TMS evidence. Cerebral Cortex, 25(10), 3894-3902.

Sebastian, C. L., Fontaine, N. M., Bird, G., Blakemore, S. J., De Brito, S. A., McCrory E. J. P., et al. (2012). Neural processing associated with cognitive and affective Theory of Mind in adolescents and adults. Social Cognitive and Affective Neuroscience, 7(1), 53-63. 
Shewan, C. M., \& Bandur, D. L. (1986). Treatment of Aphasia: A LanguageOriented Approach. London: Taylor and Francis.

Sidtis, D., Canterucci, G., \& Katsnelson, D. (2009). Effects of neurological damage on production of formulaic language. Clinical Linguistics \& Phonetics, 23(4), 270-284.

Speedie, L. J., Wertman, E., Ta'ir, J., \& Heilman, K. M. (1993). Disruption of automatic speech following a right basal ganglia lesion. Neurology, 43(9), 1768-1774.

Stahl, B., \& Van Lancker Sidtis, D. (2015). Tapping into neural resources of communication: Formulaic language in aphasia therapy. Frontiers in Psychology, 6, Article 1526.

Stahl, B., Kotz, S. A., Henseler, I., Turner, R., \& Geyer, S. (2011). Rhythm in disguise: Why singing may not hold the key to recovery from aphasia. Brain, 134(10), 3083-3093.

Szaflarski, J. P., Ball, A. L., Vannest, J., Dietz, A. R., Allendorfer, J. B., Martin, A. N., et al. (2015). Constraint-Induced Aphasia Therapy for treatment of chronic post-stroke aphasia: A randomized, blinded, controlled pilot trial. Medical Science Monitor, 21, 2861-2869.

Tomasello, M. (2005). Constructing a Language: A Usage-Based Theory of Language Acquisition. Cambridge, MA: Harvard University Press.

Van Lancker Sidtis, D., \& Postman, W. A. (2006). Formulaic expressions in spontaneous speech of left- and right-hemisphere-damaged subjects. Aphasiology, 20(5), 411-426.

Willems, R. M., Labruna, L., D’Esposito, M., Ivry, R., \& Casasanto, D. (2011). A functional role for the motor system in language understanding: Evidence from theta-burst transcranial magnetic stimulation. Psychological Science, 22(7), 849-854.

Wittgenstein L. (1953). Philosophical Investigations. Oxford: Blackwell Publishers. 


\section{Part VI}

\section{Verbal cues}

\section{Original publication}

Stahl, B., Gawron, B., Regenbrecht, F., Flöel, A., \& Kotz, S. A. (2020).

Formulaic language resources may help overcome difficulties in speechmotor planning after stroke. PLOS ONE, 15(6), Article e0233608. 


\section{Abstract}

Purpose. Decades of research have explored communication in cerebrovascular disease by focusing on formulaic expressions (e.g., "Thank you"-"You're welcome"). This category of utterances is known for engaging primarily right-hemispheric frontotemporal and bilateral subcortical neural networks, explaining why individuals with speech-motor planning disorders following left-hemispheric stroke often produce formulaic expressions comparatively well. The present proof-of-concept study aims to confirm that using verbal cues derived from formulaic expressions can alleviate word-onset difficulties, one major symptom in apraxia of speech.

Methods. Twenty individuals with chronic post-stroke apraxia of speech were asked to produce (i) verbal cues (e.g., /gu:/ or /mu:/) and (ii) subsequent German target words (e.g., "Tanz") with critical onsets (e.g., $/ t /$ ) in a cross-sectional repeated-measures design. Cues differed, most notably, in aspects of formulaicity (e.g., stereotyped prompt: /gu:/, based on formulaic phrase "Guten Morgen"; unstereotyped prompt:/mu:/, based on non-formulaic control word "Mutig"). Apart from systematic variation in stereotypy and communicative-pragmatic embeddedness, cues were matched for consonant-vowel structure, syllable-transition frequency, noun-verb classification, meter, and articulatory tempo.

Results. Statistical analyses revealed significant increases in correctly produced word onsets after verbal cues with distinct features of formulaicity (e.g., stereotyped versus unstereotyped prompts: $p<0.001$ ), as reflected in large effect sizes (Cohen's $d_{z} \leq 2.2$ ).

Conclusions. The current results indicate that using preserved formulaic language skills can relieve word-onset difficulties in apraxia of speech. This finding is consistent with a dynamic interplay of left perilesional and right intact language networks in post-stroke rehabilitation and may inspire new treatment strategies for individuals with apraxia of speech. 


\section{Introduction}

Individuals with left-hemispheric brain damage often experience a profound deficit in speech-motor planning, a syndrome especially apparent in the production of word onsets (e.g., incorrect phoneme / $\mathrm{k} /$ in "Coat"; cf. Ziegler et al., 2012). Known as apraxia of speech, this syndrome frequently occurs alongside other neurological communication disorders, including aphasia. In everyday life, apraxia of speech constrains the ability to interact verbally, and therefore, probably adds to the risk of depressive episodes in individuals with communication disorders (Mitchell et al., 2017).

Given the repeated failure in the production of critical word onsets (e.g., incorrect /k/ in the literal use of "Cool"), it is striking how effortlessly some individuals with apraxia of speech perform the same phonemes as part of formulaic expressions (e.g., correct $/ \mathrm{k} /$ in the conversational use of "Cool"). By definition, such expressions differ from newly created, grammatical utterances in that they are (i) stereotyped in form and (ii) closely related to communicative-pragmatic context (cf. Stahl \& Van Lancker Sidtis, 2015). According to neurolinguistic research, formulaic expressions may be stored and retrieved in a holistic manner (Bannard \& Matthews, 2008; Tremblay \& Baayen, 2010; Rammell et al., 2018). Although the proportion of formulaic expressions to spoken language varies with type of measure and discourse, these utterances are widely regarded as crucial to the success of social interaction in many communicative aspects of daily life (Van Lancker Sidtis \& Rallon, 2004). While left perisylvian areas of the brain seem to support primarily propositional-grammatical utterances (Heiss et al., 1999; Warburton et al., 1999; Rosen et al., 2000), processing of formulaic expressions proved to engage, in particular, right-hemispheric frontotemporal and bilateral subcortical neural networks (Hughlings-Jackson, 1879; Graves \& Landis, 1985; Speedie et al., 1993; Van Lancker Sidtis \& Postman, 2006; Sidtis et al., 2018). This may account for anecdotal evidence implying that symptoms in apraxia of speech are more common in propositionalgrammatical utterances and, in contrast, less pronounced in formulaic expressions. So far, surprisingly few attempts have been made to exploit intact 
speech-motor sequences within formulaic expressions to compensate for word-onset difficulties-an issue addressed in the present study.

To facilitate the production of phonemes, speech-language therapists typically provide a variety of cues by prompting word onsets in different modalities: audiovisually (i.e., speaking aloud and allowing lip-reading), tactile-kinesthetically (i.e., stimulating the patients' articulatory organs) or gesturally (i.e., giving hand signs; Wertz et al., 1984); further valuable approaches are available (Ballard et al., 2015). Complementing this repertoire of treatment methods, we propose an alternative strategy focusing on formulaic language resources in a two-step procedure. In step one, the therapists identify critical word onsets (e.g., incorrect / $\mathrm{k} /$ in "Coat") and formulaic expressions with intact corresponding phonemes (e.g., correct $/ \mathrm{k} /$ in "You're welcome"). In step two, patients combine these phonemes (e.g., /jvo 'wel/-/kəot/) to prepare critical word onsets (e.g., /k/) in a repeated fashion until no more help is required (e.g., correct / $\mathrm{k} /$ in "Coat"). Anecdotal evidence from pilot patients indicates that the suggested keyword technique can have an immediate positive impact on word-onset difficulties in moderate-to-severe apraxia of speech. However, these casual reports need to be substantiated by data demonstrating that the technique actually taps into language formulaicity. In fact, the postulated benefit from formulaic language resources may well result from other linguistic parameters, among them consonant-vowel structure, syllable-transition frequency, noun-verb classification, meter, and articulatory tempo.

Controlling for the above linguistic parameters, the current proof-ofconcept study seeks to determine the effect of preserved formulaic language skills on word-onset difficulties in apraxia of speech. In a cross-sectional repeated-measures design, 20 individuals with chronic moderate-to-severe apraxia of speech produced non-formulaic German target words after systematic presentation of verbal cues. These cues differed in distinct features of language formulaicity, as detailed below. Two phoneticians assessed the onsets of non-formulaic target words with regard to articulatory quality. Based on anecdotal evidence from pilot patients, we predict significant gains 
in articulatory quality if target words are preceded by cues derived from formulaic expressions.

\section{Methods}

\subsection{Participants}

Recruitment was administered in collaboration with local rehabilitation centers and support groups for individuals with neurological communication disorders in the years between 2013 and 2018. After routine referral to the study team, we contacted the potential participants and invited them to a screening session to check their eligibility. Inclusion criteria were: moderate-to-severe post-stroke apraxia of speech (main characteristics: phonetic distortions and phonemic errors; dysfluent speech with initiation problems, syllable segregation, inter-syllabic pausing, phoneme lengthening or continuous repairs; and effortful speech with obvious groping or struggling behavior), as diagnosed by two independent clinical linguists in analogy to previous work (Brendel \& Ziegler, 2008); chronic stage of symptoms at least 6 months after a cerebrovascular accident to minimize effects of spontaneous recovery; native speaker of German; intact right hemisphere to ensure relatively preserved formulaic language skills; and right-handedness according to the Edinburgh Handedness Inventory (Oldfield, 1971). Exclusion criteria were: apraxia of speech due to traumatic brain injury or neurodegenerative disease; dysarthria; and severe hearing disorder that may discourage individuals from engaging in the testing sessions.

Twenty individuals agreed to participate in the present study, a patient sample determined in an a-priori power analysis (assumed effect size in a paired-sample $t$-test: Cohen's $d_{z}=0.8$; two-tailed significance level of $\alpha=0.05$; $1-\beta=0.90$; resulting $n=19$; estimated drop-out rate: $5 \%$; final $n=20$; Faul et al., 2009). On average, individuals were aged 59.8 years (standard deviation: 12.9 years) and 32.2 months post-onset of stroke (standard deviation: 24.5 months). Each individual had suffered a cerebrovascular accident with 
subsequent lesions in parts of the left frontal, parietal, and temporal lobes, as well as in adjacent subcortical areas. Aside from apraxia of speech-the prevailing disorder in our patient sample-all individuals were diagnosed with mild-to-moderate aphasia, as confirmed by clinical records and the Aachen Aphasia Test (Huber et al., 1984). The study was approved by the ethics review board at the Charité Universitätsmedizin Berlin, Germany, with written informed consent obtained from each patient (for individual case histories, see Table 1 ). 
Table 1. Patient histories.

\begin{tabular}{|c|c|c|c|c|c|}
\hline Patient & Gender & $\begin{array}{l}\text { Age } \\
\text { (in years) }\end{array}$ & $\begin{array}{l}\text { Months after } \\
\text { onset of stroke }\end{array}$ & $\begin{array}{l}\text { Left-hemisphere } \\
\text { origin }\end{array}$ & $\begin{array}{l}\text { Clinical } \\
\text { diagnosis }\end{array}$ \\
\hline 01 & Female & 40 & 10 & MCA ischemia & Severe AoS \\
\hline 02 & Male & 72 & 6 & MCA ischemia & Severe AoS \\
\hline 03 & Male & 71 & 23 & MCA ischemia & Moderate AoS \\
\hline 04 & Male & 49 & 6 & MCA ischemia & Severe AoS \\
\hline 05 & Male & 45 & 23 & MCA ischemia & Moderate AoS \\
\hline 06 & Male & 64 & 32 & MCA ischemia & $\begin{array}{l}\text { Moderate-to- } \\
\text { severe AoS }\end{array}$ \\
\hline 07 & Male & 76 & 76 & MCA ischemia & Severe AoS \\
\hline 08 & Male & 62 & 10 & MCA ischemia & Moderate AoS \\
\hline 09 & Male & 70 & 30 & MCA ischemia & Moderate AoS \\
\hline 10 & Male & 64 & 41 & MCA ischemia & Severe AoS \\
\hline 11 & Male & 74 & 32 & MCA ischemia & Severe AoS \\
\hline 12 & Male & 51 & 43 & MCA ischemia & Severe AoS \\
\hline 13 & Female & 36 & 27 & MCA ischemia & $\begin{array}{l}\text { Moderate-to- } \\
\text { severe AoS }\end{array}$ \\
\hline 14 & Male & 60 & 12 & MCA ischemia & Severe AoS \\
\hline 15 & Female & 41 & 95 & MCA ischemia & $\begin{array}{l}\text { Moderate-to- } \\
\text { severe AoS }\end{array}$ \\
\hline 16 & Female & 58 & 12 & MCA ischemia & Severe AoS \\
\hline 17 & Male & 60 & 36 & MCA ischemia & Severe AoS \\
\hline 18 & Male & 51 & 81 & MCA ischemia & $\begin{array}{l}\text { Moderate-to- } \\
\text { severe AoS }\end{array}$ \\
\hline 19 & Male & 67 & 18 & MCA ischemia & Moderate AoS \\
\hline 20 & Female & 84 & 31 & MCA ischemia & Severe AoS \\
\hline Mean (SD) & & $59.8(12.9)$ & $32.2(24.5)$ & & \\
\hline
\end{tabular}

MCA: Middle cerebral artery; AoS: Apraxia of speech; SD: Standard deviation 


\subsection{Linguistic materials}

As target words, we chose 10 non-formulaic one-syllable nouns from the middle-frequency spectrum (e.g., "Tanz" [/tants/; German for "dance”]). The critical onsets of the target words differed in manner and place of articulation to cover a large variability of errors in speech-motor planning (plosives: /d/, /t/, /g/, /k/; fricatives: /v/, /f/, /z/, / /, /в/; nasal: /n/). To ensure comparability of target words, the critical onsets were always followed by the vowel /a/.

To identify suitable formulaic expressions, eight linguists contributed and assessed over 100 conversational phrases with regard to (i) stereotypy and (ii) embeddedness in communicative-pragmatic context (cf. Stahl \& Van Lancker Sidtis, 2015). Phrases were considered as formulaic only if they met these two criteria according to the linguists' judgement. In addition, all phrases needed to be part of a formulaic repertoire generally known to native speakers (Tabossi et al., 2009). Based on audiotaped sessions of pilot patients, two phoneticians rated the articulatory quality of critical syllable onsets within each formulaic expression (e.g., /t/ in "Guten Morgen" [/'guitn 'mәкgn/; German for "Good Morning”]; /g/ in "Ent-

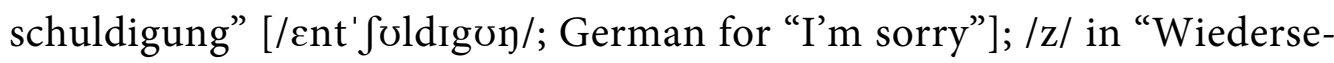
hen" [/'virde, zeiən/; German for "Good bye"]; most phrases were "symmetrical" in the sense that they can be both salutation and reply). This procedure resulted in 16 formulaic expressions with widely preserved critical syllable onsets (e.g., intact/t/ in "Guten Morgen"), thus making it possible to use the previous segments as prompts (e.g., /gu:/) to facilitate the production of specific phonemes (e.g., /t/).

Finally, we selected 16 non-formulaic control words (e.g., /mu:/ from "Mutig" [/'muitıç/; German for "brave"]) matched for linguistic parameters of the prompts originating from formulaic expressions (e.g., /gu:/ from "Guten Morgen"). As suggested by the literature, relevant linguistic parameters were: number of syllables preceding a critical phoneme (Canter et al., 1985), syllable-transition frequency (Aichert \& Ziegler, 2004), consonant-vowel structure (Riecker et al., 2008), noun-verb classification (Caramazza \& Hil- 
lis, 1991), and meter (Aichert et al., 2016). To prevent articulatory priming through consonant repetitions, none of the 32 prompts included the critical phoneme (e.g., not allowed: /gu:/ preceding/g/). Moreover, none of the prompts prepared the critical phoneme through co-articulation (e.g., not allowed: /day/from "Danke” [/'dankə/; German for "Thank you”] preceding /k/; for statistics of the linguistic materials, see Table 2).

Table 2. Linguistic materials.

\begin{tabular}{llll}
\hline & $\begin{array}{l}\text { Number of syllables } \\
\text { preceding the critical } \\
\text { phoneme }\end{array}$ & Syllable frequency & $\begin{array}{l}\text { Syllable-transition } \\
\text { frequency }\end{array}$ \\
\hline $\begin{array}{l}\text { Stereotyped } \\
\text { prompts (SD) }\end{array}$ & $1.6(0.6)$ & $3167(7807)$ & $153(174)$ \\
\hline $\begin{array}{l}\text { Unstereotyped } \\
\text { prompts (SD) }\end{array}$ & $1.6(0.6)$ & $6310(16907)$ & $173(200)$ \\
\hline
\end{tabular}

Means of linguistic parameters for stereotyped (e.g., /gu:/) and unstereotyped prompts (e.g., /mu:/) serving as verbal cues to facilitate the production of critical word onsets (e.g., /t/ in "Tanz"). Frequency characteristics are extracted from the CELEX database, with values referring to the total number of occurrence in German (Baayen et al., 1993). Syllable frequency reflects prompts (e.g., /gu:/ or /mu:/) without considering subsequent critical phonemes (e.g., /t/). Syllable-transition frequency represents prompts and subsequent critical phonemes (e.g., /gu:/./t/ or /mu:/./t/). To adequately control for prompts including the critical phoneme, matching was based on both syllable frequency and syllable-transition frequency. For each parameter, MannWhitney $U$ tests confirmed the absence of significant differences between stereotyped and unstereotyped prompts (always $z \leq 0.34$, not significant). Moreover, stereotyped and unstereotyped prompts were congruent in terms of consonant-vowel structure, noun-verb classification, and meter (for details, see section "Linguistic materials").

SD: Standard deviation

\subsection{Experimental conditions}

Each individual was asked to produce prompts (e.g., /gu:/) and target words (e.g., /tants/) with critical onsets (e.g., /t/) in six experimental conditions. These conditions were:

1. no prompt preceding the target word to estimate the actual severity of deficits in speech-motor planning (e.g., /tants/); 
2. schwa-syllable prompt preceding the target word to explore the role of non-verbal phonation (e.g., /ə:/-/tants/);

3. stereotyped prompt to determine the clinical potential of formulaic language resources (e.g., /gu:/-/tants/, derived from the phrase "Guten Morgen" that, in its entirety, was not explicitly mentioned to the patient);

4. unstereotyped prompt serving as non-formulaic control utterance for the previous task (e.g., /mu:/-/tants/, derived from the adjective "Mutig");

5. communicative-pragmatic prompt to investigate the benefit from revealing the origin of the stereotyped prompt in a conversational context (e.g., the experimenter repeatedly used the phrase "Guten Morgen" to address the patient who, without repeating the formulaic expression as a whole, produced /gu:/-/tants/ subsequently); and

6. active-motor prompt to measure the influence of articulatory priming (e.g., the patient repeatedly used the complete phrase "Guten Morgen" and then produced /gu:/-/tants/; for an overview of the experimental conditions, see Table 3 ).

As baselines, each individual produced the full repertoire of 16 formulaic phrases and 16 non-formulaic control words to compare the articulatory quality of critical syllable onsets (e.g., /t/ in "Guten Morgen" and /t/ in "Mutig"). 
Table 3. Experimental conditions.

\begin{tabular}{|c|c|c|c|c|c|c|}
\hline & $\begin{array}{l}\text { 1. No } \\
\text { prompt }\end{array}$ & $\begin{array}{l}\text { 2. Schwa- } \\
\text { syllable } \\
\text { prompt }\end{array}$ & $\begin{array}{l}\text { 3. Stereo- } \\
\text { typed } \\
\text { prompt }\end{array}$ & $\begin{array}{l}\text { 4. Un- } \\
\text { stereotyped } \\
\text { prompt }\end{array}$ & $\begin{array}{l}\text { 5. Comm.- } \\
\text { pragmatic } \\
\text { prompt }\end{array}$ & $\begin{array}{l}\text { 6. Active- } \\
\text { motor } \\
\text { prompt }\end{array}$ \\
\hline Prompt & - & /ə:/ & /gu:/ & /mu:/ & /gu:/ & /gu:/ \\
\hline $\begin{array}{l}\text { Critical word } \\
\text { onset }\end{array}$ & $/ \mathrm{t} /$ & $/ \mathrm{t} /$ & $/ \mathrm{t} /$ & $/ \mathrm{t} /$ & $/ \mathrm{t} /$ & $/ \mathrm{t} /$ \\
\hline $\begin{array}{l}\text { Prompt and } \\
\text { target word }\end{array}$ & /tants/ & /ə:/-/tants/ & /gu:/./tants/ & /mu:/-/tants/ & /gu:/./tants/ & /gu:/-/tants/ \\
\hline $\begin{array}{l}\text { Underlying } \\
\text { phrase or } \\
\text { word }\end{array}$ & - & - & $\begin{array}{l}\text { "Guten } \\
\text { Morgen" }\end{array}$ & "Mutig" & $\begin{array}{l}\text { "Guten } \\
\text { Morgen" }\end{array}$ & $\begin{array}{l}\text { "Guten } \\
\text { Morgen" }\end{array}$ \\
\hline $\begin{array}{l}\text { Embedding } \\
\text { phrase in } \\
\text { conversational } \\
\text { context }\end{array}$ & No & No & No & No & Yes & No \\
\hline $\begin{array}{l}\text { Producing } \\
\text { entire phrase } \\
\text { before using } \\
\text { it as prompt }\end{array}$ & No & No & No & No & No & Yes \\
\hline
\end{tabular}

Overview of the experimental conditions. Testing materials included 10 non-formulaic onesyllable target words (nouns from the middle-frequency spectrum; e.g., "Tanz"), 16 formulaic expressions (e.g., "Guten Morgen"), and 16 non-formulaic control words (e.g., "Mutig").

\subsection{Procedures}

Testing was administered in different sessions, one for each experimental condition and one for each baseline. Sessions were separated by one week to minimize carryover effects. To avoid systematic practice or fatigue effects due to stimulus order, the sequence of experimental conditions and baselines was randomly alternated across participants. In each session, individuals were seated in front of two loudspeakers at a distance of $75 \mathrm{~cm}$ and listened to a playback. The playback included a metronome (68 beats per minute) to control for articulatory tempo that may affect verbal output in neurological communication disorders (Hustad et al., 2003). Throughout all conditions and baselines, the experimenter presented verbal utterances by reading them aloud (e.g., /gu:/-/tants/). Individuals heard each utterance 
once and then repeated it five times at the pace of the metronome, with a sound signaling when to speak. To increase the reliability of the testing, five repetitions per utterance were preferred to single trials. Individuals did not directly face the experimenter to rule out the possibility of lip-reading. Utterances were audiotaped using a head microphone (C520Vocal Condenser Microphone, AKG Acoustics, Vienna, Austria). Testing duration ranged from 10 to 30 minutes per patient and session. Overall, we recorded 580 utterances per patient, resulting in 11600 utterances across participants.

\subsection{Data analysis}

Two independent phoneticians evaluated critical onsets within the recorded utterances (e.g., first/t/ in /gu:/-/tants/). The scoring system was as follows: a maximum of two points for each correct critical onset; one point for each incorrect critical onset that was, however, correct with respect to manner and place of articulation (e.g., phoneme realization /d/ instead of $/ t /$ ); no points for any further utterances or omissions (different phoneme realization: $31.9 \%$; unintelligible phoneme realization: $22.6 \%$; no phonation: $45.5 \%)$. This two-level scoring system resulted in high inter-rater reliability in the current study $(r=0.98)$ and proved to be robust in previous work (Stahl et al., 2011). We calculated percentages of correctly produced critical onsets for each experimental condition and baseline per patient. Percentages reflect averages of all scores obtained by the two phoneticians. These mean percentages were used in a random-intercept mixed-model analysis with two fixed factors: Experimental Condition (no prompt; schwasyllable prompt; stereotyped prompt; unstereotyped prompt; communicative-pragmatic prompt; and active-motor prompt) and Stimulus Order (to account for potential practice or fatigue effects). For direct comparisons between the experimental conditions, we performed paired-sample $t$-tests. All evaluations were conducted with two-tailed alpha levels of 0.05 ; for multiple comparisons, we applied the Bonferroni-Holm correction. 


\section{Results}

The random-intercept mixed-model analysis revealed a significant effect of Experimental Condition $[F(5,90)=5.28, p<0.001]$ and no significant effect of Stimulus Order $[F(5,90)=1.99, p=0.1]$. To differentiate these findings, primary evaluations focused on the proportion of correctly produced critical onsets depending on the formulaicity of the preceding verbal cues. As specified above, linguistic criteria of formulaicity were: stereotypy [condition 3 versus condition 4] and embeddedness in communicativepragmatic context [condition 3 versus condition 5; cf. Stahl \& Van Lancker Sidtis, 2015]. Paired-sample $t$-tests point to significant increases in correct word onsets after stereotyped prompts [condition 3 versus condition 4; $t(19)=9.63, p<0.001$, Cohen's $\left.d_{z}=2.2\right]$ and after communicative-pragmatic prompts [condition 3 versus condition $5 ; t(19)=2.82, p=0.01$, Cohen's $d_{z}=$ 0.6 ; for means and confidence intervals, see Fig. 1 and Table 4].

Secondary exploratory evaluations addressed the role of articulatory priming [condition 5 versus condition 6], suggesting significantly improved word onsets after active-motor prompts $[t(19)=3.57, p=0.002$, Cohen's $\left.d_{z}=0.8\right]$. Taking a closer look at the function of non-verbal phonation [condition 1 versus condition 2], the analyses yielded a significantly lower rate of correctly produced word onsets after schwa-syllable prompts $\left[t(19)=2.15, p=0.04\right.$, Cohen's $d_{z}=0.5$; for means and confidence intervals, see Fig. 1 and Table 4].

As expected, articulatory quality of critical syllable onsets was significantly higher for formulaic expressions than for non-formulaic control words, thus confirming the adequacy of the source material (e.g., "Guten Morgen" or "Mutig") for developing the experimental prompts [e.g., /gu:/ or /mu:/; baseline comparison: $t(19)=10.71, p<0.001$, Cohen's $d_{z}=2.4$; for means and confidence intervals, see Table 4]. 


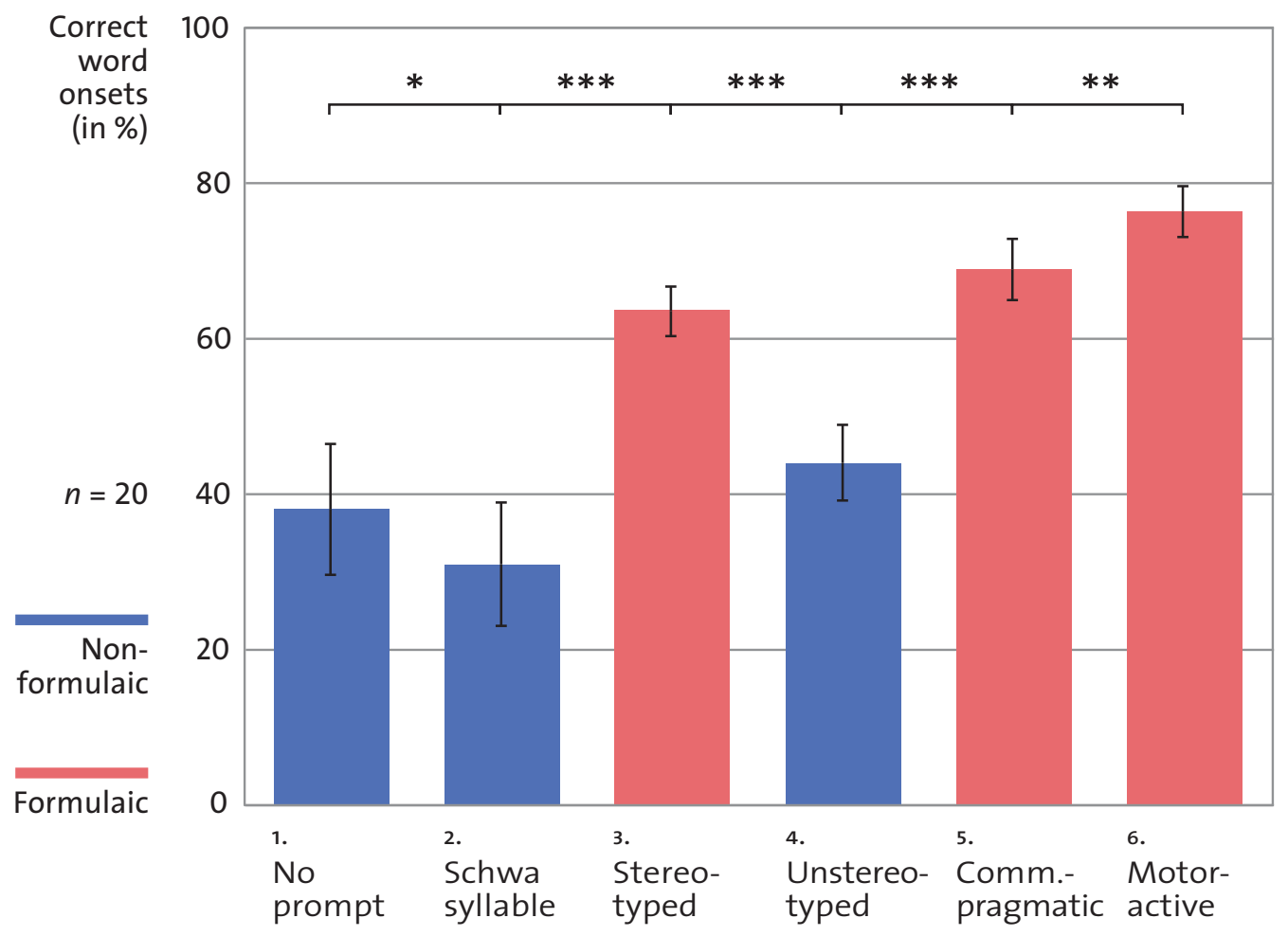

Figure 1. Results. Means of correct word onsets (e.g., /t/ in "Tanz") depending on previous verbal cues (from left to right): no prompts (e.g., /tants/), schwa-syllable prompts (e.g., /ə:/-/tants/), stereotyped prompts (e.g., /gu://tants/, derived from the formulaic phrase "Guten Morgen"), unstereotyped prompts (e.g., /mu:/-/tants/, derived from the non-formulaic control word "Mutig"), communicative-pragmatic prompts (e.g., /gu:/-/tants/, produced immediately after the experimenter uses the underlying phrase "Guten Morgen" in a conversational context), and motor-active prompts (e.g., /gu:/-/tants/, produced immediately after the patient repeatedly uses the underlying phrase "Guten Morgen" as articulatory priming). Verbal cues originate either from formulaic expressions (shown in red) or from non-formulaic control words (shown in blue; for an overview of all experimental conditions, see Table 3). Statistical analyses revealed significant gains in correct word onsets after verbal cues with distinct features of formulaicity (stereotyped and communicative-pragmatic prompts), as well as after articulatory priming (motor-active prompts; ${ }^{\star} p<0.05$; $\left.{ }^{* *} p<0.01 ;{ }^{* *} p<0.001\right)$. Error bars refer to $95 \%$-confidence intervals. 
Table 4. Results.

\begin{tabular}{lllllll}
\hline \multicolumn{9}{c}{ A. Experimental conditions } \\
& $\begin{array}{l}\text { 1. No } \\
\text { prompt }\end{array}$ & $\begin{array}{l}\text { 2. Schwa- } \\
\text { syllable } \\
\text { prompt }\end{array}$ & $\begin{array}{l}\text { 3. Stereo- } \\
\text { typed } \\
\text { prompt }\end{array}$ & $\begin{array}{l}\text { 4. Un- } \\
\text { stereotyped } \\
\text { prompt }\end{array}$ & $\begin{array}{l}\text { 5. Comm.- } \\
\text { pragmatic } \\
\text { prompt }\end{array}$ & $\begin{array}{l}\text { 6. Active- } \\
\text { motor } \\
\text { prompt }\end{array}$ \\
\hline $\begin{array}{l}\text { Correct } \\
\text { word } \\
\text { onsets, in } \\
\text { percent (Cl) }\end{array}$ & $38.5(10.8)$ & $31.5(8.3)$ & $62.9(7.0)$ & $43.9(6.5)$ & $68.8(7.7)$ & $76.2(7.3)$ \\
\hline
\end{tabular}

B. Baseline performances

\begin{tabular}{lll}
\hline & $\begin{array}{l}\text { Baseline: } \\
\text { formulaic expressions }\end{array}$ & $\begin{array}{l}\text { Baseline: } \\
\text { non-formulaic control words }\end{array}$ \\
\hline $\begin{array}{l}\text { Correct syllable } \\
\text { onsets, in } \\
\text { percent }(\mathrm{Cl})\end{array}$ & $77.8(8.4)$ & $57.6(8.3)$ \\
\hline
\end{tabular}

Means of correctly produced critical onsets for each experimental condition $(A)$ and baseline performance (B; for details, see section "Experimental conditions" and Table 3).

$\mathrm{Cl}$ : Confidence interval

\section{Discussion}

The present proof-of-concept study aimed to investigate whether or not using preserved formulaic language skills can relieve word-onset difficulties in apraxia of speech. In a cross-sectional repeated-measures design, 20 individuals with chronic moderate-to-severe apraxia of speech were asked to produce German target words (e.g., "Tanz") with critical onsets (e.g., /t/). Prior to each target word, the individuals produced verbal cues that differed in standard features of formulaicity: (i) stereotypy [condition 3 versus condition 4] and (ii) embeddedness in communicative-pragmatic context [condition 3 versus condition 5; cf. Stahl \& Van Lancker Sidtis, 2015]. Moreover, cues varied in articulatory priming [condition 5 versus condition 6] and in non-verbal phonation [condition 1 versus condition 2]. Aside from these experimental alterations, cues were matched for consonant-vowel structure, syllable-transition frequency, noun-verb classifica- 
tion, meter, and articulatory tempo (for means of linguistic parameters, see Table 2; for an overview of all experimental conditions, see Table 3). Statistical analyses revealed significant gains in correctly produced word onsets after verbal cues with high stereotypy [ $p<0.001$, Cohen's $\left.d_{z}=2.2\right]$ and embeddedness in communicative-pragmatic context [ $p=0.01$, Cohen's $d_{z}=$ $0.6]$. Over and above language formulaicity, these gains were even more pronounced after articulatory priming $\left[p=0.002\right.$, Cohen's $\left.d_{z}=0.8\right]$, whereas cues of non-verbal phonation affected the quality of critical word onsets in a negative way [ $p=0.04$, Cohen's $d_{z}=0.5$ ]. In summary, these results indicate that preserved formulaic language skills and articulatory priming can have an immediate positive impact on word-onset difficulties in apraxia of speech.

Our data point to an articulatory benefit from stereotyped prompts derived from formulaic expressions - that is, knowledge about the origin of verbal cues was implicit (e.g., the experimenter did not mention the underlying phrase "Guten Morgen" to the patient who produced/gu:/-/tants/; see Table 3). Notably, the effect size resulting from stereotyped prompts was large (Cohen's $d_{z}=2.2$ ). It could be argued that this strong effect emerges from linguistic variables other than language formulaicity, such as syllable frequency (i.e., total occurrence of prompts in German; e.g., /gu:/) or syllable-transition frequency (i.e., total occurrence of prompts and subsequent critical phonemes in German; e.g., /gu:/-/t/). However, our design carefully controlled for syllable frequency, syllable-transition frequency, and similar parameters (for details, see Table 2). As an explanation for the superiority of stereotyped prompts (e.g., /gu:/), we presume that this type of verbal cue triggered, in a holistic manner, the retrieval of speech-motor patterns necessary to complete the remaining syllables of formulaic expressions (e.g., /tn ' /'guitn ' тәьgn/) were only partially executed to facilitate critical word onsets (e.g., /t/) of divergent target utterances (e.g., /tants/). Consistent with the idea that stereotyped prompts rely on holistic properties of formulaic language, we noticed in our testing sessions that some individuals occasionally had problems to stop the production of entire phrases once the articulatory process was started. Finally, we are open to the possibility of lower er- 
rors rates within stereotyped prompts (e.g., incorrect /g/ in /gu:/) compared to unstereotyped prompts (e.g., incorrect $/ \mathrm{m} / \mathrm{in} / \mathrm{mu} /$ ). Indeed, holistic processing of formulaic language may have especially reduced the probability of errors within stereotyped prompts, which in turn may have diminished articulatory distraction and improved the quality of the following target utterances-a hypothesis to be investigated in future research.

Our results yielded an increase in correct word onsets after communicative-pragmatic prompts - that is, knowledge about the origin of verbal cues was explicit (e.g., the experimenter used the phrase "Guten Morgen" to address the patient who, subsequently, produced /gu:/-/tants/; see Table 3). This increase through communicative-pragmatic prompts corresponds to a medium effect size (Cohen's $d_{z}=0.6$ ). We propose that there may be an added value associated with engagement of the language network and, potentially, with relatedness to conversational context when identifying the origin of verbal cues. Support for the latter notion comes from data demonstrating an advantage of aphasia therapy protocols that require embedding target utterances in social interaction (e.g., requesting objects) compared to non-communicative exercises (e.g., confrontation naming; Stahl et al., 2016). Moreover, anecdotal evidence implies that preserved language skills in aphasia are most apparent in communicative-pragmatic context (e.g., "My poor Jacqueline, I don't even know your name!"; Alajouanine, 1960). In analogy to aphasia research, our results emphasize the promising role of communicative-pragmatic context along with language stereotypy in clinical trials on apraxia of speech.

As another interesting exploratory finding of our study, articulatory priming proved to increase the benefit from verbal cueing (large positive effect: Cohen's $d_{z}=0.8$ ), while non-verbal phonation per se led to the lowest rate of correct syllable onsets across all experimental conditions (moderate negative effect: Cohen's $d_{z}=0.5$; see Fig. 1 and Table 4 ). Hence, repeated production of formulaic expressions (e.g., "Guten Morgen") prior to their use as motor-active prompts (e.g., /gui/-/tants/) may be a helpful add-on strategy to boost the articulatory outcome of cueing techniques. In contrast, the non-favorable influence of schwa-syllable prompts is congruent with the 
claim that the success of cueing techniques arises from higher-level language processing rather than simple voicing (e.g., phoneme realization /a:/). Accordingly, modern linguistic theories tend to interpret symptoms in apraxia of speech as deficits in higher-level language processing (Ziegler et al., 2012).

The current results indicate that language formulaicity may be a valuable resource in clinical practice. However, the cross-sectional design does not allow conclusions with regard to symptom recovery over time. A longitudinal section will be needed to substantiate the possible long-term effect of using preserved formulaic language skills in individuals with apraxia of speech. This is particularly true when comparing the proposed keyword technique based on language formulaicity with established methods in speech-language therapy, among them audiovisual, tactile-kinesthetic or gestural cues (Wertz et al., 1984) alongside more recent approaches (Ballard et al., 2015). To our knowledge, there is no evidence from randomized controlled trials on the outcome of treatment programs focusing on word-onset production. Subsequent research will be required to determine the most appropriate attempt to permanently alleviate word-onset difficulties.

Although limited by the cross-sectional design, our results still suggest that using preserved formulaic language skills may enable individuals to overcome word-onset difficulties in apraxia of speech. More specifically, individuals may be capable of retrieving intact speech-motor sequences within formulaic expressions in order to restore incorrect initial segments of nonformulaic target utterances. As mentioned previously, formulaic language is known for relying on right-hemispheric frontotemporal and bilateral subcortical neural networks (Hughlings-Jackson, 1879; Graves \& Landis, 1985; Speedie et al., 1993; Van Lancker Sidtis \& Postman, 2006; Sidtis et al., 2018). If indeed preserved formulaic language skills are suitable to reduce failures in speech-motor planning, neuroscience data will have to clarify how such benefits relate to the interplay of left perilesional and right intact language networks in post-stroke rehabilitation. In this context, the present behavioral results may establish a biological basis for future research on treatment-induced neuroplasticity of language function. Just as importantly, our 
results will hopefully inspire clinical trials on preserved formulaic language skills as a potential means to promote recovery from apraxia of speech. 


\section{References}

Aichert, I., \& Ziegler, W. (2004). Syllable frequency and syllable structure in apraxia of speech. Brain and Language, 88(1), 148-159.

Aichert, I., Späth, M., \& Ziegler, W. (2016). The role of metrical information in apraxia of speech. Perceptual and acoustic analyses of word stress. Neuropsychologia, 82, 171-178.

Alajouanine, T. (1960). Baillarger and Jackson: The principle of BaillargerJackson in aphasia. Journal of Neurology, Neurosurgery and Psychiatry, 23(3), 191-193.

Baayen, R. H., Piepenbrock, R., \& van Rijn, H. (1993). The CELEX Lexical Database. Philadelphia: Linguistic Data Consortium.

Ballard, K. J., Wambaugh, J. L., Duffy, J. R., Layfield, C., Maas, E., Mauszycki, S., et al. (2015). Treatment for acquired apraxia of speech: A systematic review of intervention research between 2004 and 2012. American Journal of Speech-Language Pathology, 24(2), 316-337.

Bannard, C., \& Matthews, D. (2008). Stored word sequences in language learning: The effect of familiarity on children's repetition of four-word combinations. Psychological Science, 19(3), 241-248.

Brendel, B., \& Ziegler, W. (2008). Effectiveness of metrical pacing in the treatment of apraxia of speech. Aphasiology, 22(1), 77-102.

Canter, G. J., Trost, J. E., \& Burns, M. S. (1985). Contrasting speech patterns in apraxia of speech and phonemic paraphasia. Brain and Language, 24(2), 204-222.

Caramazza, A., \& Hillis, A. E. (1991). Lexical organization of nouns and verbs in the brain. Nature, 349(6312), 788-790.

Faul, F., Erdfelder, E., Buchner, A., \& Lang, A.-G. (2009). Statistical power analyses using $\mathrm{G}^{\star}$ Power 3.1: Tests for correlation and regression analyses. Behavior Research Methods, 41(4), 1149-1160. 
Graves, R., \& Landis, T. (1985). Hemispheric control of speech expression in aphasia. Archives of Neurology, 42(3), 249-251.

Heiss, W. D., Kessler, J., Thiel, A., Ghaemi, M., \& Karbe, H. (1999).

Differential capacity of left and right hemispheric areas for compensation of poststroke aphasia. Annals of Neurology, 45(4), 430438.

Huber, W., Poeck, K., \& Willmes, K. (1984). The Aachen Aphasia Test. Advances in Neurology, 42, 291-303.

Hughlings-Jackson, J. (1878). On affection of speech from disease of the brain. Brain, 2(3), 203-222.

Hustad, K. C., Jones, T., \& Dailey, S. (2003). Implementing speech supplementation strategies: Effects on intelligibility and speech rate of individuals with chronic severe dysarthria. Journal of Speech, Language, and Hearing Research, 46(2), 462-474.

Mitchell, A. J., Sheth, B., Gill, J., Yadegarfar, M., Stubbs, B., Yadegarfar, M., et al. (2017). Prevalence and predictors of post-stroke mood disorders: A meta-analysis and meta-regression of depression, anxiety and adjustment disorder. General Hospital Psychiatry, 47, 48-60.

Oldfield, R. C. (1971). The assessment and analysis of handedness: The Edinburgh inventory. Neuropsychologia, 9(1), 97-113.

Rammell, C. S., Pisoni, D., \& Van Lancker Sidtis, D. (2018). Perception of formulaic and novel expressions under acoustic degradation: Evidence for a unitary memory. The Mental Lexicon, 12(2), 234-262.

Riecker, A., Brendel, B., Ziegler, W., Erb, M., \& Ackermann, H. (2008). The influence of syllable onset complexity and syllable frequency on speech motor control. Brain and Language, 107(2), 102-113.

Rosen, H. J., Petersen, S. E., Linenweber, M. R., Snyder, A. Z., White, D. A., Chapman, L., et al. (2000). Neural correlates of recovery from aphasia after damage to left inferior frontal cortex. Neurology, 55(12), 18831894. 
Sidtis, J. J., Van Lancker Sidtis, D., Dhawan, V., \& Eidelberg, D. (2018).

Switching language modes: Complementary brain patterns for formulaic and propositional language. Brain Connectivity, 8(3), 189196.

Speedie, L. J., Wertman, E., Ta'ir, J., \& Heilman, K. M. (1993). Disruption of automatic speech following a right basal ganglia lesion. Neurology, 43(9), 1768-1774.

Stahl, B., \& Van Lancker Sidtis, D. (2015). Tapping into neural resources of communication: Formulaic language in aphasia therapy. Frontiers in Psychology, 6, Article 1526.

Stahl, B., Kotz, S. A., Henseler, I., Turner, R., \& Geyer, S. (2011). Rhythm in disguise: Why singing may not hold the key to recovery from aphasia. Brain, 134(10), 3083-3093.

Stahl, B., Mohr, B., Dreyer, F. R., Lucchese, G., \& Pulvermüller, F. (2016). Using language for social interaction: Communication mechanisms promote recovery from chronic non-fluent aphasia. Cortex, 85, 90-99.

Tabossi, P., Fanari, R., \& Wolf, K. (2009). Why are idioms recognized fast? Memory \& Cognition, 37(4), 529-540.

Tremblay, A., \& Baayen, R. H. (2010). Holistic processing of regular fourword sequences: A behavioral and ERP study of the effects of structure, frequency, and probability on immediate free recall. In D. Wood (Ed.), Perspectives on Formulaic Language: Acquisition and Communication (pp. 151-173). London: The Continuum International Publishing Group.

Van Lancker Sidtis, D., \& Postman, W. A. (2006). Formulaic expressions in spontaneous speech of left- and right-hemisphere-damaged subjects. Aphasiology, 20(5), 411-426.

Van Lancker Sidtis, D., \& Rallon, G. (2004). Tracking the incidence of formulaic expressions in everyday speech: Methods for classification and verification. Language \& Communication, 24(3), 207-240. 
Warburton, E., Price, C. J., Swinburn, K., Wise, R. J. S. (1999). Mechanisms of recovery from aphasia: Evidence from positron emission tomography studies. Journal of Neurology, Neurosurgery and Psychiatry, 66(2), 155-161.

Wertz, R. T., LaPointe, L. L., \& Rosenbek, J. C. (1984). Apraxia of Speech in Adults: The Disorder and its Management. Orlando, FL: Grune \& Stratton.

Ziegler, W., Aichert, I., \& Staiger, A. (2012). Apraxia of speech: Concepts and controversies. Journal of Speech, Language, and Hearing Research, 55(5), 1485-1501. 


\section{Author contribution}

Part I. Concept and elaboration.

Part II. Scientific and clinical trial coordination; study concept and methodological design; treatment protocols and materials; participant recruitment; therapy sessions; statistical analyses; original manuscript drafting and revision; artwork.

Part III. Concept and elaboration; original manuscript drafting and revision.

Part IV. Concept and elaboration; original manuscript drafting and revision.

Part V. Scientific and clinical trial coordination; study concept and methodological design; treatment protocols and materials; participant recruitment; therapy sessions; statistical analyses; original manuscript drafting and revision; artwork.

Part VI. Scientific and clinical trial coordination; funding acquisition; study concept and methodological design; experimental protocols and materials; participant recruitment; statistical analyses; original manuscript drafting and revision; artwork. 